\title{
INEEL/EXT-97-01073
}

September 1997

\section{FLAMMABILITY ASSESSMENT METHODOLOGY PROGRAM PHASE I: FINAL REPORT}

C. A. Loehr

S. M. Djordjevic

K. J. Liekhus

M. J. Connolly

LOCKNED WATINT/ 


\title{
RECEIVED DEC 112000 \\ OSTI
}

\section{Flammability Assessment Methodology Program Phase I: Final Report}

\author{
C. A. Loehr* \\ S. M. Djordjevic* \\ K. J. Liekhus \\ M. J. Connolly \\ Published September 1997 \\ Idaho National Engineering and Environmental Laboratory \\ Lockheed Martin Idaho Technologies Company \\ Transuranic Waste Programs \\ Idaho Falls, Idaho 83415 \\ * Developed in conjunction with \\ Benchmark Environmental Corporation \\ Under Subcontract No. C90-132787 \\ Prepared for the \\ U.S. Department of Energy, Assistant Secretary for \\ Environmental Restoration and Waste Management \\ under DOE-Idaho Operations Office \\ Contract No. DE-AC07-94ID13223
}




\section{DISCLAIMER}

This report was prepared as an account of work sponsored by an agency of the United States Government. Neither the United States Government nor any agency thereof, nor any of their employees, make any warranty, express or implied, or assumes any legal liability or responsibility for the accuracy, completeness, or usefulness of any information, apparatus, product, or process disclosed, or represents that its use would not infringe privately owned rights. Reference herein to any specific commercial product, process, or service by trade name, trademark, manufacturer, or otherwise does not necessarily constitute or imply its endorsement, recommendation, or favoring by the United States Government or any agency thereof. The views and opinions of authors expressed herein do not necessarily state or reflect those of the United States Government or any agency thereof. 


\section{DISCLAIMER}

Portions of this document may be illegible in electronic image products. Images are produced from the best available original document. 


\section{EXECUTIVE SUMMARY}

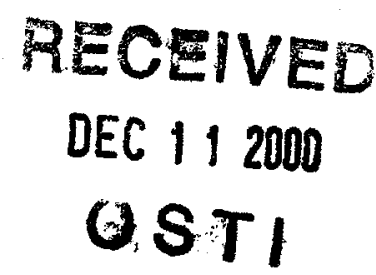

The Flammability Assessment Methodology Program (FAMP) was established to investigate the flammability of gas mixtures found in transuranic (TRU) waste containers. The FAMP results provide a basis for increasing the permissible concentrations of flammable volatile organic compounds (VOCs) in TRU waste containers. The FAMP results will be used to modify the Safety Analysis Report for the TRUPACT-II Shipping Package (TRUPACT-II SARP) (U.S. Nuclear Regulatory Commission [NRC] 1996) upon acceptance of the methodology by the NRC. Implementation of the methodology would substantially increase the number of drums that can be shipped to the Waste Isolation Pilot Plant (WIPP) without repackaging or treatment.

Central to the program was experimental testing and modeling to predict the gas mixture lower explosive limit (MLEL) of gases observed in TRU waste containers. The flammability experimental work, conducted by the National Institute of Occupational Safety and Health, Pittsburgh Research Center (PRC), was successful in measuring MLELs for mixtures of VOCs and flammable gases (i.e., hydrogen and methane) found in TRU waste drums. The experimental data supported selection of an MLEL model that was used in constructing screening limits for flammable VOC and flammable gas concentrations. The MLEL values predicted by the model for individual drums will be utilized to assess flammability for drums that do not meet the screening criteria. Finally, the predicted MLEL values will be used to derive acceptable gas generation rates, decay heat limits, and aspiration time requirements for drums that do not pass the screening limits. The results of the program demonstrate that an increased number of waste containers can be shipped to WIPP within the flammability safety envelope established in the TRUPACT-II SARP.

\section{Background and Objective}

A requirement for use of the TRU Package Transporter-II (TRUPACT-II) is that the concentration of flammable gases (i.e., hydrogen and methane) must not exceed $5 \%$ (by volume) during a 60 -day shipping period after the TRUPACT-II is sealed. In addition, the total concentration of potentially flammable VOCs is limited to $500 \mathrm{ppmv}$ in the headspace of a waste container. The FAMP was established with the intent of providing a basis for increasing the permissible flammable VOC concentration limits in the TRUPACT-II, thereby increasing the number of drums that may be shipped without treatment or repackaging. To meet the objective, the FAMP investigated the flammability of gases in TRU waste; designed and tested a series of gas mixtures; selected a model for predicting the MLEL of gases in TRU waste drums; developed screening limits for flammable gas and VOC concentrations; developed a strategy for determining flammability of gases in drums that do not pass screening limits; and delineated the approach for determining acceptable gas generation rates, decay heat limits, and aspiration time requirements.

\section{Flammability Experiments}

The design for flammability experiments focused on investigating the following classes of compounds: flammable gases, nonflammable VOCs, and three groups of flammable VOCs (based on VOC lower explosive limits [LELs] and structural characteristics of the compounds). Hydrogen was used as the flammable gas and carbon tetrachloride was used to represent nonflammable VOCs. VOCs were selected based on prevalence in TRU waste and physical characteristics that facilitated testing.

The lowest flammable concentrations in air of all mixtures specified in the experimental design were determined in a 19-L heavy-walled stainless steel test chamber using a strong spark ignition source. Except for 1,2-dichloroethane, LELs of individual VOCs were within the narrow range of literature values. Experimental MLELs generally agreed with calculated values for the mixtures to within 10\% (PRC 1997). 


\title{
Methodology Implementation
}

\author{
Model Development, Evaluation, and Selection
}

This report evaluates seven models for predicting MLELs for gas mixtures, including (a) the original method of Le Chatelier; (b) a modified Le Chatelier method based on accounting for the nonflammable VOC proportion in the mixture; (c) a group contribution factor method, which accounts for the compound stoichiometry; (d) a group contribution factor method that accounts only for flammable VOCs (Flammable Group method); (e) a group contribution factor method that uses experimental LELs as input; (f) predictions using the American Society for Testing and Materials code, CHETAH; and (g) linear regressions of test MLELs on proportions of compounds in the classifications used for flammability testing. In addition, the effect of imposing bias on relatively unbiased models was investigated.

Model predictions for the test mixtures were compared to MLELs determined in flammability testing. Statistics on measures of the degree and consistency of agreement between predicted and test MLELs were generated. An evaluation of the models was also performed using innermost layer concentrations for 532 drums characterized under the TRU waste characterization programs at the Idaho National Engineering and Environmental Laboratory and the Rocky Flats Environmental Technology Site.

In applying the models to actual drum data, it was found that some methods resulted in unrealistic MLELs. For instance, all methods except the Flammable Group method resulted in extremely high MLELs predicted for some drums. Also, group contribution methods that accounted for nonflammable constituents resulted in negative MLELs in some instances. Because such anomalous MLEL values do not complement the flammability assessment methodology, where the flammable VOC and flammable gas characteristics need to be examined separately, the methods that predict unrealistic MLELs are not appropriate for use. For this reason and because of favorable results in the experimental-based evaluation, the Flammable Group model was used to develop screening limits and is included in the strategy for evaluating individual drums.

\section{Development of Screening Limits}

Conservative screening limits were developed to segregate containers with no potential for flammability from those requiring more detailed evaluation. The screening limits are based on statistics for gas concentrations in innermost confinement layers of drums predicted to be nonflammable based on MLELs predicted using the Flammable Group model. Screening limits were developed for (a) flammable gas concentration, and (b) flammable VOC concentration for each waste type. Statistics on the performance of the screening limits relative to drums determined to be flammable show that no drums determined to be flammable (by MLEL modeling) pass both screening limits; therefore, no flammable drums would be deemed nonflammable.

\section{Strategy for Drum Flammability Evaluations}

Because of the conservatism in the screening limits, some drums will exceed one or both limits, but may not be flammable. Therefore, drums exceeding a limit will be subjected to one or two additional stages of evaluation. The first stage involves using the selected MLEL model to predict the drum-specific MLEL and comparing the sum of steady-state innermost confinement layer flammable gas and VOC concentrations to the MLEL. If the drum concentration sum exceeds the MLEL, flame testing of gases that represent the steady-state innermost layer gas concentration in the drum may be performed.

\section{Strategy for Determinations of Drum Decay Heat and Aspiration Time Requirements}

For drums that pass the screening limits, the applicable screening limit for flammable gas concentration is used to determine the acceptable flammable gas generation rate, the decay heat limit, and the required aspiration 
time. For drums that fail a screening limit, the maximum permissible flammable gas generation rate is calculated for the drum and used to determine the allowable decay heat and aspiration time using the TRUPACT-II SARP methodology. The drum must satisfy the decay heat and aspiration requirements prior to shipment.

\section{Conclusions and Recommendations}

The flammability experimental work was successful in measuring MLELs for mixtures of VOCs and flammable gases found in TRU waste drums. The experimental data supported selection of an MLEL model, the Flammable Group model, which was used to construct limits for flammable VOC and flammable gas concentrations. The limits are higher than the current $500 \mathrm{ppmv}$ limit for waste types with relatively high concentrations of flammable VOCs. For the 532 drums examined, more than $20 \%$ have flammable VOCs in innermost layers of confinement that exceeded the $500 \mathrm{ppmv}$ limit, but only $2.44 \%$ were flammable by the conservative Flammable Group model. All drums that were classified as flammable did not pass one or both screening limits. This provides evidence that the screening limits are a reliable, though conservative, indicator of flammability. Overall, the program demonstrates that an increased number of waste containers can be shipped to WIPP within the flammability safety envelope established in the TRUPACT-II SARP.

Recommendations for finalizing the methodology include additional flammability testing to complete MLEL model validation and prior to submitting an application to the NRC, updating screening limits and assumptions on the prevalence of methane in TRU waste drums using all available headspace gas data that reflect anticipated inventory. It is recommended that flammability testing focus on testing mixtures that more closely reflect concentrations observed in TRU waste drums and investigate the effects of elevated temperature on the MLEL. 


\section{CONTENTS}

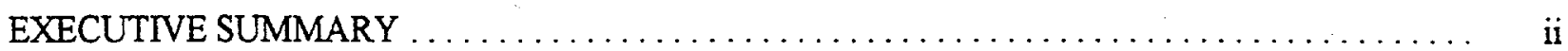

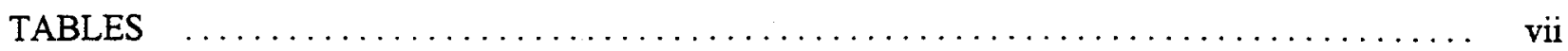

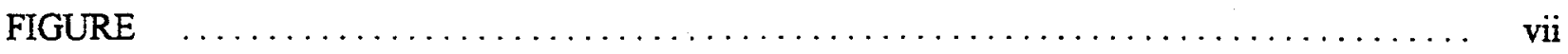

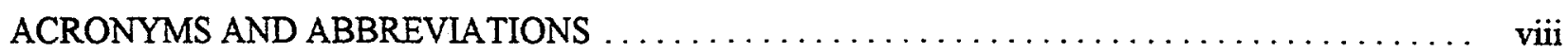

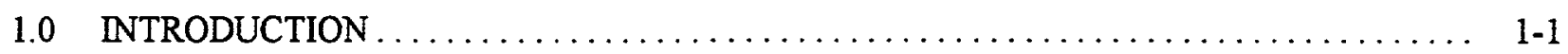

$1.1 \quad$ Background $\ldots \ldots \ldots \ldots \ldots \ldots \ldots \ldots \ldots \ldots \ldots \ldots \ldots \ldots \ldots \ldots \ldots \ldots \ldots \ldots, 1-1$

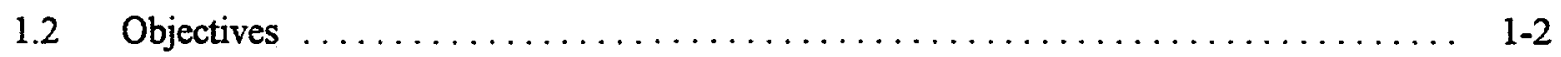

1.3 Framework and Activities $\ldots \ldots \ldots \ldots \ldots \ldots \ldots \ldots \ldots \ldots \ldots \ldots \ldots \ldots \ldots \ldots \ldots \ldots \ldots, 1-2$

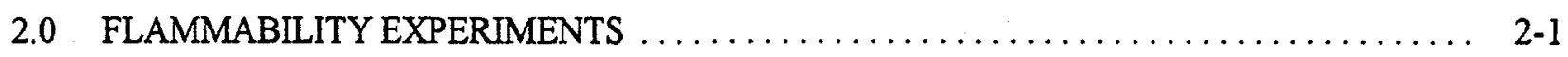

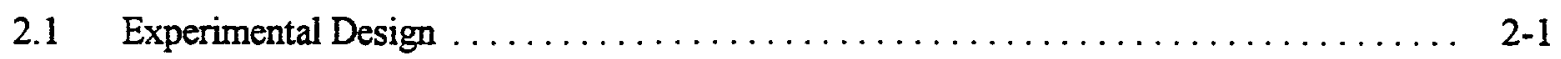

2.2 Flammability Testing Equipment and Procedures $\ldots \ldots \ldots \ldots \ldots \ldots \ldots \ldots \ldots \ldots \ldots \ldots$

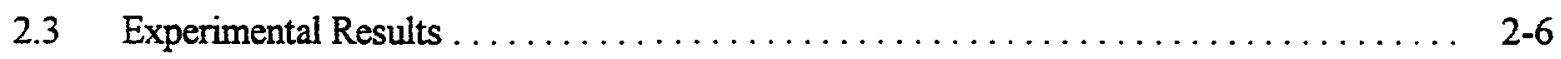

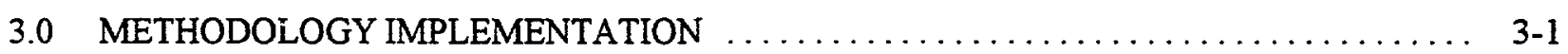

3.1 Model Development, Evaluation, and Selection $\ldots \ldots \ldots \ldots \ldots \ldots \ldots \ldots \ldots$ 3-1

3.2 Development of Screening Limits . . . . . . . . .

3.2.1 Drum Confinement Layer Concentrations $\ldots \ldots \ldots \ldots \ldots \ldots \ldots \ldots \ldots$. 3-5

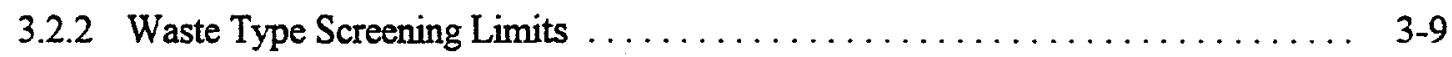

3.3 Strategy for Drum Flammability Evaluations $\ldots \ldots \ldots \ldots \ldots \ldots \ldots \ldots \ldots \ldots \ldots \ldots \ldots \ldots$

3.4 Strategy for Determination of Drum Decay Heat and Aspiration Time Requirements ... 3-14

3.4.1 Decay Heat Limits $\ldots \ldots \ldots \ldots \ldots \ldots \ldots \ldots \ldots \ldots \ldots \ldots \ldots \ldots \ldots \ldots \ldots \ldots \ldots, 3-14$

3.4.2 Aspiration Times $\ldots \ldots \ldots \ldots \ldots \ldots \ldots \ldots \ldots \ldots \ldots \ldots \ldots \ldots \ldots \ldots \ldots \ldots \ldots, 15$

4.0 CONCLUSIONS AND RECOMMENDATIONS $\ldots \ldots \ldots \ldots \ldots \ldots \ldots \ldots \ldots \ldots \ldots \ldots \ldots, 4,1$

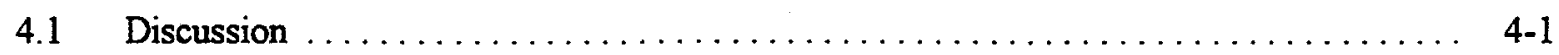

4.2 Recommendations $\ldots \ldots \ldots \ldots \ldots \ldots \ldots \ldots \ldots \ldots \ldots \ldots \ldots \ldots \ldots, 4-1$

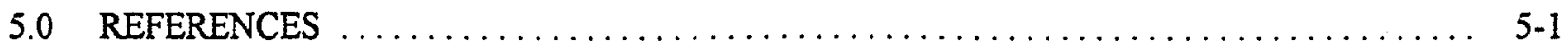




\section{APPENDICES}

A Experimental Apparatus and Procedure for Vapor Explosibility Testing in the 19-L Chamber, Revision 0

B Final Report: Measurements of the Lower Flammability Limits of Mixtures of Volatile Organic Compounds Plus Hydrogen in Air

C Mixture Lower Explosive Limit and Limiting Adiabatic Flame Temperature Models 


\section{TABLES}

2-1 Flammable and nonflammable volatile organic compounds and flammable gases considered in the Flammability Assessment Methodology Program . . . . . . . . . . . $\quad 2-2$

2-2 Classification of flammable volatile organic compounds $\ldots \ldots \ldots \ldots \ldots \ldots \ldots \ldots \ldots$

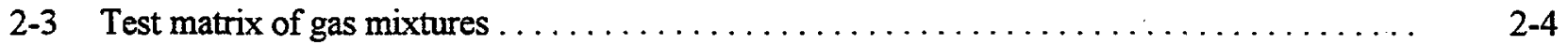

2-4 Experimental MLEL results for test mixtures $\ldots \ldots \ldots \ldots \ldots \ldots \ldots \ldots \ldots \ldots \ldots \ldots \ldots \ldots$

3-1 Results of predictive mixture lower explosive limits modeling $\ldots \ldots \ldots \ldots \ldots \ldots \ldots \ldots$

3-2 Statistics for parameters used in the experimental-based evaluation $\ldots \ldots \ldots \ldots \ldots \ldots \ldots$ 3-4

3-3 Percentage of drums predicted to be flammable of 532 drums used in the FAMP ...... 3-6

3-4 Drum inner layer and outer layer methane concentration comparison $\ldots \ldots \ldots \ldots \ldots \ldots$

3-5 Volatile organic compound prediction factors by waste type $\ldots \ldots \ldots \ldots \ldots \ldots \ldots \ldots$

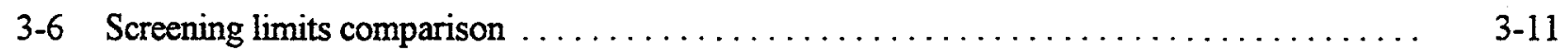

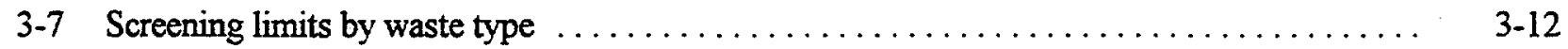

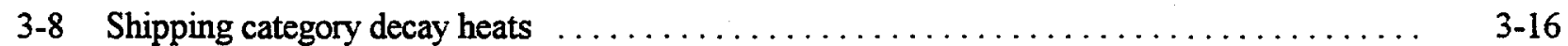

4-1 Variation of predicted MLEL with temperature at $63.3^{\circ} \mathrm{C} \ldots \ldots \ldots \ldots \ldots \ldots \ldots .2$

\section{FIGURE}

3-1 Steps in evaluating individual waste drums for flammability 


\section{ACRONYMS AND ABBREVIATIONS}

\begin{tabular}{|c|c|}
\hline $\mathrm{AIChE}$ & American Institute of Chemical Engineers \\
\hline ASTM & American Society for Testing and Materials \\
\hline $\mathrm{CAO}$ & Carlsbad Area Office \\
\hline $\mathrm{CH}$ & contact-handled \\
\hline $\mathrm{DAC}$ & drum age criterion \\
\hline DOE & U.S. Department of Energy \\
\hline DOE-ID & DOE-Idaho Area Office \\
\hline DQO & data quality objective \\
\hline FAMP & Flammability Assessment Methodology Program \\
\hline FAMP Test Plan & $\begin{array}{l}\text { Flammability Assessment Methodology Program Test Plan, Revision } 0 \text { (Connolly et al. } \\
\text { 1997) }\end{array}$ \\
\hline FGN & functional group number \\
\hline GCF & group contribution factor \\
\hline GF & group factor \\
\hline GGTP & Gas Generation Testing Program \\
\hline ICV & inner containment vessel \\
\hline IDC & item description code \\
\hline INEEL & Idaho National Engineering and Environmental Laboratory \\
\hline LEL & lower explosive limit \\
\hline LGN & lower explosive limit group number \\
\hline LTL & lower tolerance limit \\
\hline MDP & Matrix Depletion Program \\
\hline MLEL & mixture lower explosive limit \\
\hline MPHMC & maximum permissible hydrogen and methane concentration \\
\hline NASA & National Aeronautics and Space Administration \\
\hline NRC & U.S. Nuclear Regulatory Commission \\
\hline PRC & Pittsburgh Research Center \\
\hline QA & quality assurance \\
\hline QAPD & Quality Assurance Program Document (DOE 1996) \\
\hline QAPjP & Quality Assurance Project Plan \\
\hline QAPP & Transuranic Waste Characterization Quality Assurance Program Plan (DOE 1995) \\
\hline RFETS & Rocky Flats Environmental Technology Site \\
\hline SARP & Safety Analysis Report for the TRUPACT-II Shipping Package (NRC 1996) \\
\hline SFVOC & sum of flammable volatile organic compounds in the innermost confinement layer \\
\hline SHM & sum of steady-state innermost confinement layer hydrogen and methane concentration \\
\hline TRU & transuranic \\
\hline TRUCON & TRUPACT II content code \\
\hline TRUPACT-II & Transuranic Package Transporter-II \\
\hline TWCP & Transuranic Waste Characterization Program \\
\hline UTL & upper tolerance limit \\
\hline VOC & volatile organic compound \\
\hline WIPP & Waste Isolation Pilot Plant \\
\hline WMCG & waste matrix code group \\
\hline vol\% & volume percent \\
\hline
\end{tabular}




\subsection{INTRODUCTION}

The Flammability Assessment Methodology Program (FAMP) was established to investigate the flammability of various gas mixtures found in transuranic (TRU) waste containers. The FAMP results provide a basis for increasing the permissible concentrations of flammable volatile organic compounds (VOCs) in TRU waste containers. This report provides background information, details the objectives and activities of the FAMP, and documents how the components of the FAMP support implementation of a methodology for evaluating the flammability of gas mixtures in TRU waste containers. Considerable experimental data exist on the flammability of gas mixtures found in industrial and mining applications, such as mixtures composed of hydrogen, methane, carbon monoxide, carbon dioxide, nitrogen, and oxygen. However, no experimental data are publicly available for the types of gas mixtures observed in TRU waste containers. Therefore, central to the program was experimental testing and modeling to predict the mixture lower explosive limit (MLEL) of gases observed in TRU waste containers. The FAMP results will be used to modify the Safety Analysis Report for the TRUPACT-II Shipping Package (TRUPACT-II SARP) (U.S. Nuclear Regulatory Commission [NRC] 1996) upon acceptance of the methodology by the NRC. Implementation of the methodology would substantially increase the number of drums that can be shipped to the Waste Isolation Pilot Plant (WIPP) without repackaging or treatment.

The flammability experimental work was successful in measuring MLELs for mixtures of VOCs and flammable gases, and provided valuable data for evaluating MLEL prediction models. Using the data, a model was selected for use in the FAMP. Conservative screening limits were developed for use in identifying drums that require assessments using the MLEL predictive model. The limits are based on conservative predictions of innermost layer gas concentrations using available headspace gas analysis data, on data for drums conservatively identified as nonflammable, and high confidence for concentration percentiles of the nonflammable population. Screening limits determined using the available data performed well, with no conservatively identified flammable drums passing both screening limits. The study indicates that the methodology can be safely implemented on actual waste containers while increasing the number of containers that can be shipped to the WIPP. Recommendations for finalizing the methodology include additional flammability testing to complete MLEL model validation and updating screening limits with additional headspace gas data.

\subsection{Background}

A major transportation requirement for use of the Transuranic Package Transporter-II (TRUPACT-II) is that the concentration of flammable gases (i.e., hydrogen and methane) must not exceed $5 \%$ (by volume) during a 60-day shipping period after the TRUPACT-II is sealed. In addition, the total concentration of potentially flammable VOCs is limited to 500 ppmv in the headspace of a waste container.

The methodology for determining flammable gas concentration limits will be based on the waste designations established for transportation. For purposes of transporting TRU waste to the WIPP in the TRUPACT-II, the U.S. Department of Energy (DOE) classified contact-handled (CH) TRU waste into four major waste types based on their chemical and physical characteristics, as described in TRUPACT-II Content Codes (TRUCON) (DOE 1994):

I Solidified aqueous or homogeneous inorganic solids

II Solid inorganics

III Solid organics

IV Solidified organics

Each CH TRU waste container is assigned a TRUPACT-II shipping category based on waste type and packaging (number and type of confinement layers) present inside the container. The confinement layers in a drum include polymer (i.e., plastic) bags, rigid drum liners, and drum filter vents. Drums containing waste types 
I or IV are referred to as sludge waste drums and may contain absorbed, adsorbed, or solidified inorganic or organic liquids, soils, or solidified particulates and residues. Drums containing waste types II or III are referred to as solid waste drums that may contain glass, metal, crucibles, plastics, cellulose, or other solid organics and inorganics.

Based on the current limits and headspace gas data for over 500 drums stored at the Idaho National Engineering and Environmental Laboratory (INEEL) and Rocky Flats Environmental Technology Site (RFETS), approximately $20 \%$ of the CH TRU waste drums exceed the 500 ppmv limit. However, analyses indicate less than $3 \%$ of the drums may be potentially flammable. Cost impacts associated with treating or repackaging the waste for shipment are substantial. Such activities may also adversely impact the scheduling of shipments to the WIPP. The flammability assessment methodology documented in this report is intended to increase the permissible flammable VOC concentration limits and, thereby, increase the number of drums that may be shipped without treating or repackaging; reduce costs; and minimize delays in waste shipments.

\subsection{Objectives}

The FAMP was established by the DOE Carlsbad Area Office (CAO) to investigate the MLELs of various flammable gas mixtures found in TRU waste containers. Specifically, the FAMP was tasked to investigate the flammability of gases in TRU waste; develop an approach for increasing the allowable concentrations of flammable VOCs; finalize a methodology for evaluating flammability of gases in TRU waste; identify activities required to verify and validate the methodology; and document the results of the FAMP.

\subsection{Framework and Activities}

The participants in the FAMP are the CAO, the DOE-Idaho Area Office (DOE-ID), the National Institute for Occupational Safety and Health, Pittsburgh Research Center (PRC), and the two sites performing the sampling, analytical, experimental, and modeling analyses (the INEEL and RFETS). The TRU waste program manager, located at DOE-ID, is the primary interface between CAO and the FAMP coordinator, located at the INEEL. The TRU waste program manager is responsible for review and approval of the Flammability Assessment Methodology Program Test Plan, Revision 0 (FAMP Test Plan) (Connolly et al. 1997) and review of this final report of the FAMP. The FAMP coordinator, located at the INEEL, is responsible for reviewing and approving FAMP documentation and providing technical direction and coordination for the FAMP.

The following activities were completed under the FAMP.

- The FAMP Test Plan was prepared and describes the experimental design of the flammability testing and the investigation strategy for the FAMP. The flammable VOCs were organized into lower explosive limit (LEL) groups to facilitate the experimental design. The FAMP Test Plan also documents responsibilities of the FAMP participants; quality assurance (QA) requirements, including data quality objectives; and data management and analysis activities. The QA requirements for the FAMP were based on the CAO Quality Assurance Program Document (QAPD) (DOE 1996) and the Transuranic Waste Characterization Quality Assurance Program Plan (QAPP) (DOE 1995). Section 2.0 of this report describes the experimental design and the flammability testing equipment and procedures.

- A Readiness-to-Test Assessment checklist was prepared and approved by the FAMP Coordinator and QA Officer. The checklist was prepared in accordance with the requirements of the QAPD. The INEEL FAMP Principal Investigator and the FAMP QA Officer met with PRC staff members on March 20 and 21,1997 , at the PRC to discuss procedures, finalize the checklist, observe a preliminary test run, and complete the checklist. 
- The PRC performed flammability testing between January and June 1997, to determine the MLELs of 38 test gas mixtures composed of various combinations of hydrogen, and flammable and nonflammable headspace gas VOCs listed in the QAPP. The PRC conducted flammability testing in accordance with the requirements established by their QA program, including those in the Experimental Apparatus and Procedure for Vapor Explosibility Testing in the 19-L Chamber (PRC 1997) (Appendix A) that was prepared to ensure that the experimental data generated are consistent with and satisfy the requirements of the QAPD. The PRC transmitted monthly technical status reports and quarterly cost management reports to the INEEL. The results of the experimental testing are documented in the Final Report: Measurements of the Lower Flammability Limits of Mixtures of Volatile Organic Compounds Plus Hydrogen in Air (Zlochower et al. 1997) (Appendix B).

- Gas transport models were used to relate the concentrations of flammable gases and VOCs within the innermost confinement layer to the corresponding concentrations in the drum headspace (Connolly et al. 1995; Djordjevic et al. 1997). The highest concentrations of hydrogen, methane, and VOCs will typically occur within the innermost confinement layer in a drum. Thus, the innermost confinement layer has the highest potential to contain flammable gas mixtures. Section 3.3.1 provides discussion of the models.

- The experimentally determined MLELs were used to develop and evaluate models for evaluating the flammability of mixtures of VOCs and flammable gases in TRU waste containers. Under the Transuranic Waste Characterization Program (TWCP), the INEEL and RFETS have sampled headspace gases of hundreds of drums stored at these sites and analyzed them for VOCs, hydrogen, and methane. Using the experimental data and headspace gas data from 532 drums, both empirical and theoretical models that represent the full spectrum of flammability determination methods identified in the literature were evaluated to select the predictive method to use in the flammability assessment methodology. The predictive methods are described in detail in Appendix C. The results of predictive modeling and the selection of the prediction method are discussed in Section 3.0.

- Screening limits for total concentrations of flammable VOCs and for maximum permissible hydrogen and methane concentrations (MPHMCs) based on statistics for the population of drums for which flammable gas concentrations do not exceed predicted drum-specific MLELs (i.e., drum gases are nonflammable) were established for each of the four major waste types. The selected prediction method was used to predict the MLEL for each drum using the VOC and flammable gas concentrations within the innermost confinement layer for each drum. MPHMCs were derived from the predicted total concentrations of flammable gases and the total concentrations of flammable VOCs in the innermost confinement layer.

- The strategy for evaluating drum flammability was finalized and is described in Section 3.3. The strategy involves comparison of the sum of innermost confinement layer flammable VOC (SFVOC) concentrations and sum of flammable gases (i.e., sum of hydrogen and methane concentrations [SHM]) to the waste-type specific screening limits, comparison with less conservative drum-specific limits as necessary, and flame testing for drums that exceed the drum-specific limits. The SHM screening limit or drum-specific MPHMCs (as appropriate) will be used to establish the maximum allowable flammable gas generation rates using the TRUPACT-II SARP methodology, decay heat limits, and aspiration time requirements.

The flammability assessment methodology may be further validated through testing of additional gas mixtures to address potential temperature and concentration issues. In addition, screening limits should be updated as more headspace gas analyses become available. Section 4.2 discusses recommendations for finalizing the methodology. 


\subsection{FLAMMABILITY EXPERIMENTS}

Flammability testing was conducted by the PRC, as described in the FAMP Test Plan (Connolly et al. 1997). The MLELs of the gas mixtures in the flammability tests were used to develop and evaluate models for predicting the flammability of TRU waste drum contents. PRC's final report (Zlochower et al. 1997), including a discussion of the actual tests and results, is included in Appendix B. A summary of the test design, equipment and procedures, and results is provided below.

\subsection{Experimental Design}

The experimental design focused on investigating classes of compounds, including nonflammable VOCs, to predict MLELs and to provide data that represent a variety of TRU waste gas mixtures for evaluating models. Table 2-1 lists the compounds (flammable VOCs, nonflammable VOCs, and flammable gases) observed in TRU waste containers and considered in the FAMP. Flammable VOCs were classified according to their chemical structural characteristics and LEL group. The functional groups considered were aromatics, ketones, alcohols, and alkanes/alkenes. The LEL groups were designated by LELs of $0.9-1.3 \%, 1.4-2.6 \%$, and 5.6-6.7\%. In general, there is a correlation between functional and LEL group. LEL groups were chosen as classifications for flammable VOCs in the experimental design. Table 2-2 summarizes flammable VOCs by functional and LEL groups.

In addition to LEL groups as classifications for flammable VOCs, flammable gases and nonflammable VOCs were two additional classes of compounds considered in the experimental design. Test mixtures for flammability testing were determined based on the following factors:

- Presence or absence of a flammable VOC from one or more of the three LEL groups

- Presence or absence of hydrogen

- Presence or absence of a nonflammable VOC.

VOCs were selected to represent compound classes based on prevalence in TRU waste and on physical characteristics that facilitated testing.

A full factorial design of the experimental factors plus a quarter replication and minus combinations that resulted in no gas in the mixture resulted in a test matrix of 38 gas mixtures. Replicate runs were included in the test matrix to assess the experimental error. All runs were performed in a random order to help ensure that experimental errors and factor effects were properly estimated and not confounded with experimental procedure trends and other possible experimental effects.

The experimental test mixtures consisted of hydrogen and four VOCs, including 1,2-dichloroethane, to represent chlorinated hydrocarbons and alkanes; methyl ethyl ketone (2-butanone) to represent oxygenated hydrocarbons and ketones; toluene to represent aromatic hydrocarbons; and carbon tetrachloride to represent nonflammable VOCs. These VOCs were chosen to represent the LEL and, thus, the functional groups, because they have sufficient vapor pressures to remain in the gas phase under test conditions of standard temperature and pressure $\left(25^{\circ} \mathrm{C}\right.$ and $1 \mathrm{~atm}$ ). Ethyl ether (an ether) and cyclohexane (a cycloalkane) were not included in the test mixtures because they are not prevalent in TRU waste. The test mixtures contained equimolar amounts of the above constituents as shown in Table 2-3.

In planning the experiments, errors were anticipated for measuring the actual concentration of a mixture component injected into the test chamber, the component vapor pressure and associated temperature, and the actual final mixture pressure. The required overall data quality objective (DQO) was to maintain the error in the experimental MLEL result to less than $5 \%$. 
Table 2-1. Flammable and nonflammable volatile organic compounds and flammable gases considered in the Flammability Assessment Methodology Program.

\begin{tabular}{|c|c|c|}
\hline Flammable VOCs & Nonflammable VOCs & Flammable Gases \\
\hline Acetone & Bromoform & Hydrogen \\
\hline Benzene & Carbon tetrachloride & Methane \\
\hline 1-Butanol & Chloroform & \\
\hline Chlorobenzene & Formaldehyde ${ }^{\mathrm{a}}$ & \\
\hline Cyclohexane & Methylene chloride ${ }^{b}$ & \\
\hline 1,1-Dichloroethane & 1,1,2,2-Tetrachloroethane & \\
\hline 1,2-Dichloroethane & Tetrachloroethene & \\
\hline 1,1-Dichloroethene & 1,1,1-Trichloroethane ${ }^{\mathfrak{c}}$ & \\
\hline cis-1,2-Dichloroethene & Trichloroethene ${ }^{d}$ & \\
\hline Ethyl benzene & 1,1,2-Trichloro-1,2,2-triflu & \\
\hline \multicolumn{3}{|l|}{ Ethyl ether } \\
\hline \multicolumn{3}{|l|}{ Methanol } \\
\hline \multicolumn{3}{|l|}{ Methyl ethyl ketone } \\
\hline \multicolumn{3}{|l|}{ Methyl isobutyl ketone } \\
\hline \multicolumn{3}{|l|}{ Toluene } \\
\hline \multicolumn{3}{|l|}{ 1,2,4-Trimethylbenzene } \\
\hline \multicolumn{3}{|l|}{ 1,3,5-Trimethylbenzene } \\
\hline \multicolumn{3}{|l|}{ m-Xylene } \\
\hline \multicolumn{3}{|l|}{ o-Xylene } \\
\hline \multicolumn{3}{|l|}{ p-Xylene } \\
\hline \multicolumn{3}{|l|}{ Ref. Table 12-2 (DOE 1995) } \\
\hline \multicolumn{3}{|c|}{$\begin{array}{l}\text { a. Flash point of } 85^{\circ} \mathrm{C} \text { is well above the maximum temperature of } 63^{\circ} \mathrm{C} \text { in the TRUPACT-II. } \\
\text { b. Flash point of } 100^{\circ} \mathrm{C} \text { is well above the maximum temperature of } 63^{\circ} \mathrm{C} \text { in the TRUPACT-II. } \\
\text { c. No flash point (NFPA 1988). Hawley's Condensed Chemical Dictionary describes it as nonflammable (Sax and Lewis 1987). } \\
\text { d. The Material Safety Data Sheet (GPC 1988) describes the compound as a colorless, nonflammable mobile liquid. Hawley's Condensed } \\
\text { Chemical Dictionary describes it as nonflammable (Sax and Lewis 1987). }\end{array}$} \\
\hline
\end{tabular}


Table 2-2. Classification of flammable volatile organic compounds.

\begin{tabular}{|c|c|c|c|c|}
\hline Flammable VOC & Structural Type & $\begin{array}{l}\text { Functional } \\
\text { Group Number }^{a}\end{array}$ & LEL (vol.\%) & $\begin{array}{l}\text { LEL Group } \\
\text { Number }^{b}\end{array}$ \\
\hline Acetone & ketone & 2 & 2.6 & 2 \\
\hline Benzene & aromatic & 1 & 1.3 & 1 \\
\hline 1-Butanol & alcohol & 3 & 1.7 & 2 \\
\hline Chlorobenzene & aromatic & 1 & 1.3 & 1 \\
\hline Cyclohexane & cycloalkane & - & 1.3 & 1 \\
\hline 1,1-Dichloroethane & alkane & 4 & 5.6 & 3 \\
\hline 1,2-Dichloroethane & alkane & 4 & $\sim 5$ & 3 \\
\hline 1,1-Dichloroethene & alkene & 4 & 6.5 & 3 \\
\hline cis-1,2-Dichloroethene & alkene & 4 & 5.6 & 3 \\
\hline Ethyl benzene & aromatic & 1 & 1.0 & 1 \\
\hline Ethyl ether & ether & - & 1.9 & 2 \\
\hline Methanol & alcohol & 3 & 6.7 & 3 \\
\hline Methyl ethyl ketone & ketone & 2 & 1.9 & 2 \\
\hline Methyl isobutyl ketone & ketone & 2 & 1.4 & 2 \\
\hline Toluene & aromatic & 1 & 1.2 & 1 \\
\hline 1,2,4-Trimethylbenzene & aromatic & 1 & 0.9 & 1 \\
\hline 1,3,5-Trimethylbenzene & aromatic & 1 & 1.0 & 1 \\
\hline o-Xylene & aromatic & 1 & 1.1 & 1 \\
\hline $\mathrm{m} / \mathrm{p}$-Xylene & aromatic & 1 & 1.1 & 1 \\
\hline
\end{tabular}

a. Functional group numbers are assigned as follows: (1) aromatics, (2) ketones, (3) alcohols, and (4) alkanes/alkenes.

b. LEL group numbers are assigned as follows: (1) $0.9 \%-1.3 \%$, (2) $1.4 \%-2.6 \%$, and (3) $5.6 \%-6.7 \%$. 
Table 2-3. Test matrix of gas mixtures.

\begin{tabular}{|c|c|c|c|c|c|c|}
\hline \multirow[b]{2}{*}{$\begin{array}{l}\text { Order of } \\
\text { Experimentation }\end{array}$} & \multirow[b]{2}{*}{$\begin{array}{c}\text { Test } \\
\text { Mixture }\end{array}$} & \multirow[b]{2}{*}{$\begin{array}{c}1,2 \\
\text { Dichloroethane }\end{array}$} & \multicolumn{4}{|c|}{$\begin{array}{l}\text { Fuel Makeup in Test Mixture } \\
\text { (proportion in gas phase on air-free basis, \%) }\end{array}$} \\
\hline & & & $\begin{array}{l}\text { Methyl } \\
\text { ethyl ketone }\end{array}$ & Toluene & Hydrogen & $\begin{array}{l}\text { Carbon } \\
\text { tetrachloride }\end{array}$ \\
\hline 01 & 12 & 33 & 0 & 33 & 33 & 0 \\
\hline 02 & 30 & 0 & 33 & 0 & 33 & 33 \\
\hline 03 & 33 & 33 & 0 & 33 & 0 & 33 \\
\hline 04 & 3 & 50 & 50 & 0 & 0 & 0 \\
\hline 05 & 25 & 0 & 0 & 33 & 33 & 33 \\
\hline 06 & 19 & 0 & 50 & 50 & 0 & 0 \\
\hline 07 & 32 & 0 & 0 & 0 & 0 & 0 \\
\hline 08 & 36 & 0 & 33 & 0 & 33 & 33 \\
\hline 09 & 6 & 33 & 33 & 0 & 33 & 0 \\
\hline 10 & 1 & 20 & 20 & 20 & 20 & 20 \\
\hline 11 & 21 & 0 & 25 & 25 & 25 & 25 \\
\hline 12 & 16 & 50 & 0 & 0 & 0 & 50 \\
\hline 13 & 5 & 25 & 25 & 25 & 25 & 0 \\
\hline 14 & 8 & 33 & 33 & 0 & 0 & 33 \\
\hline 15 & 37 & 0 & 0 & 0 & 0 & 0 \\
\hline 16 & 38 & 50 & 50 & 0 & 0 & 0 \\
\hline 17 & 7 & 25 & 25 & 0 & 25 & 25 \\
\hline 18 & 23 & 0 & 0 & 50 & 0 & 50 \\
\hline 19 & 22 & 0 & 0 & 100 & 0 & 0 \\
\hline 20 & 34 & 0 & 33 & 33 & 0 & 33 \\
\hline 21 & 17 & 0 & 100 & 0 & 0 & 0 \\
\hline 22 & 20 & 0 & 50 & 0 & 50 & 0 \\
\hline 23 & 40 & 25 & 25 & 25 & 25 & 0 \\
\hline 24 & 35 & 33 & 0 & 0 & 33 & 33 \\
\hline 25 & 24 & 0 & 0 & 50 & 50 & 0 \\
\hline 26 & 15 & 33 & 0 & 0 & 33 & 33 \\
\hline 27 & 26 & 0 & 0 & 0 & 100 & 0 \\
\hline 28 & 27 & 0 & 0 & 0 & 50 & 50 \\
\hline 29 & 29 & 0 & 33 & 33 & 33 & 0 \\
\hline 30 & 18 & 0 & 50 & 0 & 0 & 50 \\
\hline 31 & 2 & 100 & 0 & 0 & 0 & 0 \\
\hline 32 & 13 & 25 & 0 & 25 & 25 & 25 \\
\hline 33 & 39 & 0 & 0 & 50 & 50 & 0 \\
\hline 34 & 28 & 0 & 33 & 33 & 0 & 33 \\
\hline 35 & 9 & 25 & 25 & 25 & 0 & 25 \\
\hline 36 & 14 & 50 & 0 & 0 & 50 & 0 \\
\hline 37 & 10 & 50 & 0 & 50 & 0 & 0 \\
\hline 38 & 4 & 33 & 33 & 33 & 0 & 0 \\
\hline 39 & 11 & 33 & 0 & 33 & 0 & 33 \\
\hline 40 & 31 & 0 & 0 & 0 & 0 & 100 \\
\hline
\end{tabular}




\subsection{Flammability Testing Equipment and Procedures}

A heavy-walled, stainless steel test chamber with an approximate volume of $19 \mathrm{~L}$ was used for the gas mixture flammability tests. The chamber has been used extensively for dust and gas explosibility measurements. Such chambers are now the standard laboratory chambers for dust explosibility measurements (American Society for Testing and Materials [ASTM] E1515-96, "Standard Test Method for Minimum Explosible Concentration of Combustible Dusts" [ASTM 1997a]), and are highly useful for gas explosibility measurements as well. They are considerably larger than the 5-L spherical glass flasks specified in the ASTM vapor flammability test procedure (ASTM E681-94 "Standard Test Method for Concentration Limits of Flammability of Chemicals" [ASTM 1997b]), but are consistent with the ASTM standard (ASTM 1997c). The larger size of the chamber allows for the potential use of stronger ignitors to ensure the absence of ignition limitations when measuring flammability limits, and minimizes wall effects on flammability. The question of ignition limitation and wall effects are particularly important in testing halogenated VOCs. The equipment uses objective pressure criteria for explosions rather than purely visual and subjective criteria as in ASTM E681-94.

The chamber is equipped with viewing ports and various access ports for pressure and temperature sensors, electronic ignition, evacuation, gas admission, and VOC liquid injection. Ignition was attempted using a 41-joule energy spark, and the resulting pressure trace was monitored to determine flammability or nonflammability for each test. By using the test chamber, stronger ignition sources can be used so as to ensure the absence of ignition limitations when measuring flammability limits, and minimizing wall effects (i.e., heat losses) on flammability.

A computer-controlled data acquisition system was used to display the pressure, rate of pressure rise (dP/dt), and temperature data versus time. The partial pressures of the VOCs, hydrogen, and air were monitored using two Viatran $(B$ pressure transducers for the explosion pressures and a Baratron $(B$ pressure transducer for the component pressures. Chamber temperature was monitored by a Chromel-Alumel 8 (type K) thermocouple.

The PRC measured the MLEL in dry air at a total pressure of 1 atm for the VOC mixtures discussed in Section 2.1. All testing used known amounts of the appropriate individual components. To ensure complete volatilization of the VOCs, each component was introduced under reduced pressure into the test chamber. Once the appropriate components were introduced into the chamber and pressures were checked to ensure proper component concentrations, the chamber was brought to atmospheric pressure using dry air. Once a uniform mixture was obtained, the test was started by energizing the appropriate ignition source and recording pressure and temperature. Ignition of the mixture was identified by the pressure rise of the test chamber vessel. A positive ignition was required for those test mixtures that contain a flammable gas. This was accomplished by increasing the component concentrations, while maintaining the required component ratio, until the sample gave a positive ignition. The ignition source selected was of sufficient energy and duration as to avoid ignition limitations as discussed below.

An initial testing phase was completed prior to initiation of testing the 38 gas mixtures in order to verify and establish the following:

- LELs of the individual components (hydrogen and VOCs). The LELs determined through the initial testing were compared to values previously determined at the PRC for hydrogen and taken from the literature for the VOCs.

- Criterion (i.e., pressure rise) for a positive ignition. Based on the preliminary testing and comparisons to earlier measurements, a pressure rise of $0.5 \mathrm{psi}$ was chosen as the LEL criterion.

- Equipment performance. 
- An appropriate ignition source for flammability tests. Preliminary tests on the LELs of toluene and methyl ethyl ketone had used a stored spark energy of 17 joule. The LELs were found to be in agreement with the reported values from closed flammability tubes. Despite the apparent adequacy of the spark energy used, it was determined to use an even more energetic spark of 41 joule for the test series to help ensure that the more difficult to ignite halogenated VOCs (e.g., 1,2-dichloroethane) and mixtures (those with 1,2-dichloroethane or carbon tetrachloride) would not be ignition limited. Switching to the higher capacitance spark did not reduce the LEL for methyl ethyl ketone. There was, therefore, no indication that the more energetic spark was "overdriving" the chamber mixture, nor was there any expectation that the actual thermal energy deposited in the chamber by the spark (about 1 joule) could possibly do so.

The following measurements were made during an experimental run:

- Pressure Measurements. Individual component partial pressure (VOCs, hydrogen, and air) and total chamber pressure were established before each test. The time development of chamber pressure and rate of pressure rise in the chamber were recorded once the appropriate ignition source was energized. The pressure rise criterion, which was determined experimentally, was used to establish ignition of the test gas mixture. In addition to the pressure transducer used to measure component pressures (Baratron(B)), two pressure transducers (Viatran(B) were used to measure the gas mixture explosion pressure.

- Temperature measurements. Test chamber temperature was monitored during each test using a Chromel-Alumel $B$ (type $\mathrm{K}$ ) thermocouple and recorded as a function of time. The thermocouple was able to give qualitative data on flame propagation and temperature, but did not have the response time to allow the monitoring of the actual peak explosion temperature. Because the thermocouple was cemented in place inside the reaction chamber, it was considered impractical to recalibrate the temperature output on a regular basis. Therefore, the temperature output was treated as a relative rather than an absolute measurement, with more significance given to the measured explosion temperature rise than on the absolute initial starting temperature.

- Concentration Measurements. The partial pressure of all gases (VOCs, hydrogen, and air) was used to determine concentrations prior to running a test.

Prior to their use, instruments used in the flammability tests were checked against known standards. Pressure transducers with built in calibrations were checked daily.

\subsection{Experimental Results}

The lowest flammable concentrations in air of all mixtures specified in the experiment design were determined in the 19-L laboratory flammability chamber using a strong spark ignition source. Except for 1,2-dichloroethane, LELs of pure VOCs were within the narrow range of literature values cited by the PRC. The experimental LEL for 1,2-dichloroethane is below the range of values cited in the literature, but may be more accurate because a larger chamber was used in combination with a more energetic spark and it is known that the halogenated species are prone to exhibiting wall effects and ignition limitations. Experimental MLELs generally agreed with calculated values for the mixtures to within $10 \%$ (PRC 1997).

Partial pressures of the VOC and hydrogen components were used to determine test mixture composition and concentration in air for MLEL determinations. Mixture explosion pressure and temperature data were also measured during the experimental tests. Temperature rise measurements and visual observations of the flame propagation were found to correlate well with pressure rise measurements (Zlochower et al. 1997). MLELs (Table 2-4) are based on pressure versus component concentration data plots. 
Table 2-4. Experimental MLEL results for test mixtures.

\begin{tabular}{|c|c|c|c|c|c|c|}
\hline \multirow[b]{2}{*}{$\begin{array}{l}\text { Mixture } \\
\text { No. }\end{array}$} & \multicolumn{5}{|c|}{ Proportion of Compound in Mixture on Air-Free Basis (\%) } & \multirow[b]{2}{*}{$\begin{array}{c}\text { MLEL } \\
(\%)\end{array}$} \\
\hline & $\begin{array}{l}\text { 1,2-Dichloro- } \\
\text { ethane }\end{array}$ & $\begin{array}{l}\text { Methyl ethyl } \\
\text { ketone }\end{array}$ & Toluene & Hydrogen & $\begin{array}{c}\text { Carbon } \\
\text { tetrachloride }\end{array}$ & \\
\hline 1 & 20 & 20 & 20 & 20 & 20 & $3.40 \pm 0.10$ \\
\hline 2 & 100 & 0 & 0 & 0 & 0 & $4.85 \pm 0.05$ \\
\hline 3 & 50 & 50 & 0 & 0 & 0 & $2.65 \pm 0.05$ \\
\hline 4 & 33 & 33 & 33 & 0 & 0 & $1.95 \pm 0.03$ \\
\hline 5 & 25 & 25 & 25 & 25 & 0 & $2.40 \pm 0.05$ \\
\hline 6 & 33 & 33 & 0 & 33 & 0 & $3.40 \pm 0.07$ \\
\hline 7 & 25 & 25 & 0 & 25 & 25 & $5.15 \pm 0.05$ \\
\hline 8 & 33 & 33 & 0 & 0 & 33 & $4.85 \pm 0.10$ \\
\hline 9 & 25 & 25 & 25 & 0 & 25 & $2.80 \pm 0.05$ \\
\hline 10 & 50 & 0 & 50 & 0 & 0 & $2.05 \pm 0.03$ \\
\hline 11 & 33 & 0 & 33 & 0 & 33 & $3.50 \pm 0.05$ \\
\hline 12 & 33 & 0 & 33 & 33 & 0 & $2.65 \pm 0.05$ \\
\hline 13 & 25 & 0 & 25 & 25 & 25 & $3.95 \pm 0.05$ \\
\hline 14 & 50 & 0 & 0 & 50 & 0 & $5.35 \pm 0.20$ \\
\hline 15 & 33 & 0 & 0 & 33 & 33 & $9.7 \pm 0.50$ \\
\hline 16 & 50 & 0 & 0 & 0 & 50 & $\mathrm{ND}$ \\
\hline 17 & 0 & 100 & 0 & 0 & 0 & $1.95 \pm 0.03$ \\
\hline 18 & 0 & 50 & 0 & 0 & 50 & $4.65 \pm 0.03$ \\
\hline 19 & 0 & 50 & 50 & 0 & 0 & $1.45 \pm 0.05$ \\
\hline 20 & 0 & 50 & 0 & 50 & 0 & $3.15 \pm 0.07$ \\
\hline 21 & 0 & 25 & 25 & 25 & 25 & $2.90 \pm 0.05$ \\
\hline 22 & 0 & 0 & 100 & 0 & 0 & $1.20 \pm 0.03$ \\
\hline 23 & 0 & 0 & 50 & 0 & 50 & $2.90 \pm 0.05$ \\
\hline 24 & 0 & 0 & 50 & 50 & 0 & $2.05 \pm 0.03$ \\
\hline 25 & 0 & 0 & 33 & 33 & 33 & $3.65 \pm 0.10$ \\
\hline 26 & 0 & 0 & 0 & 100 & 0 & $5.00 \pm 0.40$ \\
\hline 27 & 0 & 0 & 0 & 50 & 50 & $10.8 \pm 0.80$ \\
\hline 28 & 0 & 33 & 33 & 0 & 33 & $2.45 \pm 0.05$ \\
\hline 29 & 0 & 33 & 33 & 33 & 0 & $2.00 \pm 0.05$ \\
\hline 30 & 0 & 33 & 0 & 33 & 33 & $5.20 \pm 0.10$ \\
\hline 31 & 0 & 0 & 0 & 0 & 100 & NF \\
\hline 32 & 0 & 0 & 0 & 0 & 0 & NA \\
\hline 33 & 33 & 0 & 33 & 0 & 33 & $3.45 \pm 0.10$ \\
\hline 34 & 0 & 33 & 33 & 0 & 33 & $2.35 \pm 0.05$ \\
\hline 35 & 33 & 0 & 0 & 33 & 33 & $10.1 \pm 0.50$ \\
\hline 36 & 0 & 33 & 0 & 33 & 33 & $5.20 \pm 0.07$ \\
\hline 37 & 0 & 0 & 0 & 0 & 0 & $\mathrm{NA}$ \\
\hline 38 & 50 & 50 & 0 & 0 & 0 & $2.70 \pm 0.05$ \\
\hline 39 & 0 & 0 & 50 & 50 & 0 & $2.05 \pm 0.03$ \\
\hline 40 & 25 & 25 & 25 & 25 & 0 & $2.40 \pm 0.10$ \\
\hline $\begin{array}{l}A=\text { Not } a \\
D=\text { Not } d \\
F=\text { Not } f l\end{array}$ & $\begin{array}{l}\text { cable. } \\
\text { mined because } \\
\text { nable. }\end{array}$ & condensed. & & & & \\
\hline
\end{tabular}


The precision of the MLELs reported in Table 2-4 is based on the number of data points in the near vicinity of the LEL value, how close the data points are to the LEL, the effect of using a range of pressure rise criteria ( 0.5 $\pm 0.2 \mathrm{psi}$ ), and sensitivity of explosion pressures near the LEL. The relative precision values from replicate runs, less than or equal to $5 \%$ of the LEL value, is consistent with the DQO identified in the FAMP Test Plan.

The largest uncertainty in the MLEL determinations was due to a gradual increase in explosion pressure with hydrogen concentration and the dominance of hydrogen in some mixtures, particularly the hydrogen and carbon tetrachloride mixture, which combines the lightest, most diffusible molecule, hydrogen, with the heaviest VOC, carbon tetrachloride, selected for the experimental tests. The flammability of equimolar mixtures containing hydrogen are expected to be more influenced by hydrogen because of its diffusibility and reactivity as a fuel. This behavior is greatest when other mixture components are much heavier and slower than hydrogen, such as the halogenated components carbon tetrachloride and 1,2-dichloroethane. The other hydrogen-containing mixtures and the pure VOC mixtures (excluding hydrogen and carbon tetrachloride) show a sharp discontinuity at the flammability boundary and, therefore, have more well-defined MLEL and LEL values (Zlochower et al. 1997). 


\subsection{METHODOLOGY IMPLEMENTATION}

The implementation of the flammability assessment methodology involves several discrete activities: (a) model development, evaluation, and selection; (b) development of screening limits; (c) evaluation of drum flammability; and (d) determination of drum decay heat and aspiration time requirements. The first two activities were accomplished using flammability test data and TRU waste drum headspace gas data, and are summarized below. The last two activities are performed on a drum-by-drum basis and will be implemented when the methodology has been approved by the NRC; the strategy for performing these activities is described in subsequent sections.

For the predictive model evaluation and selection, various predictive methods were used to calculate the MLEL for each of the 38 test gas mixtures that were determined experimentally by the PRC. Next, statistical analyses were performed to obtain statistical parameters that were used to evaluate the various predictive models. The statistical parameters were obtained by comparing the experimentally determined MLELs with MLEL predictions made using empirical and theoretical models. A predictive model was then selected that performed well relative to experimental data, adequately accounted for gas mixture compositions in drums, and also demonstrated an acceptable level of conservatism. Finally, the selected predictive model was used to develop screening limits by waste type for evaluating drum flammability. Screening limits were based on statistics for gas concentrations in innermost confinement layers of drums determined to be nonflammable based on predicted drum MLELs. Gas concentrations in innermost confinement layers were estimated using previously established relationships between the innermost confinement layer concentrations and the drum headspace concentrations that were derived using gas transport models.

For the drum-specific flammability evaluation and determination of decay heat and aspiration time requirements, data from drums that are characterized under the TWCP will be used. The strategy involves comparison of the SHM and the log of the SFVOC to the waste type specific screening limits, comparison with less conservative drum-specific limits as necessary, and flame testing for drums that exceed the drum-specific limits. The screening limit or drum-specific MPHMC, as appropriate, will be used to establish the maximum allowable flammable gas generation rate, decay heat, and aspiration time requirements for an individual drum.

\subsection{Model Development, Evaluation, and Selection}

Central to FAMP activities is the use of a model for predicting MLELs in TRU waste containers. Seven different models or methods are evaluated in this report. The models include the original method of Le Chatelier, a modified Le Chatelier method (i.e., Le Chatelier with Nonflammable Mole Fraction) based on accounting for the nonflammable VOC proportion, a group contribution factor (Group) method, a Flammable Group method, a Group Corrected method, and predictions made using the ASTM CHETAH beta version 7.1 code ASTM 1997c). The experimentally determined MLELs were used to develop a seventh model, a Linear Regression model, to predict MLELs. The linear regression model was evaluated in two forms, one using logs of test MLELs and one using the original, untransformed, MLELs. In subsequent text, these models are referred to as Le Chatelier Original, Le Chatelier with Nonflammable Mole Fraction (or modified Le Chatelier), Group, Flammable Group, Group Corrected, ASTM CHETAH, Linear Regression (Ln), and Linear Regression, respectively. In addition, the effect of imposing bias on relatively unbiased models was investigated. A complete description of the predictive methods is provided in Appendix C.

In addition to predicting the MLELs, the limiting adiabatic flame temperature corresponding to the MLEL was estimated for each test mixture using the Aspen Plus code and the National Aeronautics and Space Administration (NASA) CET93/CETPC code McBride et al. (1994). The calculated limiting adiabatic flame temperatures were used to develop a linear regression model to predict limiting adiabatic flame temperatures. The model predictions 
and a discussion of the performance of predicted limiting adiabatic flame temperatures in determining flammability of TRU waste drums is provided in Appendix C.

The results of predictive modeling were used to select the method for developing waste type-specific screening limits, as discussed in Section 3.2. The selected method will also be used to assess the flammability of individual waste containers. In selecting the predictive method, two types of evaluations were made. An experimental-based evaluation compared the MLEL model predictions for the 38 test gas mixtures to the actual PRC test results. Table 3-1 summarizes the results of using the methods in predicting the MLEL for the test mixtures as well as the experimentally determined MLELs. A drum-based evaluation compared the MLEL model predictions for the 532 TWCP drums used in the FAMP.

Statistics for parameters that describe the relationship of predictions to test MLELs were generated for use in the experimental-based evaluation. These parameters are:

- Residuals, which are the differences between the test MLEL and the predicted MLEL

- Residuals scaled by the test MLEL

- Ratio of the test MLEL to the predicted MLEL

- Log of the ratio of the test MLEL to the predicted MLEL

- Percentage of predictions that are within \pm two times the experimental error

- Percentage of predictions that are under the test MLEL

- Percentage of predictions that the $\log$ of the ratio of the test MLEL to predicted MLEL is greater than zero

- Percentage of predictions that are more than two times the experimental error lower than the test MLEL.

These parameters are measures of the degree and consistency of agreement between predicted and test MLELs.

The statistics were generated for the seven models mentioned previously. In addition, two models, the Group model and the Linear Regression ( $\mathrm{Ln}$ ) model, were adjusted based on experimental error to derive models that are conservative in predictions. The adjustments are based on absolute experimental error and relative experimental errors, resulting in the following four additional models referred to as Group Absolute Adjusted, Linear Regression (Ln) Absolute Adjusted, Group Relative Adjusted, and Linear Regression (Ln) Relative Adjusted.

The statistics for the experimental-based evaluation are presented in Table 3-2. The statistics show that the linear regression models and, to a lesser extent, the Group and Group Corrected models, are unbiased and have relatively low errors. Bias-adjusted Linear Regression ( $\mathrm{Ln}$ ) and Group models consistently underpredict test MLELs by the largest amount. The Flammable Group and Le Chatelier models are also fairly consistent underpredictors. The ASTM CHETAH model is a large underpredictor with high error.

Except for the linear regression models, the models tended to overpredict the $50 \%$ hydrogen and $50 \%$ carbon tetrachloride test MLEL value. This value, and also the 100\% 1,2-dichloroethane value had high influence measures for the linear regression models. Log transformation of the test MLELs prior to regression reduced the influence of specific test values in the regression and also improved the ability of the models to meet necessary model assumptions on error distributions. 
Table 3-1. Results of predictive mixture lower explosive limits modeling.

\begin{tabular}{|c|c|c|c|c|c|c|c|c|}
\hline $\begin{array}{l}\text { Mixture } \\
\text { No. }\end{array}$ & Experimental & $\begin{array}{l}\text { Le Chatelier } \\
\text { Original }\end{array}$ & $\begin{array}{c}\text { Le Chatelier } \\
\text { with } \\
\text { Nonflammable } \\
\text { Mole Fraction }\end{array}$ & $\begin{array}{l}\text { Flammable } \\
\text { Group }\end{array}$ & Group & $\begin{array}{l}\text { Group } \\
\text { Corrected }\end{array}$ & $\begin{array}{c}\text { ASTM } \\
\text { CHETAH }\end{array}$ & $\begin{array}{l}\text { Linear } \\
\text { Regression } \\
\text { (Ln) }\end{array}$ \\
\hline 1 & 3.40 & 2.28 & 2.85 & 2.35 & 3.09 & 3.00 & 2.55 & 3.28 \\
\hline 2 & 4.85 & 4.85 & 4.85 & 5.52 & 5.52 & 4.85 & 4.89 & 4.88 \\
\hline 3 & 2.65 & 2.78 & 2.78 & 2.89 & 2.89 & 2.78 & 2.84 & 2.66 \\
\hline 4 & 1.95 & 1.95 & 1.95 & 2.02 & 2.02 & 1.95 & 1.97 & 1.97 \\
\hline 5 & 2.40 & 2.28 & 2.28 & 2.35 & 2.35 & 2.28 & 2.55 & 2.42 \\
\hline 6 & 3.40 & 3.30 & 3.30 & 3.40 & 3.40 & 3.30 & 4.00 & 3.47 \\
\hline 7 & 5.15 & 3.26 & 4.35 & 3.36 & 4.95 & 4.79 & 4.00 & 5.30 \\
\hline 8 & 4.85 & 2.82 & 4.21 & 2.93 & 4.99 & 4.77 & 2.84 & 4.87 \\
\hline 9 & 2.80 & 1.93 & 2.58 & 2.00 & 2.82 & 2.72 & 1.97 & 2.75 \\
\hline 10 & 2.05 & 1.92 & 1.92 & 2.02 & 2.02 & 1.92 & 1.96 & 2.02 \\
\hline 11 & 3.50 & 1.95 & 2.92 & 2.05 & 3.34 & 3.17 & 1.96 & 3.48 \\
\hline 12 & 2.65 & 2.44 & 2.44 & 2.54 & 2.54 & 2.44 & 2.81 & 2.69 \\
\hline 13 & 3.95 & 2.42 & 3.23 & 2.52 & 3.61 & 3.46 & 2.81 & 4.06 \\
\hline 14 & 5.35 & 4.92 & 4.92 & 5.25 & 5.25 & 4.92 & 8.00 & 5.25 \\
\hline 15 & 9.70 & 5.00 & 7.46 & 5.33 & 10.20 & 9.41 & 8.00 & 9.82 \\
\hline 16 & ND & 4.85 & 9.70 & 5.52 & 20.62 & 16.40 & 4.89 & ND \\
\hline 17 & 1.95 & 1.95 & 1.95 & 1.96 & 1.96 & 1.95 & 2.00 & 1.95 \\
\hline 18 & 4.65 & 1.95 & 3.90 & 1.96 & 4.69 & 4.67 & 2.00 & 4.65 \\
\hline 19 & 1.45 & 1.49 & 1.49 & 1.51 & 1.51 & 1.49 & 1.52 & 1.45 \\
\hline 20 & 3.15 & 2.81 & 2.81 & 2.81 & 2.81 & 2.81 & 3.67 & 3.13 \\
\hline 21 & 2.90 & 1.94 & 2.59 & 1.97 & 2.78 & 2.74 & 2.20 & 2.97 \\
\hline 22 & 1.20 & 1.20 & 1.20 & 1.23 & 1.23 & 1.20 & 1.22 & 1.20 \\
\hline 23 & 2.90 & 1.20 & 2.40 & 1.23 & 2.75 & 2.67 & 1.22 & 2.90 \\
\hline 24 & 2.05 & 1.94 & 1.94 & 1.98 & 1.98 & 1.94 & 2.32 & 2.04 \\
\hline 25 & 3.65 & 1.96 & 2.93 & 2.01 & 3.27 & 3.19 & 2.32 & 3.60 \\
\hline 26 & 5.0 & 5.00 & 5.00 & 5.00 & 5.00 & 5.00 & 22.00 & 5.02 \\
\hline 27 & 10.80 & 5.00 & 10.00 & 5.00 & 17.27 & 17.27 & 22.00 & 10.86 \\
\hline 28 & 2.45 & 1.51 & 2.25 & 1.54 & 2.45 & 2.40 & 1.52 & 2.41 \\
\hline 29 & 2.00 & 1.96 & 1.96 & 1.99 & 1.99 & 1.96 & 2.20 & 1.97 \\
\hline 30 & 5.20 & 2.85 & 4.25 & 2.86 & 4.84 & 4.82 & 3.67 & 5.16 \\
\hline 31 & NF & NA & NA & NA & -11.88 & -11.88 & NA & NA \\
\hline 32 & NA & NA & NA & NA & NA & NA & NA & NA \\
\hline 33 & 3.45 & 1.95 & 2.92 & 2.05 & 3.34 & 3.17 & 1.96 & 3.48 \\
\hline 34 & 2.35 & 1.51 & 2.25 & 1.54 & 2.45 & 2.40 & 1.52 & 2.41 \\
\hline 35 & 10.10 & 5.00 & 7.46 & 5.33 & 10.20 & 9.41 & 8.00 & 9.82 \\
\hline 36 & 5.20 & 2.85 & 4.25 & 2.86 & 4.84 & 4.82 & 3.67 & 5.16 \\
\hline 37 & NA & NA & NA & NA & $\mathrm{NA}$ & NA & $\mathrm{NA}$ & NA \\
\hline 38 & 2.70 & 2.78 & 2.78 & 2.89 & 2.89 & 2.78 & 2.84 & 2.66 \\
\hline 39 & 2.05 & 1.94 & 1.94 & 1.98 & 1.98 & 1.94 & 1.96 & 2.04 \\
\hline 40 & 2.40 & 2.28 & 2.28 & 2.35 & 2.35 & 2.28 & 2.55 & 2.42 \\
\hline & ble. & & & & & & & \\
\hline
\end{tabular}


Table 3-2. Statistics for parameters used in the experimental-based evaluation.

\begin{tabular}{|c|c|c|c|c|c|c|}
\hline Model & $\begin{array}{c}\text { Average } \\
\text { (Standard } \\
\text { Deviation) of } \\
\text { MLEI }_{\text {test }} \\
\text { MLEL pred }^{\prime}\end{array}$ & $\begin{array}{c}\% \text { Test } \\
\text { Values } \\
\text { Predicted } \\
\text { within } \pm 2 \mathrm{e}^{\mathrm{a}} \\
\end{array}$ & $\begin{array}{c}\% \text { Test } \\
\text { Values } \\
\text { Underpredicted } \\
\end{array}$ & $\begin{array}{c}\% \text { Test } \\
\text { Values } \\
\text { Underpredicted } \\
\text { by } 2 \mathrm{e}^{\mathbf{a}} \\
\end{array}$ & $\begin{array}{c}\text { Average } \\
\text { (Standard } \\
\text { Deviation) of } \\
\text { Residuals } \\
\end{array}$ & $\begin{array}{c}\text { Average } \\
\text { (Standard } \\
\text { Deviation) of } \\
\text { Residuals }{ }^{b} \\
\text { Predicted } \\
\text { Values }\end{array}$ \\
\hline $\begin{array}{l}\text { ASTM } \\
\text { CHETAH }\end{array}$ & $\begin{array}{c}1.20 \\
(0.45)\end{array}$ & 16.67 & 55.56 & 52.78 & $\begin{array}{c}-0.26 \\
(3.62)\end{array}$ & $\begin{array}{c}0.20 \\
(0.45)\end{array}$ \\
\hline $\begin{array}{l}\text { Flammable } \\
\text { Group }^{\circ}\end{array}$ & $\begin{array}{c}1.38 \\
(0.44)\end{array}$ & 27.78 & 77.78 & 61.11 & $\begin{array}{c}1.05 \\
(1.49)\end{array}$ & $\begin{array}{c}0.38 \\
(0.44)\end{array}$ \\
\hline Group & $\begin{array}{c}1.00 \\
(0.08)\end{array}$ & 50.00 & 63.89 & 36.11 & $\begin{array}{l}-0.15 \\
(1.11)\end{array}$ & $\begin{array}{c}2.84 \mathrm{E}-03 \\
(0.08)\end{array}$ \\
\hline $\begin{array}{l}\text { Group } \\
\text { Corrected }\end{array}$ & $\begin{array}{c}1.04 \\
(0.09)\end{array}$ & 47.22 & 75.00 & 47.22 & $\begin{array}{c}-1.22 \mathrm{E}-02 \\
(1.12)\end{array}$ & $\begin{array}{c}3.57 \mathrm{E}-02 \\
(0.09)\end{array}$ \\
\hline $\begin{array}{l}\text { Le Chatelier } \\
\text { Original }\end{array}$ & $\begin{array}{c}1.42 \\
(0.44)\end{array}$ & 27.78 & 80.56 & 69.44 & $\begin{array}{c}1.14 \\
(1.50)\end{array}$ & $\begin{array}{c}0.42 \\
(0.44)\end{array}$ \\
\hline $\begin{array}{l}\text { Le Chatelier } \\
\text { with } \\
\text { Nonflammable } \\
\text { Mole Fraction }\end{array}$ & $\begin{array}{l}1.11 \\
(0.10)\end{array}$ & 33.33 & 80.56 & 63.89 & $\begin{array}{c}0.43 \\
(0.59)\end{array}$ & $\begin{array}{c}0.11 \\
(0.10)\end{array}$ \\
\hline $\begin{array}{l}\text { Linear } \\
\text { Regression }\end{array}$ & $\begin{array}{c}1.00 \\
(0.03)\end{array}$ & 83.33 & 58.33 & 5.56 & $\begin{array}{c}-3.64 \mathrm{E}-08 \\
(0.11)\end{array}$ & $\begin{array}{c}8.00 \mathrm{E}-04 \\
(0.03)\end{array}$ \\
\hline $\begin{array}{l}\text { Linear } \\
\text { Regression }(\mathrm{Ln})^{c}\end{array}$ & $\begin{array}{c}1.00 \\
(0.02)\end{array}$ & 94.44 & 50.00 & 0.00 & $\begin{array}{c}1.12 E-03 \\
(0.07)\end{array}$ & $\begin{array}{c}1.11 E-04 \\
(0.02)\end{array}$ \\
\hline $\begin{array}{l}\text { Group Absolute } \\
\text { Adjusted }^{\mathrm{f}}\end{array}$ & $\begin{array}{c}1.20 \\
(0.15)\end{array}$ & 8.33 & 97.22 & 86.11 & $\begin{array}{c}0.30 \\
(1.11)\end{array}$ & $\begin{array}{c}0.20 \\
(0.15)\end{array}$ \\
\hline $\begin{array}{l}\text { Linear } \\
\text { Regression (Ln) } \\
\text { Absolute } \\
\text { Adjusted } \\
\text { e,f }\end{array}$ & $\begin{array}{c}1.19 \\
(0.11)\end{array}$ & 11.11 & 100.00 & 88.89 & $\begin{array}{c}0.45 \\
(0.07)\end{array}$ & $\begin{array}{c}0.19 \\
(0.11)\end{array}$ \\
\hline $\begin{array}{l}\text { Group Relative } \\
\text { Adjusted }^{\mathrm{B}}\end{array}$ & $\begin{array}{c}1.06 \\
(0.09)\end{array}$ & 30.56 & 94.44 & 63.89 & $\begin{array}{c}7.98 \mathrm{E}-02 \\
(0.98)\end{array}$ & $\begin{array}{c}6.43 E-02 \\
(0.09)\end{array}$ \\
\hline $\begin{array}{l}\text { Linear } \\
\text { Regression (Ln) } \\
\text { Relative } \\
\text { Adjusted }^{\mathrm{e}, \mathrm{g}}\end{array}$ & $\begin{array}{c}1.06 \\
(0.02)\end{array}$ & 27.78 & 100.00 & 72.22 & $\begin{array}{c}0.22 \\
(0.16)\end{array}$ & $\begin{array}{c}6.15 E-02 \\
(0.02)\end{array}$ \\
\hline $\begin{array}{l}\text { a. Experimental err } \\
\text { b. MIEI test - MLE } \\
\text { c. Excludes nonflar } \\
\text { d. Includes nonflan } \\
\text { e. Regression fit to } \\
\text { f. Adjusted by (mea } \\
\text { g. Adjusted by (1- ( }\end{array}$ & $\begin{array}{l}\text { red. } \\
\text { nable constituer } \\
\text { lable constituen } \\
\text { g transformed e } \\
\text { experimental er } \\
\text { ean relative exp }\end{array}$ & $\begin{array}{l}\text { In mole fraction } \\
\text { mole fraction } \\
\text { erimental data. } \\
+2 \text { standard } \\
\text { imental error }\end{array}$ & $\begin{array}{l}d \text { as a group. } \\
\text { as a group, and } \\
\text { iations) }=-0.449 \\
\text { tandard deviation }\end{array}$ & $=x(1-0.05781)$ & & \\
\hline
\end{tabular}


The drum-based evaluation consisted of comparing the performance of the models in predicting MLELs for TRU waste containers using headspace gas data for the 532 TWCP drums used in the FAMP. Innermost confinement layer concentrations were used in the evaluation. Section 3.2 describes estimation methods for obtaining the innermost layer concentrations.

Models used in the drum-based evaluation are those that performed well in the experimental-based evaluation. Table 3-3 gives the percentage of drums used in the evaluation predicted to be flammable using MLELs predicted with the models. The adjusted group models predict the greatest number of flammable drums, followed by the Group, Flammable Group, and modified Le Chatelier methods, with the linear regression models predicting the least number of flammable drums.

In applying the models to actual drum data, it was found that some of the methods resulted in unrealistic MLELs. For instance, all methods except the Flammable Group method resulted in extremely high MLELs predicted for some drums. Also, group methods that used negative group contribution factors (i.e., those that accounted for nonflammable constituents) resulted in negative MLELs in some instances, depending on the proportions of constituents in the headspace gas. This results in a higher percentage of drums predicted to be flammable than is appropriate because any sum of flammable gas and flammable VOC concentrations exceeds a negative MLEL. Because such anomalous MLEL values do not complement the flammability assessment methodology, where the flammable VOC and flammable gas characteristics need to be examined separately, the methods that provide these predictions are not appropriate to use. For this reason, and because of favorable results in the experimental-based evaluation, the Flammable Group model was used in developing screening limits and was included in the strategy for evaluating individual drums.

\subsection{Development of Screening Limits}

Screening limits were developed to provide a process for establishing that the gases in a drum either are not potentially flammable or need further evaluation. Such a process uses functions of measured headspace gas concentrations and eliminates more extensive evaluations on drums with flammable gas concentrations within conservative screening limits. The first step in developing screening limits was to predict the concentrations of flammable gases and VOCs within the innermost confinement layer of drums that were sampled under the TWCP at the INEEL and RFETS. The second step involved predictions of the MLELs for each of the 532 TWCP drums and the identification and screening out of flammable drums. The last step involved calculation of statistical tolerance limits for the screening limits.

\subsubsection{Drum Confinement Layer Concentrations}

The TWCP is an established program at both the INEEL and RFETS. INEEL instituted its TWCP in 1991, and RFETS instituted its TWCP in 1993. Hundreds of drums stored at the INEEL and the RFETS have been sampled and analyzed for VOCs, hydrogen, and methane under the TWCP. Samples are obtained from headspace gases under the drum lid with the rigid drum liner punctured. The samples are analyzed for the 29 VOCs listed in Table 2-1 as well as for hydrogen and methane. To date, 1,331 drums have been sampled at the INEEL under the TWCP and 778 drums of TRU waste have been sampled under the TWCP at the RFETS. The FAMP used data from 441 drums characterized by the INEEL and 91 drums characterized by the RFETS. In addition to the gas concentrations, the container history (i.e., dates of closure, venting, and sampling) for each drum and classification by waste type were collected.

The highest concentrations of hydrogen, methane, and VOCs will typically occur within the innermost confinement layer in a drum. Thus, the innermost confinement layer has the highest potential to contain flammable gas mixtures. However, only concentrations in the drum headspace are typically available from the TWCP sampling program. Thus, a methodology to relate the concentrations of gases within the innermost 
Table 3-3. Percentage of drums predicted to be flammable of 532 drums used in the FAMP.

\begin{tabular}{|c|c|c|c|c|c|}
\hline \multirow[b]{2}{*}{ Model } & \multicolumn{4}{|c|}{ Waste Type } & \multirow[b]{2}{*}{$\begin{array}{c}\text { All Waste } \\
\text { Types }\end{array}$} \\
\hline & $I$ & II & III & IV & \\
\hline Flammable Group ${ }^{a}$ & 0.00 & 0.55 & 4.02 & 8.93 & 2.44 \\
\hline Group & 0.00 & 0.55 & 4.02 & 17.86 & 3.38 \\
\hline \multicolumn{6}{|l|}{$\begin{array}{l}\text { Le Chatelier with } \\
\text { Nonflammable Mole }\end{array}$} \\
\hline Fraction & 0.00 & 0.55 & 3.45 & 7.14 & 2.07 \\
\hline Linear Regression $(\mathrm{Ln})^{b}$ & 0.00 & 0.55 & 2.87 & 5.36 & 1.69 \\
\hline Group Absolute Adjusted ${ }^{\mathrm{C}}$ & 0.00 & 0.55 & 4.60 & 19.64 & 3.76 \\
\hline \multicolumn{6}{|l|}{ Linear Regression (Ln) } \\
\hline Group Relative Adjusted ${ }^{d}$ & 0.00 & 0.55 & 4.02 & 19.64 & 3.57 \\
\hline \multicolumn{6}{|l|}{ Linear Regression (Ln) } \\
\hline $\begin{array}{l}\text { a. Excludes nonflammable consti } \\
\text { b. Regression fit to log transform } \\
\text { c. Adjusted by (mean experiment } \\
\text { d. Adjusted by ( } 1 \text {-[mean relative }\end{array}$ & $\begin{array}{l}n \text { mole } \\
\text { eriment: } \\
r+2 \text { sta } \\
\text { nental e }\end{array}$ & $\begin{array}{l}\text { as a gro } \\
\text { tions) }= \\
\text { adard de }\end{array}$ & 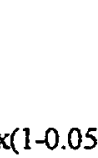 & & \\
\hline
\end{tabular}


confinement layer to the concentrations in the drum headspace was required for the FAMP. The required relationships for flammable gases and for VOCs have been established in other TRU waste studies described below.

Drums are either sealed and then vented (i.e., condition of the drum with a punctured rigid liner and one or more filters installed in the drum lid), or vented at the time of packaging and closure. The TRUPACT-II SARP (DOE 1996) requires that all drums are at steady state with respect to flammable gas concentrations within each confinement layer at the time of shipment. To have reached steady state, a drum must have been vented or aspirated for a sufficient period of time (referred to as the aspiration time). Aspiration times for containers stored in an unvented condition are tabulated by shipping category in aspiration tables contained in Appendix 3.6.11 of the TRUPACT-II SARP. Aspiration times were calculated using a computer code to simulate generation, accumulation, and transport of flammable gases across confinement layers. Furthermore, the aspiration tables were generated assuming that the drum is generating flammable gases at the maximum allowable flammable gas generation rate. The allowable flammable gas generation rates were established using theoretical worst-case pseudo steady-state calculations.

A recently completed TRU transportation initiative developed a methodology to allow the use of headspace flammable gas sampling as an alternative approach to certifying TRU waste containers for shipment (Djordjevic et al. 1997). An integral part of the methodology was development of the AltMeth computer code to calculate the actual container flammable gas generation rates and aspiration times.

The AltMeth code is ideally suited to establish steady-state flammable gas concentrations within the innermost confinement layer of the 532 TWCP drums used in the FAMP and was modified to do so. The revised AltMeth code (named PredH2) was documented and verified by running the 20 test cases (as a single input file) that were used to verify the original AltMeth code. The PredH2 code produced the same results as the original AltMeth code for the test cases.

Although the term flammable gases includes both hydrogen and methane, methane was not included in calculations of the screening limits because drum gas data suggest it is either not present or is present in very low concentrations. A comparison was made between drum inner layer and outer layer methane concentrations. For the comparison, the outer layer included drum bag and drum headspace samples; only 10 drums contained methane concentration results for both an inner layer and outer layer. All of the methane concentrations reported for these 10 drums were less than the analytical detection limit, which ranged from 0.017 to 0.04 volume percent (vol\%). In each case, the methane detection limit for the inner layer was either equal to or higher than the outer layer, usually 0.019 and $0.017 \mathrm{vol} \%$, respectively. The greatest difference was for a drum that had an inner layer detection limit of $0.04 \mathrm{vol} \%$ and an outer layer detection limit of $0.017 \mathrm{vol} \%$.

Several drums had multiple observations for inner layer and/or outer layer methane concentration. To develop a conservative comparison, the maximum detection limit for inner layer concentration was compared to that for the minimum outer layer concentration. Average and standard deviations were determined by dividing inner by outer layer detection limits for each drum, item description code (IDC), TRUPACT-II content code (TRUCON), waste matrix code group (WMCG), and waste type. Results are shown in Table 3-4. Two drums did not have IDC, TRUCON, WMCG, and waste type assigned, and are represented as "unknown" in Table 3-4. Since the detection limits are similar, the average of the inner layer divided by the outer layer methane concentration is 1.19 for all of the drums, with a standard deviation of 0.41 . Average and standard deviation vary only slightly depending on the comparison group (i.e., IDC, TRUCON, WMCG) and number of observations in each. The results indicate that methane, if present in drum gases, is present in low concentrations and innermost layer concentrations are not appreciably different from headspace gas concentrations. 
Table 3-4. Drum inner layer and outer layer methane concentration comparison.

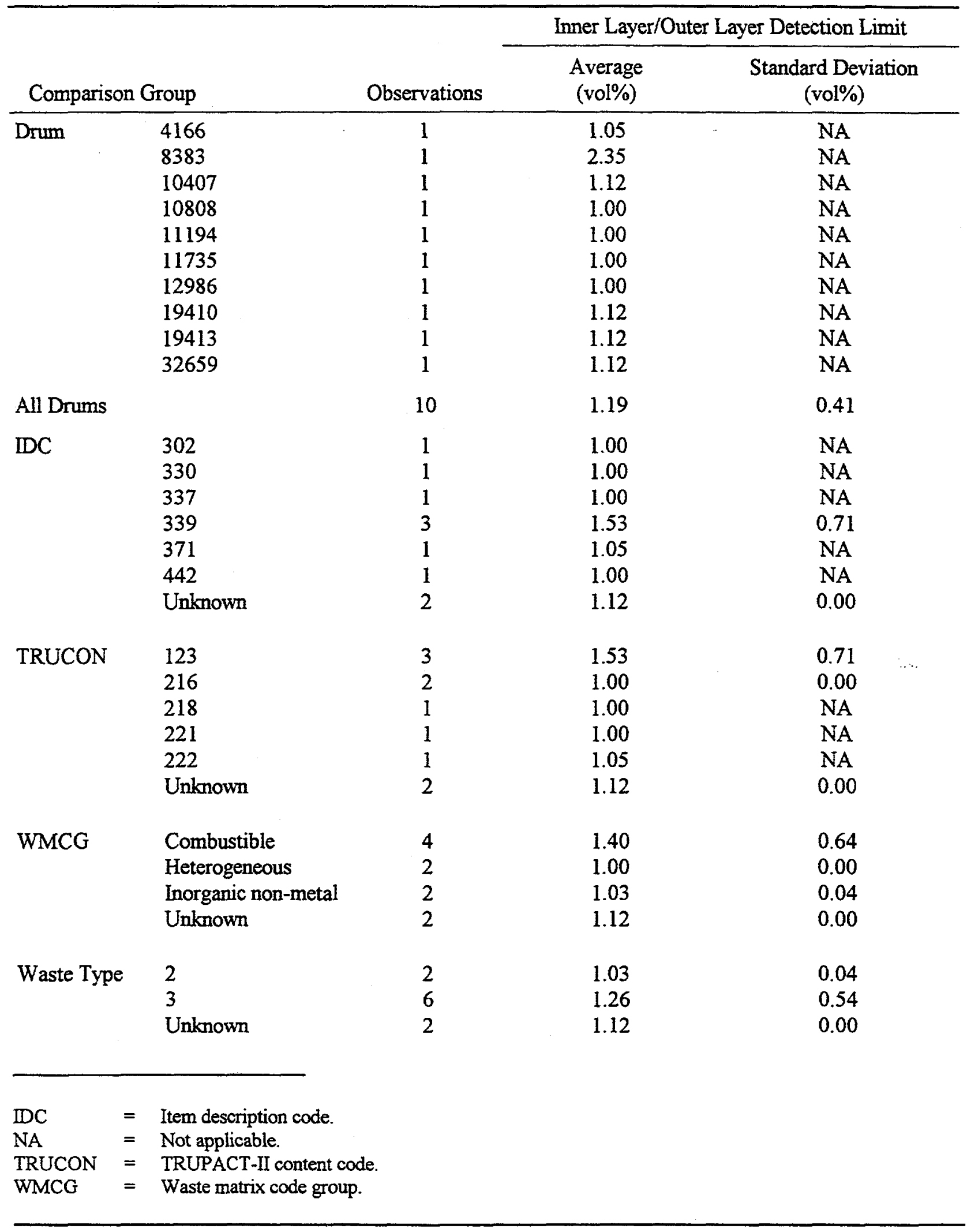


For determining the innermost layer VOC concentrations in TRU waste drums, a methodology is used that uses the results of INEEL VOC transport studies conducted at the INEEL (Connolly et al. 1995). The methodology specifies conditions under which waste drum headspace gases can be concluded as being representative of gases within all layers of confinement. Connolly et al. (1995) also describes a method for predicting gas concentrations within inner layers of confinement in situations where the drum headspace gas concentration is not representative. The methodology is based on steady-state and transient modeling, which incorporated theoretical diffusion and permeation transport principles. The model predictions were verified using the results of sampling simulated waste and waste from the INEEL and RFETS.

The transient VOC transport models were used to establish a drum age criterion (DAC) that each TRU waste drum must meet prior to sampling and analysis of the headspace gases. The DAC defines the time required after waste packaging to reach $90 \%$ of steady-state concentration within all plastic confinement layers. The DAC is 225 days for drums of waste type(s) I and IV, and 142 days for drums of waste type(s) II and III. The innermost confinement layer headspace gas phase VOC concentration is predicted from the drum headspace VOC concentration using a VOC-specific and waste type-specific prediction factor. The prediction factors for the various VOCs by waste type are summarized in Table 3-5. Only drums that satisfied the DAC were used in the FAMP. Data from sampling and analyzing the headspace under the drum lid for each of the 532 drums sampled under the TWCP were used to predict the concentrations of VOCs in the headspace gas of the innermost confinement layer. The predictions were performed by taking the product of waste type-specific prediction factors for each VOC and the drum headspace VOC concentration. Headspace gas measurements reported as less-than-detectable were assumed to be half the reported detection limit.

\subsubsection{Waste Type Screening Limits}

Screening limits were developed to provide a process for establishing that the gases in a drum either are not potentially flammable or need further evaluation. Only those drums that exceed a screening limit must be evaluated with respect to flammability on an individual basis. The screening limits are based on statistics for gas concentrations in innermost confinement layers of drums predicted to be nonflammable based on MLELs predicted using the Flammable Group model. The maximum permissible hydrogen and methane concentration (MPHMC) for each drum was calculated as the difference between the MLEL and the SFVOC. The MPHMCs and SFVOC for nonflammable drums were then used to establish screening limits by waste type.

The process used tolerance limits for the SFVOC and MPHMCs in the 532 drum population for screening limits. Tolerance limits for $85 \%$ of the population and $95 \%$ confidence $(95 / 85)$ were used for the limits because they offer the ability to make confidence statements on a specified percentile of a population. Assumptions of normal distributions for the application tolerance limits were evaluated. The MPHMCs were found to be normally distributed, while the SFVOC were found to be $\log$ normally distributed and required a $\log$ transformation. For the limits, a 95/85 upper tolerance limit (UTL) was used for the log of the SFVOC and a 95/85 lower tolerance limit (LTL) was developed using MPHMC data, which is the limit for drum SHM values. Statistics were generated on the performance of the screening limits relative to drums determined to be flammable (determined using both the Group model and the Flammable Group model) and are presented in Table 3-6. The statistics show that no drums determined to be flammable pass both screening limits, so no flammable drums would be deemed nonflammable. Sixty-two drums do not pass one or both limits and, thus, would be further evaluated, as described in Section 3.3. Table 3-7 lists the screening limits by waste type. 
Table 3-5. Volatile organic compound prediction factors by waste type.

\begin{tabular}{|c|c|c|}
\hline Compound & $\begin{array}{c}\text { Prediction Factor } \\
\text { Waste Types I \& IV }\end{array}$ & $\begin{array}{c}\text { Prediction Factor } \\
\text { Waste Types II \& III }\end{array}$ \\
\hline \multicolumn{3}{|l|}{ Flammable VOCs } \\
\hline Acetone & 1.9 & 5.1 \\
\hline Benzene & 1.5 & 3.4 \\
\hline 1-Butanol & 1.5 & 3.2 \\
\hline Chlorobenzene & 1.3 & 2.3 \\
\hline Cyclohexane & 9.5 & 39 \\
\hline 1,1-Dichloroethane & 1.7 & 4.1 \\
\hline 1,2-Dichloroethane & 1.4 & 2.7 \\
\hline 1,1-Dichloroethene & 2.1 & 6.1 \\
\hline cis-1,2-Dichloroethene & 1.5 & 3.3 \\
\hline Ethyl benzene & 1.4 & 3.2 \\
\hline Ethyl ether & 3.8 & 13 \\
\hline Methanol & 2.3 & 6.8 \\
\hline Methyl ethyl ketone & 1.8 & 4.5 \\
\hline Methyl isobutyl ketone & 1.8 & 4.8 \\
\hline Toluene & 1.2 & 2.3 \\
\hline 1,2,4-Trimethylbenzene & 1.4 & 2.8 \\
\hline 1,3,5-Trimethylbenzene & 1.4 & 3.0 \\
\hline o-Xylene & 1.4 & 2.7 \\
\hline $\mathrm{m} / \mathrm{p}$-Xylene & 1.4 & 3.1 \\
\hline \multicolumn{3}{|l|}{ Nonflammable VOCs } \\
\hline Bromoform & 1.1 & 1.7 \\
\hline Carbon tetrachloride & 1.6 & 3.9 \\
\hline Chloroform & 1.5 & 3.5 \\
\hline Methylene chloride & 1.6 & 3.7 \\
\hline 1,1,2,2-Tetrachloroethane & 1.2 & 1.8 \\
\hline Tetrachloroethene & 1.3 & 2.3 \\
\hline 1,1,1-Trichloroethane & 1.8 & 4.8 \\
\hline Trichloroethene & 1.3 & 2.4 \\
\hline 1,1,2-Trichloro-1,2,2-trifluoroethane & 3.6 & 13 \\
\hline
\end{tabular}


Table 3-6. Screening limits comparison.

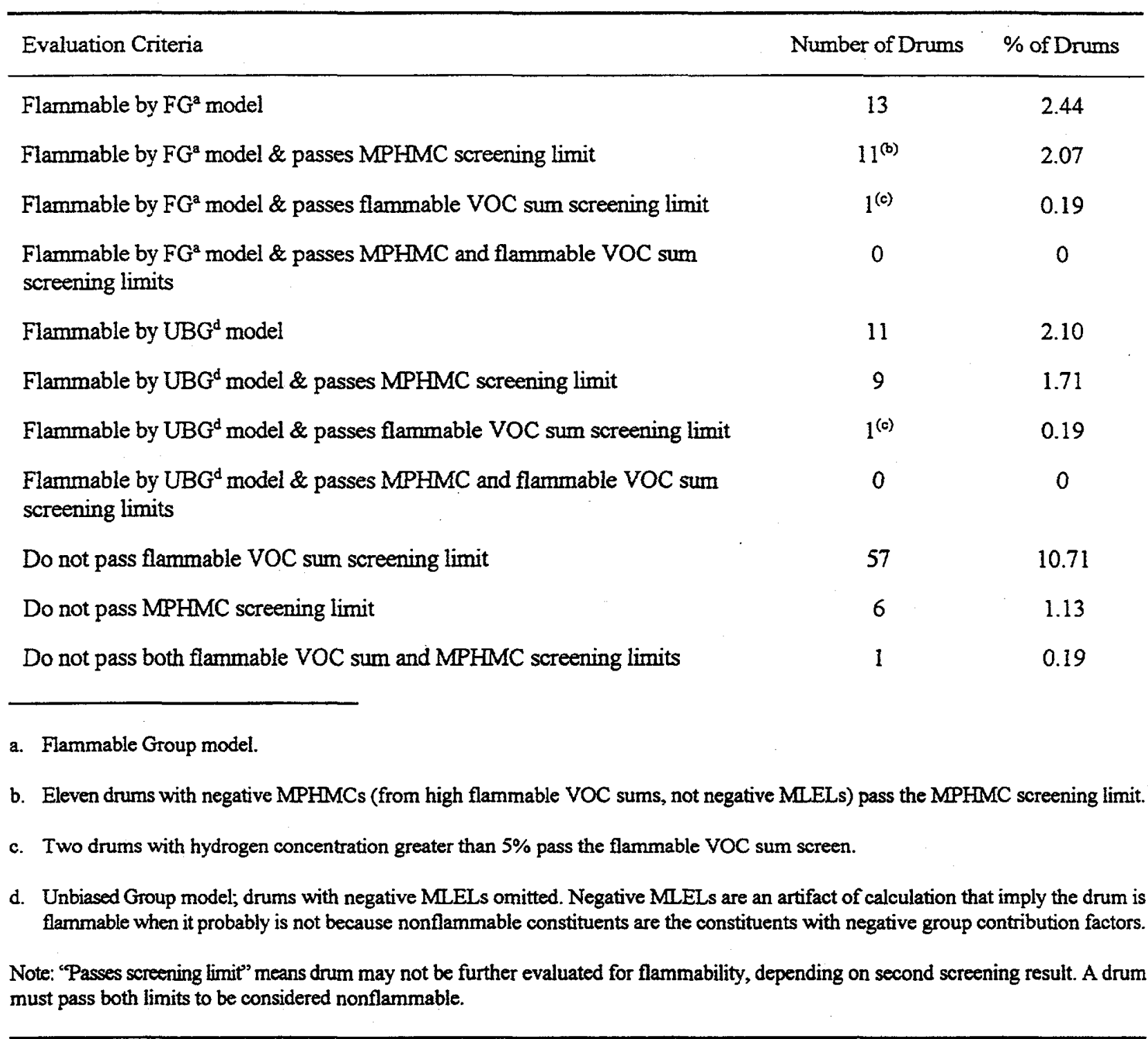


Table 3-7. Screening limits by waste type.

\begin{tabular}{lcc}
\hline Waste Type & $\begin{array}{c}\text { Screening Limit for Log of SFVOC } \\
\text { (Ln[ppmv]) }\end{array}$ & $\begin{array}{c}\text { Screening Limit for SHM } \\
\text { (vol\%) }\end{array}$ \\
\hline I & 5.27 & 2.96 \\
II & 6.49 & 3.25 \\
III & 7.11 & 2.92 \\
IV & 9.29 & 1.85 \\
& & \\
SFVOC $=$ & Sum of flammable volatile organic compound concentrations in the innermost confinement layer. \\
SHM $=$ & Sum of hydrogen and methane concentrations in the innermost layer. \\
\end{tabular}

\subsection{Strategy for Drum Flammability Evaluations}

Because of the conservatism in the screening limits, some drums will exceed one or both limits, but may not be flammable. Therefore, drums exceeding a limit will be subjected to up to two additional stages of evaluation. Figure 3-1 outlines detailed steps of the drum evaluation process, which is described below.

The first six steps in Figure 3-1 involve the evaluation of drum characteristics to screening limits. The DAC must be met (Step 1) prior to sampling of headspace gases under drum lids (Step 2). Conformance with the DAC helps ensure that quasi steady-state conditions within drum package layers exist and thus, predictions of headspace gas steady-state concentrations in innermost confinement layers are accurate or conservative. Steps 3 and 4 are performed using the methods described in Section 3.2.1. In Step 5, the sums of steady-state innermost confinement layer flammable gas concentrations are calculated for comparison to the appropriate (according to waste type) screening limits (Table 3-7) in Step 6. If both drum SFVOC and SHM are less than screening values, the drum must be evaluated in terms of meeting decay heat and aspiration time requirements (Step 13). The procedure for accomplishing Step 13 is different from that given in the current version of the TRUPACT-II SARP, and is described in further detail in Section 3.4.

For drums exceeding the screening limits, the second stage of drum evaluation involves prediction of drumspecific MLELs and MPHMCs (Step 7) and comparison of the sum of steady-state innermost confinement layer flammable gas and VOC concentrations (VOCs, hydrogen, and methane) to the drum-specific MLEL (Step 8). Drums with a flammable gas and VOC concentration sum less than the MLEL are then evaluated for meeting decay heat and aspiration time requirements for shipment (Step 13), as described in Section 3.4. Drum-specific MPHMCs calculated in Step 7 are used in evaluating decay heat and aspiration time requirements.

For drums exceeding screening limits and drum-specific MLELs, the third and final stage of evaluation involves flame testing of gas mixtures found in the drum. The mixture tested must represent the steady-state innermost layer gas concentration. Drums must satisfy the decay heat and aspiration time requirements (Step 9) and pass the flame test (i.e., contain gases that are not flammable) (Step 10) for shipment (Step 14). Drums that do not pass must be repackaged or treated prior to reevaluation and shipment. 


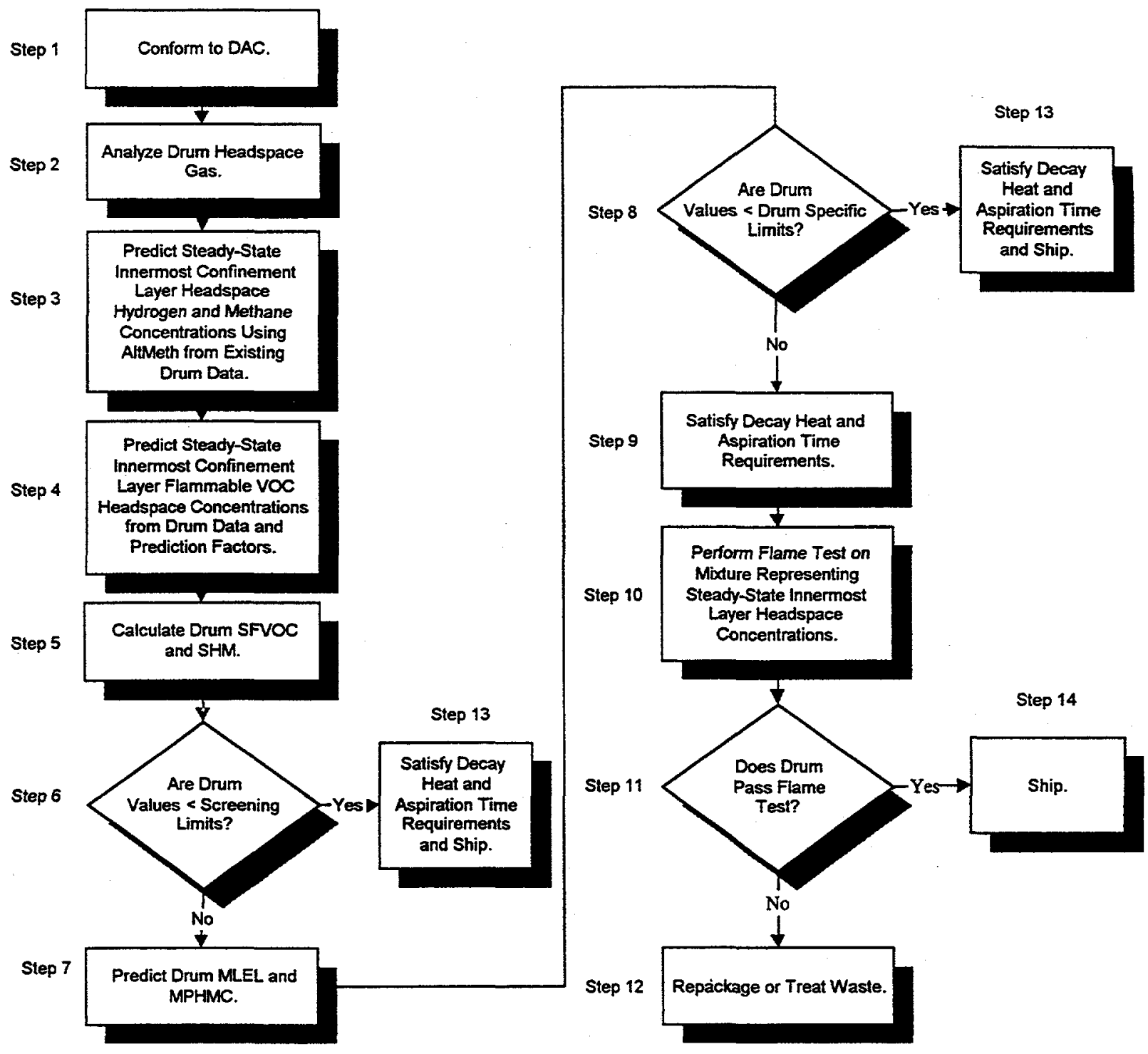

\begin{tabular}{|ll|}
\hline DAC & Drum age criteria. \\
MLEL & $=$ Mixture lower explosive limit. \\
MPHMC & $=$ Maximum permissible hydrogen and methane concentrations. \\
SFVOC & $=$ Sum of steady-state innermost confinement layer flammable VOC concentrations: \\
SHM & $=$ Sum of steady-state innermost confinement layer hydrogen and methane concentrations. \\
\hline
\end{tabular}

Figure 3-1. Steps in evaluating individual waste drums for flammability. 


\subsection{Strategy for Determination of Drum Decay Heat and Aspiration Time Requirements}

The steps involved in determining drum decay heat and aspiration time requirements differ from those given in the TRUPACT-II SARP. Under the flammability assessment methodology described here, there exists the potential for a drum to contain different concentrations of flammable gases than those assumed in the TRUPACT-II SARP for setting decay heat limits and required aspiration times. An application for an amendment to the TRUPACT-II Certificate of Compliance reflecting the revised approach to determining decay heat and aspiration time requirements must be submitted to the NRC prior to implementing this approach. The proposed steps for determining decay heat and aspiration time requirements are described below.

\subsubsection{Decay Heat Limits}

In Step 1 of determining decay heat limits for a drum, the pseudo steady-state methodology used in the TRUPACT-II SARP will be used to calculate the allowable flammable gas generation rate that corresponds to the MPHMC for the drum. The MPHMC corresponds to the maximum allowable hydrogen and methane concentration within the innermost confinement layer of a container at the end of a 60-day shipping period in a TRUPACT-II. The 95/85 LTL for the MPHMC based on existing drum data (the screening limit for the SHM) will be used for drums not exceeding waste-type specific screening limits. The use of a LTL for the MPHMC will provide a conservative value of the allowable container decay heat limit. For containers that exceed the screening limits, the drum-specific MPHMC will be used to calculate the allowable flammable gas generation rate.

Step 2 in determining decay heat limits is to combine the allowable flammable gas generation rate with the effective flammable gas G-value and appropriate conversion factors (as documented in the TRUPACT-I SARP), to arrive at the allowable decay heat for the container. G-values represent the amount of gas generated as a result of absorption of ionizing radiation by a target material (i.e., waste matrix).

The allowable flammable gas generation rate for a given shipping category was calculated in the TRUPACT-II SARP using Equation 3-1:

$$
C G=\frac{X_{\text {inner }}}{r_{\text {eff }}+\left(\frac{t N_{g e n}}{N_{\text {tg }}}\right)}
$$

where

$$
\begin{aligned}
& \mathrm{CG} \quad=\text { hydrogen gas generation rate per innermost confinement layer (mol/sec) } \\
& \mathrm{X}_{\text {inner }}=\text { maximum permissible hydrogen mole fraction }(0.05) \\
& \mathrm{r}_{\mathrm{eff}} \quad=\text { effective resistance to the release of hydrogen }(\mathrm{sec} / \mathrm{mol}) \\
& t \quad=\text { shipping period duration (60 days) } \\
& \mathrm{N}_{\text {gen }} \quad=\text { number of generators in inner containment vessel (ICV) (i.e., } 14 \text { drums) } \\
& \mathrm{N}_{\mathrm{tg}} \quad=\text { total moles of gas inside the TRUPACT-II ICV cavity (mol). }
\end{aligned}
$$


The decay heat is calculated using Equation 3-2 from the TRUPACT-II SARP:

$$
Q_{i}=\frac{\left(C G N_{A} 1.602 \times 10^{-19}\right)}{\frac{G}{100}}
$$

where

$\mathrm{Q}_{\mathrm{i}} \quad=$ decay heat per innermost confinement layer (watts)

$\mathrm{N}_{\mathrm{A}} \quad=$ Avogadro's number $\left(6.0225 \times 10^{23}\right.$ molecules $\left./ \mathrm{mole}\right)$

$\mathrm{G} \quad=$ effective $\mathrm{G}$ value for flammable gas (molecules of hydrogen generated/100eV emitted energy).

The results of the FAMP can be readily integrated into the existing methodology of calculating the allowable flammable gas generation and decay heat limit by replacing the 0.05 hydrogen mole fraction within the innermost confinement layer by the MPHMC (either the waste-type specific SHM screening value or the drum-specific MPHMC value, as appropriate) in Equation 3-1. Table 3-8 lists the decay heat limits for the various shipping categories that are currently in the TRUPACT-II SARP as well as the allowable decay heats that result by applying the MPHMC screening limits by waste type.

\subsubsection{Aspiration Times}

In Step 1 of determining required aspiration times, the MPHMC will be used to establish the flammable gas generation rates using the existing TRUPACT-II SARP pseudo steady-state methodology. The conservative 95/85 LTL for the MPHMC based on existing drum data will be used for drums not exceeding waste-type specific screening limits. The use of LTL for the MPHMC will provide a conservative estimate of the required container aspiration time. For containers that exceed the screening limits, the drum-specific MPHMC will be used to calculate the allowable flammable gas generation rate and corresponding aspiration time.

The aspiration time is a function of the packaging configuration (i.e., the number and types of confinement layers) within the container, the flammable gas generation rate, and condition of the container (i.e., sealed or vented) at the time of headspace sampling. The AltMeth computer code (Djordjevic et al. 1997) will be used to derive the aspiration time. The AltMeth code mathematically simulates the generation of flammable gas and subsequent transport across layers of confinement in a TRU waste drum. The code predicts concentrations within actual TRU waste containers as a function of time. Thus, the code can be used to predict steady-state concentrations and aspiration times. Each container must then be aspirated for the required time prior to shipment in the TRUPACT-II. 
Table 3-8. Shipping category decay heats.

Decay Heat (W)

Based on Maximum Hydrogen Mole Fraction Equivalent to

\begin{tabular}{|c|c|c|}
\hline $\begin{array}{l}\text { Payload Shipping } \\
\text { Category }\end{array}$ & $0.05^{\mathrm{a}}$ & MPHMC Screening Limit ${ }^{\mathrm{b}}$ \\
\hline I. $1 \mathrm{AO}$ & 0.2060 & 0.1219 \\
\hline $1.1 \mathrm{Al}$ & 0.1797 & 0.1063 \\
\hline I. $1 \mathrm{~A} 2$ & 0.1594 & 0.0943 \\
\hline I.1A3 & 0.0466 & 0.0275 \\
\hline $1.2 \mathrm{AO}$ & 0.2536 & 0.1500 \\
\hline $1.2 \mathrm{Al}$ & 0.2212 & 0.1308 \\
\hline $1.2 \mathrm{~A} 2$ & 0.1962 & 0.1160 \\
\hline I. $2 \mathrm{A3}$ & 0.0573 & 0.0339 \\
\hline $1.2 \mathrm{A4}$ & 0.0418 & 0.0247 \\
\hline $1.3 \mathrm{AO}$ & 0.8241 & 0.4875 \\
\hline $1.3 \mathrm{Al}$ & 0.7189 & 0.4252 \\
\hline $1.3 \mathrm{~A} 2$ & 0.6375 & 0.3771 \\
\hline $1.3 \mathrm{~A} 3$ & 0.1863 & 0.1102 \\
\hline I.3A4 & 0.1359 & 0.0804 \\
\hline II. $1 \mathrm{AO}$ & 0.2251 & 0.1464 \\
\hline II. $1 \mathrm{~A} 1$ & 0.1924 & 0.1251 \\
\hline II. $1 \mathrm{~A} 2 \mathrm{a}$ & 0.1680 & 0.1093 \\
\hline II. $1 \mathrm{~A} 2$ & 0.0869 & 0.0565 \\
\hline II. $1 \mathrm{A3}$ & 0.0561 & 0.0365 \\
\hline II. $1 \mathrm{~A} 4$ & 0.0414 & 0.0269 \\
\hline II. 1 A5 & 0.0328 & 0.0213 \\
\hline II. $1 \mathrm{~A} 6$ & 0.0272 & 0.0177 \\
\hline II. $2 \mathrm{AM}$ & $\mathrm{NA}$ & $\mathrm{NA}$ \\
\hline III. $1 \mathrm{~A} 0$ & 0.1126 & 0.0657 \\
\hline III.1Al & 0.0962 & 0.0562 \\
\hline III. $1 \mathrm{~A} 2 \mathrm{a}$ & 0.0840 & 0.0490 \\
\hline III. 1 A2 & 0.0434 & 0.0253 \\
\hline III. $1 \mathrm{~A} 3$ & 0.0280 & 0.0164 \\
\hline III. $1 \mathrm{~A} 4$ & 0.0207 & 0.0121 \\
\hline III. $1 \mathrm{~A} 5$ & 0.0164 & 0.0096 \\
\hline III. $1 \mathrm{~A} 6$ & 0.0136 & 0.0079 \\
\hline
\end{tabular}

a. Maximum permissible hydrogen mole fraction for innermost confinement layer identified in the TRUPACT-II SARP.

b. Maximum permissible hydrogen mole fraction based on screening limits as follows:

Shipping Category Type Hvdrogen mole fraction

$\begin{array}{ll}\text { I } & 0.0296 \\ \text { II } & 0.0325 \\ \text { III } & 0.0292\end{array}$

$\mathrm{NA}=$ Not applicable. 


\subsection{CONCLUSIONS AND RECOMMENDATIONS}

\subsection{Discussion}

The flammability experimental work successfully measured MLELs for mixtures of VOCs and flammable gases and provided valuable data for evaluating MLEL prediction models to be used in the FAMP. With the data, model performance could be evaluated on the direction, magnitude, and consistency in bias in predicting MLELs; models such as the Flammable Group model that were found to underpredict consistently were considered viable for use in the FAMP. Using the actual waste drum data, the model evaluation identified methods that, because constituent proportions in drums are different from those used in experimental work, predicted MLELs that in some cases are not feasible to use in the methodology. From these evaluations, the Flammability Group method was selected for use in the FAMP.

Conservative screening limits were developed for use in the flammability assessment methodology to identify drums requiring assessments using the MLEL model. The limits are based on conservative predictions of innermost layer gas concentrations, on data for drums identified as nonflammable using an underpredicting MLEL model, and high confidence for percentiles of the nonflammable population. Screening limits determined using the available data performed well, with no conservatively identified flammable drums passing both screening limits. The limits are higher than the current $500 \mathrm{ppmv}$ limit for waste types with relatively high concentrations of flammable VOCs. For the 532 drums examined, more than $20 \%$ have flammable VOCs in innermost layers of confinement that exceeded the $500 \mathrm{ppmv}$, but only $2.44 \%$ were flammable by the conservative Flammable Group model.

The study indicates that the methodology can be safely implemented on actual waste containers while increasing the number of containers that can be shipped to the WIPP. Section 4.2 provides recommendations for finalizing the methodology.

\subsection{Recommendations}

Recommendations for finalizing the methodology include additional flammability testing to complete MLEL model validation, updating screening limits, and updating assumptions on the prevalence of methane in TRU waste drums. The experimental design would be finalized in the revision of the FAMP Test Plan (Connolly et al. 1997) upon funding of the testing.

Available headspace gas data was used to construct screening limits and for inference on the prevalence of methane in TRU waste drums. The range of IDCs covered by these data has not been examined, nor has the distribution of IDCs. Also, the number of drums with information available on methane concentrations in innermost layers is small. It is recommended that prior to submitting an application to the NRC, headspace gas data available at that time be examined for these properties, assumptions on methane prevalence updated, and screening limits updated as necessary.

It is recommended that flammability testing focus on testing mixtures that more closely reflect mixtures observed in TRU waste drums, and investigate the effects of elevated temperature on the MLEL. A preliminary investigation was performed to predict the variation of LELs with temperature. The Burgess-Wheeler law modified by Zabetakis (Kuchta 1985) was used to predict LELs at $63.3^{\circ} \mathrm{C}$ using Equation 4-1. A temperature of $63.3^{\circ} \mathrm{C}$ corresponds to the highest expected temperature expected in the TRUPACT-II shipping package during an assumed 60-day shipping period. Table 4-1 lists LEL predictions at ambient and at elevated temperatures. 
Table 4-1. Variation of predicted MLEL with temperature at $63.3^{\circ} \mathrm{C}$.

\begin{tabular}{|c|c|c|c|c|}
\hline Compound & $\begin{array}{l}\text { Heat of Combustion } \\
\qquad\left(\mathrm{H}_{\mathrm{c}}\right) \\
\left(\mathrm{kcal} / \mathrm{mol} \text { at } 25^{\circ} \mathrm{C}\right)\end{array}$ & $\begin{array}{c}\text { Lower Explosive } \\
\text { Limit } \\
\left(\mathrm{L}_{25}\right) \\
\left(\% \text { at } 25^{\circ} \mathrm{C}\right)\end{array}$ & $\begin{array}{c}\text { Lower Explosive } \\
\text { Limit } \\
\left(\mathrm{L}_{63.3}\right) \\
\left(\% \text { at } 63.3{ }^{\circ} \mathrm{C}\right)\end{array}$ & $\begin{array}{c}\text { Ratio } \\
\left(\mathrm{L}_{63.3} \text { to } \mathrm{L}_{25}\right)\end{array}$ \\
\hline \multicolumn{5}{|l|}{ Flammable VOCs } \\
\hline Acetone & 403 & 2.60 & 2.53 & 0.9726 \\
\hline Benzene & 757.5 & 1.30 & 1.26 & 0.9708 \\
\hline 1-Butanol & 596 & 1.70 & 1.65 & 0.9716 \\
\hline Chlorobenzene & 714 & 1.30 & 1.26 & 0.9691 \\
\hline Cyclohexane & 881.7 & 1.30 & 1.27 & 0.9749 \\
\hline 1,1-Dichloroethane & 259 & 5.60 & 5.49 & 0.9802 \\
\hline 1,2-Dichloroethane & 259 & 4.85 & 4.76 & 0.9821 \\
\hline 1,1-Dichloroethene & 232 & 6.50 & 6.38 & 0.9810 \\
\hline cis-1,2-Dichloroethene & 232 & 5.60 & 5.48 & 0.9779 \\
\hline Ethyl benzene & 1049 & 1.00 & 0.97 & 0.9726 \\
\hline Ethyl ether & 605 & 1.90 & 1.85 & 0.9750 \\
\hline Methanol & 159 & 6.70 & 6.52 & 0.9730 \\
\hline Methyl ethyl ketone & 548 & 1.95 & 1.90 & 0.9724 \\
\hline Methyl isobutyl ketone & 818 & 1.40 & 1.36 & 0.9749 \\
\hline Toluene & 901.5 & 1.20 & 1.17 & 0.9734 \\
\hline 1,2,4-Trimethylbenzene & 1189.92 & 0.90 & 0.88 & 0.9732 \\
\hline 1,3,5-Trimethylbenzene & 1189.41 & 1.00 & 0.98 & 0.9758 \\
\hline 0-Xylene & 1046 & 1.10 & 1.07 & 0.9750 \\
\hline $\mathrm{m} / \mathrm{p}$-Xylene & 1046 & 1.10 & 1.07 & 0.9750 \\
\hline \multicolumn{5}{|l|}{ Flammable Gases } \\
\hline Hydrogen & 57.8 & 5.00 & 4.50 & 0.9006 \\
\hline Methane & 191.8 & 5.00 & 4.85 & 0.9700 \\
\hline
\end{tabular}




$$
\frac{L_{t}}{L_{25}}=1-\frac{0.75}{L_{25} H_{C}}(T-25)
$$

where

$\mathrm{L}_{\mathrm{t}}=$ lower explosive limit at temperature $t$ (vol\%)

$\mathrm{L}_{25}=$ lower explosive limit at $25^{\circ} \mathrm{C}(\mathrm{vol} \%)$

$\mathrm{H}_{\mathrm{c}}=$ net heat of combustion $(\mathrm{kcal} / \mathrm{mol})$

$\mathrm{T}=$ temperature $\left({ }^{\circ} \mathrm{C}\right)$.

The results indicate that, under elevated temperatures, the MLELs are consistently lower by approximately $3 \%$ for single constituents other than hydrogen and $10 \%$ for hydrogen. The flammability testing will investigate the effect of elevated temperature for mixtures of flammable VOCs and gases. The results will be incorporated into MLEL modeling and the FAMP, as required. 


\subsection{REFERENCES}

AIChE. 1994. Procedure B: Method for Estimating Lower Flammability Limit of Pure Compounds in the Data Prediction Manual. New York, New York, American Institute of Chemical Engineers.

ASTM. 1997a "Standard Test Method for Minimum Explosible Concentration of Combustible Dusts," E151596, West Conshohocken, Pennsylvania, American Society for Testing and Materials.

ASTM. 1997b. "Standard Test Method for Concentration Limits of Flammability of Chemicals," E681-94, West Conshohocken, Pennsylvania, American Society for Testing and Materials.

ASTM. 1997c. CHETAH, Version 7.1, The ASTM Computer Program for Chemical Thermodynamic and Energy Release Evaluation (NIST Special Database 16). 3rd Edition, ASTM Data Series DS51 B. Philadelphia, Pennsylvania, ASTM Subcommittee E27.07 on Estimation Methods of ASTM Committee E-27 on Hazard Potential of Chemicals.

Burgess et al. (D. S. Burgess, A. L. Furno, J. M. Kuchta, and K. E. Mura). 1982. Flammability of Mixed Gases. PRC Report of Investigations 8709. Pittsburgh, Pennsylvania, Pittsburgh Research Center, U.S. Department of the Interior.

Connolly et al. (M. J. Connolly, S. M. Djordjevic, L. Evans, K. J. Liekhus, and C. A. Loehr). 1997. Flammability Assessment Methodology Program Test Plan, Revision O. INEL 96/0352. Idaho Falls, Idaho, Idaho National Engineering and Environmental Laboratory.

Connolly et al. (M. J. Connolly, S. M. Djordjevic, K. J. Liekhus, C. A. Loehr, and L. R. Spangler). 1995. Position for Determining Gas Phase Volatile Organic Compound Concentrations in Transuranic Waste Containers. INEL-95/0109, Revision 1. Idaho Falls, Idaho, Lockheed Idaho Technologies Company.

DOE. 1996. Quality Assurance Program Document. CAO-94-1012, Current Revision, Carlsbad, New Mexico, Carlsbad Area Office, U.S. Department of Energy.

DOE. 1995. Transuranic Waste Characterization Quality Assurance Program Plan, Revision 0. CAO-941010, Carlsbad, New Mexico, U.S. Department of Energy.

DOE. 1994. TRUPACT-II Content Codes (TRUCON). Rev. 8. DOE/WIPP 89-004, Waste Isolation Plant, U.S. Department of Energy, September.

Djordjevic et al. (S. M. Djordjevic, L. R. Spangler, M. J. Connolly, and K .J. Liekhus). 1997. Use of Headspace Flammable Gas Sampling as an Alternative Method of Certifying TRU Waste Containers Project Final Report. INEL/EXT-97-00720, Revision 0. Idaho Falls, Idaho, Lockheed Martin Idaho Technologies Company.

Drysdale, D. 1985. An Introduction to Fire Dynamics. Chichester, England, John Wiley and Sons, Ltd.

Fried, L. E. 1995. CHETAH 1.22 User's Manual. CURL-MA-117541 Rev. 2. Livermore, California, Energetics Material Center, Lawrence Livermore National Laboratory.

GPC. 1988. Material Safety Data Sheet from Genium's Reference Collection, Genium Publishing Corporation, Schenectady, New York. 
Kuchta. 1985. Investigation of Fire and Explosion Accidents in the Chemical, Mining, and Fuel-Related Industries-A Manual. Bulletin 680. Washington, D.C., PRC, U.S. Department of the Interior.

McBride et al. (B.J. McBride, M.A. Reno, and S. Gordon). 1994. CET93 and CETPC: An Interim Updated Version of the NASA Lewis Computer Program for Calculating Complex Chemical Equilibria With Applications. NASA Technical Memorandum 4557. Cleveland, Ohio, National Aeronautics and Space Administration, Lewis Research Center.

NFPA. 1988. SFPE Handbook of Fire Protection Engineering. First Edition. Quincy, Massachusetts, National Fire Protection Association and the Society of Fire Protection Engineers.

NRC. 1996. Safety Analysis Report for the TRUPACT-II Shipping Package. Revision 16, NRC Docket No. 9218, U.S. Nuclear Regulatory Commission, Washington, D.C.

PRC. 1997. Experimental Apparatus and Procedure for Vapor Explosibility Testing in the 19-L Chamber. Pittsburgh, Pennsylvania, Fires and Explosions, Pittsburgh Research Center.

Sax and Lewis. 1987. Hawley's Condensed Chemical Dictionary, New York, New York, Van Nostrand Reinhold Company.

Wendt, J.O.L. 1993. User Instructions for CHEMEQ. Tucson, Arizona, Department of Chemical Engineering, University of Arizona.

Zlochower et al. (I. A. Zlochower, K. L. Cashdollar, and G. M. Green). 1997. Final Report, Measurements of the Lower Flammability Limits of Mixtures of Volatile Organic Compounds Plus Hydrogen in Air. Pittsburgh, Pennsylvania, National Institute for Occupational Safety Health, Pittsburgh Research Center. 


\begin{abstract}
Appendix A
EXPERIMENTAL APPARATUS AND PROCEDURE FOR VAPOR EXPLOSIBILITY TESTING IN THE 19-L CHAMBER, REVISION 0
\end{abstract}


Project No. 14-09-0050-3738

April 10, 1997

\section{EXPERIMENTAL APPARATUS and PROCEDURE for}

\section{VAPOR EXPLOSIBILITY TESTING \\ in the 19-L CHAMBER \\ Revision 0}

for

Memorandum of Agreement No. 14-09-0050-3738

Measurement of the Lower Flammability Limits

of Mixtures of Volatile Organic Compounds

(P1us Hydrogen) in Air

between

Pittsburgh Research Center - NIOSH

and

Lockheed-Martin Idaho Technologies Co. 


\section{EXPERIMENTAL APPARATUS and PROCEDURE for VAPOR EXPLOSIBILITY \\ TESTING in the 19-L CHAMBER \\ Revision 0}

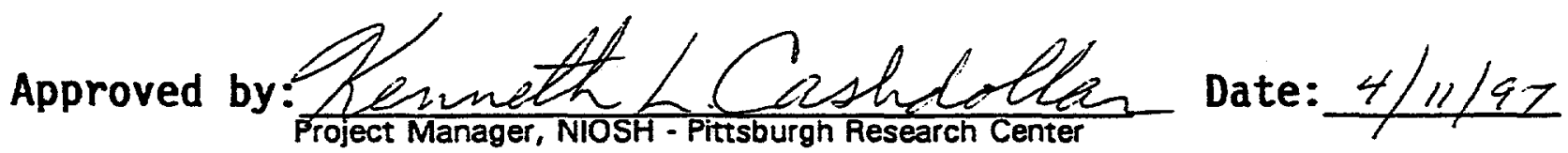

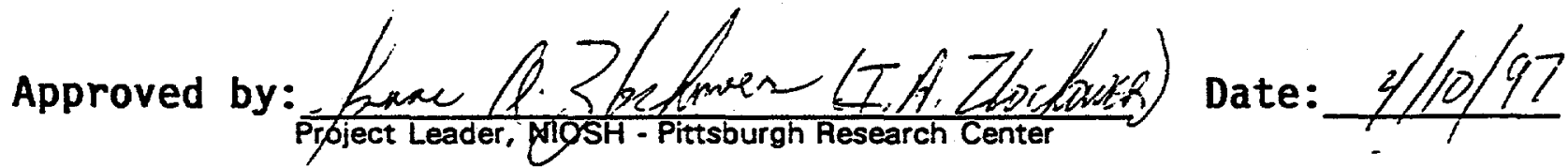

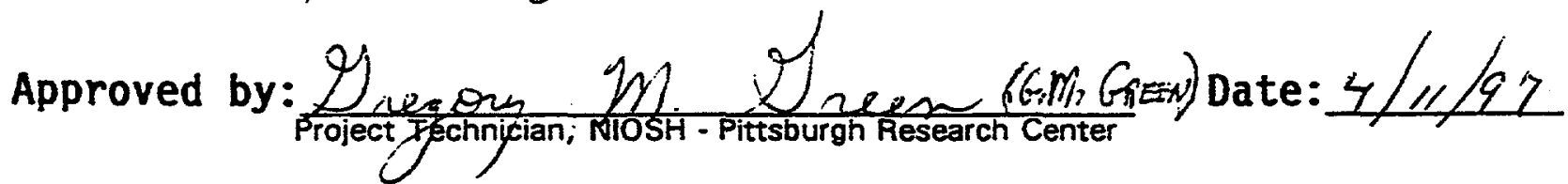
Concurred by: $\frac{\text { Kain in }}{\text { coordinator, Flamryability Assessment Methodology Program, iNEL }}$ Date: $5 / 19 / 97$ 


\section{CHAMBER PREPARATION}

Note: The chamber used is a near-spherical 19-L stainless steel vessel with a 300 psia working pressure. The measured volume is $18.8 \mathrm{~L}$ with an estimated error of $\pm 0.1 \mathrm{~L}$. The standard operating procedures (SOP) are given in Appendix I.

A. Insure that the chamber is free of residues from previous tests. Residual vapors can be flushed out by flowing air through the chamber with sufficient velocity to scour any vapors from crevices. Any liquids and solids of low volatility must be physically removed through cleaning. After the initial cleaning, the chamber should be checked periodically for accumulated water and other residues. Gloves resistant to the specified volatile organic compounds (VOC's) must be worn for chamber cleanup and any operation involving potential contact with the VOC's, particularly the hazardous chlorine containing compounds, carbon tetrachloride and 1,2-dichloroethane. A11 materials used for clean up must be left in the laboratory fume hood housing the chamber until they are free of volatiles (at least overnight). They can then be removed and discarded, if feasible.

B. Install the required pressure sensors, thermocouple, needle valves, spark electrodes, and septa on the available ports of the chamber by means of gas-tight fittings. Use two pressure transducers of appropriate range that are connected to the computer controlled (PC) A/D data acquisition board for generating the explosion pressure data in a redundant fashion. The current units are strain gauge pressure transducers from Viatran Corp. (mode] 218) These units have a range of $0-100$ psia \pm 0.1 psi. For calibration purposes, they have zero adjustments and electrical shunt voltage readings which correspond to specified calibration pressures. The calibration pressures and zero corrected shunt voltages are then used to arrive at sensor calibration factors ( $-20 \mathrm{ps} i / \mathrm{v})$ used by the data acquisition program. With the "Viatran" pressure $A / D$ channels set at a gain of 2 , the acquired data range becomes $0-5$ $v$, or $0-100$ psia. The output voltage from the sensors is also monitored online using a sensitive voltmeter. The data acquisition/display computer program averages the output of the two transducers for the summary report page unless they differ by 5\%. In such case, the peak pressure values of both transducers are displayed to two decimal places, and a choice can be made of the "best" value to use. Typically, such differences are due to an electrical spike or noise that produces a false peak value. The provision of data smoothing capabilities in the program, or the selection of a more appropriate peak search interval will normally circumvent such problems. Replacement of a faulty transducer is in order if there is a problem that the above procedures or recalibration can not correct.

Use the sensitive, temperature controlled capacitance manometer from MKS Instruments, Inc. ("Baratron" model $390 \mathrm{HA}-10000$ ) for determining the component vapor pressures in the 19-L chamber. This pressure sensor is coupled to an MKS model 270D-4 signal conditioner and electronic readout unit that can be read to 0.1 torr or 0.001 psia over a range of 1000.0 torr $(19.337$ psia). The full range of this sensor is 10,000 torr (193.37 psia) at a meter 
resolution of 1 torr $(0.01$ psia). The readout unit allows the selection of the pressure range and units desired. The measured pressures of the VOC components (and hydrogen, if present) in the air mixture together with the measured total pressure provides a quantitative measurement of the mixture composition. This transducer is normally isolated from the chamber just prior to ignition by means of a ball valve. The object is more to protect against possible changes in sensor calibration, than protection against overpressure. The valve may remain open in cases where only a marginal explosion, and no corrosive or adherent products are expected - based on prior test results. The "Baratron" sensor can then be used to provide a superior measure of the explosion pressure, if desired. The "Baratron" sensor is, therefore, also connected to the $A / D$ data aquisition board. The calibration factor of 19.34 $\mathrm{psi} / \mathrm{v}$ that is entered into the program for the "Baratron" is based on the full range of the sensor (Rxl setting on the 2700-4 for a range of 0-193 psia). Using a gain of 4 for the Baratron data channel gives a range of $0-2.5 \mathrm{v}$, or 0-48 psia. Alternatively, the range setting can be left at $R x .1$ (at a gain of 1 for the Baratron channel) for a range of 0-19.34 psia, or a maximum pressure rise of about $4.8 \mathrm{psi}$. This setting provides the greatest sensitivity, but requires that the Baratron channel readings be divided by 10 to give the actual pressure units. The maximum pressure rise of 5 psi also limits the application to cases where the mixture concentration is at, or below, the LFL.

Measurement of the temperature of the chamber after adding each component, immediately prior to ignition, and during explosions is accomplished by means of a thermocouple junction inserted near the top of the chamber. Use a thermocouple formed from $5 \mathrm{mil}(127 \mu \mathrm{m})$ chromel-alumel wires (type $\mathrm{K}$ ) sealed in ceramic tubing that is inserted into a port in the chamber lid with a pressure tight fitting. This thermocouple has a listed time constant of about $0.1 \mathrm{~s}$. The wire diameter used is sufficiently large to provide explosion survivability, yet sufficiently sensitive to roughly follow the 1 arge but short-lived temperature excursions from an explosion (The response time of this thermocouple is too slow to sense the "true" peak temperature of an explosion, but can provide some information on its exothermicity). The thermocouple extender wires are attached to a calibrated amplifier and then to the $P C$ mounted $A / D$ data acquisition board. The wires are also attached to a temperature compensated digital meter readout from Omega Engineering, Inc. The bare thermocouple tip is placed $9 \mathrm{~cm}$ below the chamber top and $9 \mathrm{~cm}$ from the chamber axis. The range and sensitivity of the computer generated temperature readings are dependent on the gain setting of the temperature channel. At a setting of 2 , the range is $0-5 \mathrm{v}$, or $0-1230^{\circ} \mathrm{C}$; at a setting of 4 , the range is $0-2.5 \mathrm{v}$, or $0-600^{\circ} \mathrm{C}$. A strong explosion will produce temperatures well in excess of $600^{\circ} \mathrm{C}$; weak explosions will stay under that value. A gain setting of 2 is used to allow the measurement of all the generated explosion temperatures.

The septum port is used to directly inject the required amount of VOC 1iquid from an inert hypodermic syringe (glass and teflon) into the evacuated chamber. It consists of a "Swagelok" fitting with a rubber septum-seal of the type used to seal glass "Vacutainer" test tubes. The septum is secured by the "Swagelok" nut. This arrangement provides a vacuum tight seal that maintains its integrity and the chamber pressure during an explosion. The fitting is 
sufficiently short (about 2 inches) that a longer needle will allow direct injection into the chamber. Although the septum has contained explosion pressures of nearly 100 psia (over 6 atm.), it may not survive violent explosions, and care must be taken to insure that energetic mixtures (e.g. stoichiometric fuel concentrations) are not tested with this septum arrangement. The septum should be weighed to the nearest milligram before placement, and reweighed after removal to check on the extent of absorption of the VOC mixture. Replacement is required if there are indications that the chamber is no longer vacuum tight, or after completing a series of tests on a given VOC mixture.

Mixing of the gas components in the chamber involves admitting the bulk of the added air through a solenoid controlled valve at the bottom of the chamber. It is designed to discharge enough air in 0.3 seconds to bring the chamber pressure from near vacuum to near atmospheric. The object is to create adequate turbulence so as to insure good mixing of the mixture components. The final air addition is through the side port. Care must be taken, however, that the final air addition occurs while there is still turbulent mixing in the chamber. The air addition is therefore completed within 1 minute of the initial air blast.

Use spark electrodes consisting of $1 / 8$ inch $(3 \mathrm{~mm})$ brass rods that are sealed in ceramic tubes through in-1ine ports with pressure tight fittings. The rod ends are drilled to accomodate stainless steel phonograph needles which are then soldered in place. These needle points are $1 / 4 \mathrm{inch}(6 \mathrm{~mm})$ apart at the approximate center of the chamber. The electrodes are connected to a circuit consisting of 380 or $900 \mu f$ capacitors which are charged to $300 \mathrm{v}$, and then discharged through a high voltage transformer to produce the spark. This circuit provides 17 and $41 \mathrm{~J}$, respectively, of nominal (stored) energy, but the actual pressure rise in the chamber, due to the heating pulse associated with the spark discharge, is 2 and $4 \mathrm{mpsi}$ for the 380 and $900 \mu \mathrm{f}$ capacitors, respectively. These pressure pulses in the $18.8 \mathrm{~L}$ chamber correspond to relative energies (V $\Delta P$ ) of 0.26 and $0.52 \mathrm{~J}$, respectively, that are delivered to the spark gap.

The chamber has sapphire viewing ports on the top and sides. These ports are useful in observing the behavior of slowly propagating flames in the chamber. A very short flash that remains in the center of the chamber indicates virtually no expansion of the spark kernel. The corresponding pressure change is, correspondingly, virtually nil. An ascending "ring" of flame that quickly extinguishes is associated with a pressure rise that is below the pressure flammability criterion. A "ring" that reaches the top before extinguishment indicates a propagation confined to the upward and horizontal directions. The corresponding pressure rise is then approximately $1 / 2$ to 1 psi. A "ring" that fills the top and gives a view of the electrodes, indicates a flame that has propagated downwards, as we 11 . The corresponding pressure rise is then likely to be at least double the starting pressure.

C. Insure that the chamber is leak tight under vacuum by fully evacuating the chamber, and monitoring the chamber pressure with the pump off. The vacuum level should be constant for at least 10 minutes. 


\section{CALIBRATION}

A. The "Viatran" pressure transducers are cal ibrated by fully evacuating the chamber and obtaining a "zero" voltage reading. The shunt calibration reading is then obtained. After correcting for the zero reading, this value is then compared with the manufacturer's determination of the pressure corresponding to the shunt voltage for the particular sensor. The calibration factor for each transducer is the calibration pressure divided by the corrected calibration voltage. These factors are entered into the data acquisition program for the "Viatran" data channels The above calibration is to be done on a daily basis, and used to generate a calibration sheet containing the above data. The repeatability of the pressure readings is 1 isted by the manufacturer as $0.1 \%$ of full-scale. That translates to \pm 0.1 psi for the 0-100 psia units. Upon comparison with the more accurate "Baratron" sensor at our designed starting pressure (14.5 psia) and below, we find that the "Viatran" transducer differs from the more accurate readings by less than 0.1 psi. We have elected to maintain the calibration procedure for the "Viatrans" as stated above rather than forcing an agreement with the "Baratron" by adjusting the calibration factors. The advantage of independent calibrations for the three pressure sensors avoids the problem of producing inaccurate calibrations for all sensors if the "Baratron" performance should degrade during the testing program.

The "Baratron" model 390 HA-10,000 pressure sensor, the MKS model 270D-4 signal conditioner and electronic readout unit, and their connecting shielded coaxial cable were calibrated by MKS as a system, and a report of the calibration results was supplied. The cal ibration is conducted via a transfer standard which is, in turn, calibrated with a dead-weight tester traceable to NIST. After calibration, the residual deviations from the standard pressures are below the readability of the 2700-4 meter at the appropriate ranges. The readout unit of the "Baratron" provides for null $(0.000 \mathrm{v})$ and full-scale $(10.000 \mathrm{v})$ voltage calibration. In addition, a zero adjust is available if the system can be evacuated to below 0.01 torr. Normaliy, however, the chamber is evacuated to less than 0.5 torr $(0.01$ psia) to reduce the time required for evacuation.

The thermocouple calibration was originally checked outside the chamber using ice-water and boiling water baths. After installation on the chamber, which involves cementing the assembly, the boiling water bath became impractical. Instead, a container of cold tap water and water equilibrated at room temperature was substituted for the boiling water, to give a 3 point calibration. The latter calibration indicated agreement of the Omega meter, the A/D output (gain of 2 ), and a sensitive mercury thermometer to several tenths of a degree.

The top loading electronic balance used (Denver Instruments Co. model XL-300) has a weighing range of $0-300 \mathrm{~g}$ with a resolution and stated accuracy of $1 \mathrm{mg}$. A transparent cover is provided to protect against the draft in the 1aboratory hood. This balance is calibrated primarily by a high quality (E-2) $100 \mathrm{~g}$ calibration mass whose tolerance $(0.15 \mathrm{mg})$ is narrower than the highest grade ASTM classification (class I - $0.25 \mathrm{mg}$ ). The linearity was checked against a 
set of laboratory weights of $50,20,10$, and $2 \mathrm{~g}$ and found to give the listed mass to the nearest $\mathrm{mg}$.

The data aquisition and display system is based on a Data Translation Corp. A/D board (model DT 2821) that is controlled by a $80486 / 33$ microprocessor based PC. The board has 16 high speed A/D channels to allow for the use of various sensors. The program that runs the data acquisition/display was written and has been maintained by Carrie $E$. Lucci, a research physicist in our group. The program displays the pressure, $\mathrm{dp} / \mathrm{dt}$, and temperature data vs. time, provides for scale calibration, absolute and relative (gauge) pressures, scale changes, search start and end points, and data smoothing. It provides a data input form ("header"), a data summary output, and prints to okidata 300 series dot matrix printers.

Calibration of the computer output of the "Viatran" and "Baratron" pressure channels is conveniently done by the manual addition of air to the evacuated chamber. The pressures recorded by the data acquisition system were then compared to the corresponding meter readings for the "Baratron" and "Viatran"sensors. The computer output from the "Baratron" channel (gain = 4) agreed with the meter reading to within 0.1 psia for the entire pressure range tested (0-40 psia). The outputs of the "Viatran" PC channels (gain = 2) agreed with the voltmeter readings to within $0.1 \mathrm{psi}$.

\section{CHEMICALS}

A11 VOC's and gases used must be supplied as a high purity material (>99\%) by the manufacturer. The cylinders of high grade medical air that are to be used in the test program have very low ppm levels of organic and carbon monoxide impurities. The oxygen content is also consistent with that of standard dry air $(20.96 \%)$. The hydrogen cylinder to be used contains research grade hydrogen that is over $99.8 \% \mathrm{H}_{2}$. The minor impurities are nitrogen, oxygen, and carbon dioxide. The toluene, 2-butanone (MEK), 1,2 dichloroethane, and carbon tetrachloride VOC's that are to be used in the flammability tests are annhydrous, high purity chemicals that have been packaged under nitrogen in septum sealed glass containers by a major fine chemical supplier (Aldrich Chemical Co.). The toluene and 1,2 dichloroethane are $99.8 \%$ pure with $50 \mathrm{ppm}$ of water and 3-5 ppm of residue. The 2-butanone (methylethylketone, or MEK) is over $99.5 \%$ pure. It has been redistilled in glass and sealed under nitrogen. The carbon tetrachloride is over $99 \%$ pure with $50 \mathrm{ppm}$ water and 3 ppm residue. The emphasis in ordering these materials has been placed on obtaining dry, high purity chemicals in a positively sealed container. The only access to the VOC's is via hypodermic needle penetration of the septum and withdrawal of liquid into a syringe or transfer tubing. This should greatly reduce the risk of exposure to the VOC vapors, or the possibility of contact with the liquids.

MSDS sheets on the above chemicals have been obtained from Aldrich Chem. Co.

Appropriate portions of the above VOC liquids will be transferred to labelled $50 \mathrm{~cm}^{3}$ glass bottles that have an inert, closable septum seal "mininert" valves) via dedicated syringes. The object is to provide a more easily 
handled VOC container, and to be consistent with good chemical practice. The injection of appropriate amounts of each VOC component needed to make the required mixture will be made by first estimating the required volume of VOC liquid, then using the valve on the syringe to deliver the actual desired vapor pressure of the component into the evacuated 19-L chamber.

\section{CALCULATIONS}

The preparation of the equimolar mixture of VOC's is based on adding a sufficient amount of the individual VOC's to give the same number of moles of vapor for each component. The moles of component will be determined from the vapor pressure, using the ideal gas law. If hydrogen $\left(\mathrm{H}_{2}\right)$ is absent, the total gas mixture in the chamber consists of the VOC mixture and air. The mole fraction of VOC component in the gas mixture is $n_{d} / n_{t}$, where $n$ is the number of moles, is the VOC component, and is the total (air diluted) mixture. From the ideal gas law, $n_{d} / n_{t}=\left(P_{d} / P_{t}\right)\left(T_{V} / T_{0}\right)$, where $T_{0}$ is the absolute temperature $\left({ }^{\circ} \mathrm{K}\right)$ after the addition of the VOC component $\left(T_{0}\right.$ is expected to be the same for each component addition); and $T_{t}\left({ }^{\circ} \mathrm{K}\right)$ is the temperature at the time the chamber pressure $\left(P_{t}\right)$ has stabilized after the air addition. In the presence of hydrogen, use the mole fraction of $H_{2}\left(n_{h} / n_{t}\right)$ in addition to $n_{d} / n_{t}$.

The initial calculation of the desired component pressures will assume a final pressure (e.g. $14.50 \mathrm{psia}$ ), which is then multiplied by the desired mole fraction of the component to give a first approximation to the desired component pressure (e.g. a desired mixture containing $1.00 \%$ of all the designated components will require component pressures of $0.145 \mathrm{psi}$ ). The actual concentration of the component requires measurement of the stable vapor pressure reading of that component, its associated temperature, and the actual final mixture pressure with its associated temperature. Thus, corrections for the actual component and final pressures, and for the ratio of the absolute final and component temperatures will be needed to arrive at the true concentrations, as specified by the above equations.

The fact that the chamber temperature can change with addition of components is due primarily to heating by the "adiabatic compression" of the chamber contents from the rush of incoming gas. This effect is most noted with the substantial air addition, particularly when added initially at a high velocity. The temperature quickly decreases from its peak value, then falls slowly over time. It would be too time consuming to wait for the temperature to reach a true equilibrium value. Instead, the chamber pressure is read when it appears to have reached a steady-state value, and the corresponding temperature is noted and used to correct the calculated concentration, as above.

\section{LOWER FLAMMABILITY LIMIT DETERMIMATION}

The determination of the lower flammability (explosibility) limits (LFL) of the VOC mixtures shall proceed as follows: 
First determine the limits of the individual components in preliminary tests, starting with concentrations near the literature values for the pure voc's and hydrogen. For toluene and MEK, with literature LFL's of 1.2 and $1.9 \%$, respective $7 y$, use steps of $0.1 \%$ ( $<10 \%$ of the fuel concentration) in determining the limits. For hydrogen and 1,2 dichloroethane with literature LFL's of 5 and $6 \%$, respectively, use steps of $0.5 \%$. If the initial concentration is flammable, then decrease the concentration by the above steps until a non-flammable concentration is achieved. If the initial concentration is non-flammable, then increase the concentration by the above steps until a flammable concentration is achieved. Repeat the lowest flammable and highest non-flammable concentrations, and at least one intermediate concentration. Plot the pressure rise vs. concentration results on a graph, and determine the LFL from the intersection of the "best" curve fit to the data with the $\Delta P=0.5$ psi line (the flammability criterion).

Next, estimate the LFL's of the required VOC mixtures that do not contain carbon tetrachloride $\left(\mathrm{CCl}_{4}\right)$ using the Le Chatelier rule for equimolar fuel mixtures: $L(\%)=N / \Sigma l / L_{n}$, where $N$ is the number of components, $L_{n}$ is the experimental limit of the single fuel component, and $n$ is 1 to $N$. Thus, $L=$ $2 /\left(1 / L_{1}+1 / L_{2}\right)$ for binary fuel mixtures $(N=2)$. Then determine the experimental LFL of the mixture starting near the estimated LFL, and proceed in final steps of $10 \%$ (or less) of the estimated LFL (the initial steps may be $20 \%$ of the $L F L)$. Obtain several "no go' $s$ " ( $\triangle P<0.5 \mathrm{psi}$ ) $0-10 \%$ below the $L F L$ and several "go's" $0-10 \%$ above the LFL.

Mixtures containing the non-flammable VOC, carbon tetrachloride $\left(\mathrm{CCl}_{4}\right)$, may require more tests to establish their LFL's, since the literature data on binary fuel-carbon tetrachloride LFL's is very sparse. The Group Contribution Method (AIChE, 1994) will be tried as a first approximation to the LFL's of mixtures containing $\mathrm{CCl}_{4}$. The procedure will, however, follow the above out] ine.

\section{RECORDS and DOCUMENTS}

The primary data record for this program is a numbered, bound, and signed laboratory (black) notebook. A second such (green) book will be used as a workbook where detailed data on pressure and temperature readings vs. time will be kept, both for actual tests and calibrations. This workbook will also contain all calculations needed for the tests and calibrations. The black laboratory notebook will provide the summary data on the experimental conditions and results in tabular form. It. will also contain a summary of other relevant data such as analytical results, calibration data, and brief comments on the tests. The notebook pages will be signed by the personnel conducting the tests, and any corrections to data entries will be initialed by them. The laboratory notebook data will be regularly reviewed and initialed by the project manager at PRC. He will also review the computer generated data. A signature page preceeding the start of the official test program will be provided in the notebook where a 11 personnel conducting and reviewing the tests will attest that they have read, understood, and will follow the procedures and requirements specified in the SOP and Test Plan documents. 
The printed output of the data acquisition and display program for the flammability tests will also be available, in addition to copies of the computer acquired data and the executable program on data disks. The protection of the computer acquired data will be insured by daily backup of the data on the PC's "hard" drive to magnetic data disks.

Traceability of the VOC or VOC mixture used in a flammability test will be maintained by careful and prompt labelling of the $50 \mathrm{ml}$ bottles that are to be used as the VOC reservoirs for the series of flammability tests. The label will identify the bottle, the VOC liquid, and the specific reagent bottle that was used as the source of the VOC. The latter is needed since the VOC liquids were primarily supplied as several $100 \mathrm{ml}$ bottles of each material. The $1 \mathrm{~L}$ toluene (TOL) reagent bottle will be labelled "T1", the $100 \mathrm{ml}$ bottles of 2butanone (MEK) will be labelled "B1" and "B2", the $100 \mathrm{ml}$ bottles of carbon tetrachloride (CT) will be "C1" and "C2", and the $100 \mathrm{ml}$ bottles of 1,2 dichloroethane (DCE) will be "D1" and "D2". The $50 \mathrm{ml}$ bottles containing a single component will be labelled "\#1 TOL-T1", "\#1 MEK-B1", "\#1 CT-C1", and "\#1 DCE-D1" for toluene; MEK, CT, and DCE, respectively. As additional bottles are required, they will be renumbered as \#2 TOL-T1, etc. The applied labels will be covered over with transparent tape to help preserve their legibility. The syringes used to transfer VOC components to the $50 \mathrm{ml}$ bottles, and to inject the mixtures into the chamber will be 1 abelled to avoid cross-contamination. The laboratory notebook will identify the $50 \mathrm{ml}$ containers used as the VOC sources for each test. It will also provide the FAMP Test Plan designated experimental order and test mixture numbers for each mixture tested.

The final report will contain a tabular summary of all the test conditions and results, as well as a description of the apparatus and procedures, a discussion and analysis of the methodology and results, a summary of the lower flammability limits of the VOC components and mixtures, the graphs of the explosion pressure rise vs. concentration for all mixtures tested, and a conclusion. It will identify the project title and number, and will feature a document number, revision number, and date.

\section{PERSONWEL}

The personnel responsible for setting up, conducting, and supervising the flammability tests, and evaluating the test results have been well trained for their assignments and responsibilities. They will have read, understood and agreed to follow the procedures and requirements specified in the SOP and Test plan documents. The following supporting information is intended to supplement the appended resumes:

Isaac A. Zlochower, Ph.D. research chemist, is responsible for the planning, acquisition, and direct supervision of the equipment, materials, and procedures for the flammability tests, as well as the evaluation of the test results and methodology. His extensive training and experience in chemical and combustion research is an asset for this program, as is his extensive experience with computer calculations of adiabatic flame and explosion temperatures. His supervision of the similar project on the limiting oxygen 
concentrations in benzene-hydrogen mixtures is directly relevant and supportive of this project.

Kenneth L. Cashdollar, M.S. supervisory research physicist, is responsible for the overall supervision of this project and will assist with data interpretation. He has very extensive experience with explosion research, and was responsible for the basic design of the explosion chamber used for the flammability tests. He is also largely responsible for the design of the data acquisition and display system.

Gregory M. Green, physical science technician, is largely responsible for conducting the preliminary "shake-down" trials of the chamber and associated equipment. He insured that the chamber was leak-tight and that the vacuum pump was in good operating condition. He was responsible for injecting a given mass of toluene into the evacuated chamber, measuring the resulting vapor pressure, pressurizing the chamber with air, and taking samples of the mixture with gas sampling syringes for GC analysis. He also conducted the preliminary flammability tests of hydrogen in air, toluene in air, MEK in air, and a test of dce in air, together with Isaac A. Zlochower. G. M. Green is well trained in the use of an explosibility chamber for the measurement of gas flammability limits, and has been involved in a similar project involving benzene and hydrogen mixtures.

Richard A. Thomas, electronics technician, is largely responsible for setting up the test apparatus. He cleaned out the chamber, installed and calibrated the pressure and temperature sensors, measured the chamber volume, connected the sensor outputs to the A/D board, and ascertained that the spark circuit, ignition switch, and data aquisition/display program were functional. He is well trained in the electronics and computer maintenance skills that were needed for his task. 


\section{KENNETH L. CASHDOLLAR}

\section{Education:}

M.S., Astronomy, 1973, The University of Wisconsin, Madison, WI.

B.S., Physics, magna cum laude, 1969, Dickinson College, Carlisle, PA.

Experience:

1995 - present

Supervisory Research Physicist, Fires, Explosions, and Explosives Group, Pittsburgh Center, NIOSH. Principal areas of research include both laboratory and large-scale explosion hazards.

\section{3 - 1995}

Research Physicist, Fires, Explosions, and Explosives Group, Pittsburgh Research Center, U.S. Bureau of Mines. Principal areas of research include both laboratory and large-scale explosion hazard testing and the development of instrumentation for explosibility testing.

Author or coauthor of over 70 papers on dust and gas explosions and on instrumentation for explosibility testing.

Chairman of the Symposium on Industrial Dust Explosions, sponsored by ASTM, Bureau of Mines, and NFPA, Pittsburgh, PA, June 10-13, 1986. Co-Editor of Industrial Dust Explosions, (proceedings volume from the Symposium on Industrial Dust Explosions), STP 958, ASTM, 1987.

Designed 20-L explosibility test chamber and personal computer based, high-speed data acquisition system.

Patent for a Multichannel Infrared Pyrometer.

Memberships:

The Combustion Institute

American Physical Society

Optical Society of America

SPIE - The International Society for Optical Engineering

ASTM Committee E27 on the Hazard Potential of Chemicals,

Vice-Chairman of subcommittee E27.04 on Flammability,

Chairman of subcommittee E27.05 on Explosibility/Ignitability of Dusts

EuropEx: European Information Center for Explosion Protection

NFPA Committee on Explosion Protection Systems

Honors:

Special Honors in Physics, Dickinson College, 1969.

Sigma Pi Sigma (Physics Honorary), 1969.

Phi Beta Kappa, 1969.

Listed in American Men and Women of Science, Who's Who in

Science and Engineering, Who's Who in the World 
ISAAC A. ZLOCHOWER

Education:

Ph.D., Chemical Physics, Jan. 1966, Columbia University, New York, N.Y.

B. S., Chemistry, magna cum laude, June 1959, Brooklyn College, New York

Experience:

1982 - present

Research Chemist, Fires and Explosions Group, Pittsburgh Research Center, U.S. Bureau of Mines. Project Leader for the basic research program on thermochemical pyrolysis mechanisms of explosible dusts and extinguishants.

$1981-1982$

Physical Scientist, Environmental Control Group, Pittsburgh Research Center. Project Scientist on the Mine Fire Control program.

$1970-1981$

Research Associate, Fiber Glass Division, PPG, Ind., Pittsburgh, PA. Project Leader for fiber glass research in plastics, cement, and elastomer reinforcement. 2 patents on acid resistant glass fibers.

$1967-1970$

Research Chemist, Enjay Additives Div., Exxon Research \& Dev. Corp., Linden, N.J., Project Chemist on cold-flow additives for diesel fuels.

$1965-1967$

Research Associate, School of Mines, Columbia University, New York, N.Y. Postdoctoral Research on Microemulsions.

Honors:

New York State Regents Fellow, undergraduate and graduate. Honors in chemistry - Brooklyn College

Best In-house publication award, Pittsburgh Research Center, 1988.

Qualifications:

Well rounded education and research experience in chemistry. Expertise in combustion and explosion phenomena, and in performing thermodynamic calculations on explosible and inerted mixtures. 
APPENDIX I. - STANDARD OPERATING PROCEDURES

A. Daily Start-up Operations:

1. Smoking and open flames are prohibited during testing.

2. Personnel must wear safety glasses and appropriate protective gloves when cleaning the chamber and handling chemical containers.

3. Insure that equipment is on, including hood exhaust fan, balance, instrumentation, computer/printer, and gas cylinders. Note that the hood exhaust fan, balance, and "Baratron" should be left on all the time, while the other instrumentation should be turned off when not in use.

4. Insure that 19-L chamber has been ventilated.

5. Insure that the vacuum pump is in operating condition, and that its exhaust is conducted to the back of the hood.

6. Insure that the chamber instrumentation (usually, two 100-psia Viatran pressure transducers, a Baratron pressure transducer, and a type $K$ thermocouple) is operable and properly connected to the PC data acquisition system.

7. Insure that the hydrogen feed line to the chamber is purged before use.

8. Insure that the rapid air dispersion system is operational.

9. Insure that the VOC 1 iquids to be tested are in septum sealed, labelled bottles in the laboratory hood, together with appropriate gloves and labelled syringes.

10. Insure that the electronic balance is level and positioned convenientiy.

11. Open the isolation valve between the Baratron transducer and chamber, and evacuate the chamber fully to several tenths of a torr by setting the display units selector switch on the Baratron readout to $\mathrm{mm} \mathrm{Hg}$ and using the Rx.1 setting. Turn the range select switch to the "nuli" position. If necessary, use the null adjustment screw to produce a reading of $0.000 \mathrm{~V}$. Turn the switch to the $F / S$ position and adjust the $\mathrm{F} / \mathrm{S}$ screw to give a reading of $10,000 \mathrm{mV}$. The Baratron read-out is now calibrated. The above calibration requires that the Baratron sensor is fulty equilibrated (at least 4 hours) at its designed sensor head temperature of $35^{\circ} \mathrm{C}$.

If the pressure reading of the fully evacuated chamber is 0.0 torr on the Baratron, turn the range setting to $R x .01$. If the reading is now negative, adjust the "zero" coarse control slightly to make it read 0.00 torr, or a slightly positive value, and switch back to Rx.1 The units selector switch can now be set to read psi units.

12. Insure that the $P 1$ Viatran transducer reads approximately $0.000 \mathrm{~V}$ on the digital voltmeter under full vacuum. If necessary, adjust the "zero" set screw carefully to give a reading closer to $0.000 \mathrm{v}$. To check the calibration, connect the shunt leads and read the voltage. Subtract the exact "zero" voltage (both read to the fourth decimal place). Record all the voltages on the dated calibration sheet, together with the manufacturer's listed shunt calibration pressure for that unit. Calculate the calibration factor (psi/V) and enter on the sheet, together with the time of measurement. Repeat the above process for the 
P2 Viatran transducer. Enter the above calibration factors in the PC data acquisition program

13. Calibrate the top-loading electronic balance with the high quality (E2) $100.000 \mathrm{~g}$ weight using the calibrate function on the balance, after taring the balance to read $0.000 \mathrm{~g}$. Check that the balance actually registers the calibration weight $\pm 1 \mathrm{mg}$, and that the reading without the weight is back to 0.000 .

B. Periodic Operations, (as necessary):

1. Open the chamber and check that the interior is clean and dry, that the electrode tips are aligned and are $6 \mathrm{~mm}$ apart, and that the electrical connections to the spark circuit are secure.

2. Check the condition of the septum on the chamber port. A new septum should be used at the start of a series of tests on a mixture. Weigh the old septum and the new one in order to keep track of possible weight changes due to absorption of VOC liquid or vapor. Note any changes in appearance.

3. Check the calibration of the thermocouple by carefully placing a beaker of freshiy stirred ice water in the chamber so that the thermocouple probe dips in the ice bath when the chamber lid is lowered. Record the temperature, stir the ice carefully, and lower the lid again to take a second reading. Repeat until a constant reading is obtained. Replace the beaker with one containing water that has equilibrated with the air temperature, and repeat the temperature measurements, as above. Measure the temperature of the equilibrated water bath using a sensitive mercury thermometer or thermistor/thermocouple.

C. Experimental Operations:

1. Insure that 19-L chamber has been ventilated.

2. Evacuate the chamber.

3. Bring up the "header" screen on the $P C$ and input the test data, including VOC test and mixture numbers, and the mixture components.

4. Using labelled syringes that are all glass, or glass with teflon plungers, and have a flow control valve, draw in an appropriate volume of the desired VOC component from the correct, septum sealed bottle. Repeat for all the VOC components in the mixture, insuring that matching bottles and syringes are used. Record the stable pressure and temperature of the evacuated chamber from the meter readings, after turning off and isolating the pump. Inject the first liquid using the syringe valve to control the liquid flow and the rate of pressure increase in the chamber. The vapor pressure of the injected component is allowed to increase steadily, then the flow is choked to allow the pressure to slowly reach the calculated value. Record the new steady pressure and associated temperature. Calculate the component vapor pressure as the difference in chamber pressure, before and after injection. Enter the component pressure and temperature in the black notebook. Repeat for the remaining VOC components in the mixture. 
5. Add the hydrogen gas (if included in the mixture) while monitoring the increase in partial pressure and any change in chamber temperature. Record the steady pressure and temperature, and enter in the notebook.

6. With the air disperser reservoir at the correct pressure (-120 psi), activate the disperser to inject a $0.3-\mathrm{sec}$ blast of air into the chamber to bring the chamber to near atmospheric pressure. Then, quickly add air from the manual valve to give an estimated final pressure of 14.5 psi (the initial pressure will be higher due to the higher temperature from the air addition). Once the pressure reading has stabilized, record the pressure and temperature and enter in the notebook. Calculate the composition (mole percent) of the mixture from the component and final mixture pressures and temperatures, using the ideal gas law, and enter in the notebook and on the "header" screen.

7. Set the data acquisition to the "waiting" mode.

8. Isolate the Baratron sensor from the chamber, unless it is clear that the VOC concentration is not significantly above the LFL. If the Baratron valve is to be left open, change the Baratron range to Rxl.

9. Charge the spark circuit capacitor, allowing the dc voltage to rise slightly above $300 \mathrm{~V}$. When it has fallen back to $300 \mathrm{~V}$, hit the ignition switch. This causes the discharge of the 380 (or 900) $\mu \mathrm{f}$ capacitor through a high voltage transformer, generating a spark between the electrode tips in the chamber. The ignition switch also activates the PC controlled data acquisition process.

10. Visual observation of the progress of marginal explosions, through the observation ports, should be made from a distance by means of an appropriately placed mirror.

11. The chamber should be vented after each test, and air should flow through it for at least several minutes to fiush the chamber of gases, residual VOC, and water vapor.

12. The air valve and vent are then closed and the chamber is evacuated to prepare for the next test. The "Baratron" sensor should now be open to the chamber and the range reset to $\mathrm{Rx} .1$.

13. While the chamber is being evacuated for the next test, the computer output from the current test can be viewed and analyzed. Adjust the scales and smoothing for the graphs, as appropriate, to provide data output from the pressure transducers and thermocouple. Generate differential pressure data for cases where maximum explosion pressure increases are less than several psi. If necessary, change the search "start" and "stop" times. Print out the data plots and "summary" screen.

14. Record in the black notebook the PC output data for peak pressure, and pressure rise for the pressure data channels (Viatrans and Baratron). Also enter the pressure ratio (peak divided by initial), peak temperatures, and any observations or comments. The comments must include a statement regarding the acceptability (a check mark) or nonacceptability of each test result. In the latter case, a reason must be given, and a suggestion for overcoming the noted problem should be offered. In a subsequent test, reference will be made to the means used to resolve the earlier problem. 
Appendix B

FINAL REPORT: MEASUREMENTS OF THE LOWER

FLAMMABILITY LIMITS OF MIXTURES OF VOLATILE ORGANIC COMPOUNDS PLUS HYDROGEN IN AIR 
FINAL REPORT

\title{
MEASUREMENT of the LOWER FLAMMABILITY LIMITS of MIXTURES of VOLATILE ORGANIC COMPOUNDS plus HYDROGEN in AIR
}

\author{
by Isaac A. Zlochower, Kenneth L. Cashdollar, \\ and Gregory M. Green
}

for Memorandum of Agreement No. 14-09-0050-3738

between

Pittsburgh Research Center, National Institute for Occupational Safety and Health

and

Lockheed Martin Idaho Technologies Company

According to the Flammability Assessment

Methodology Program Test Plan

INEL 96/0352

September 24, 1997 


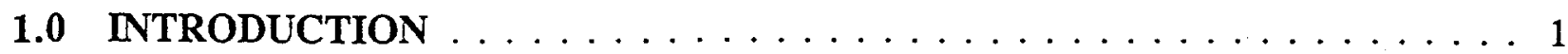

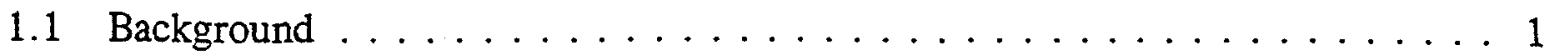

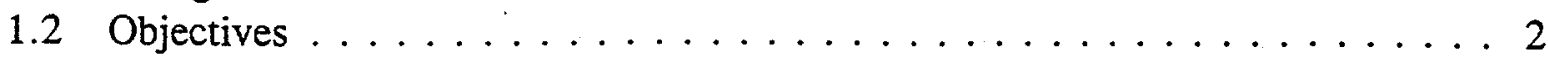

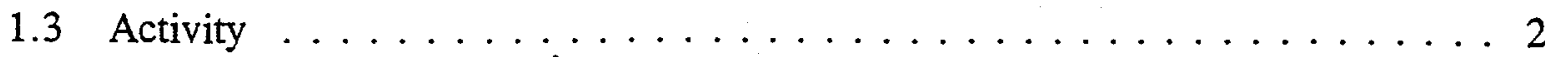

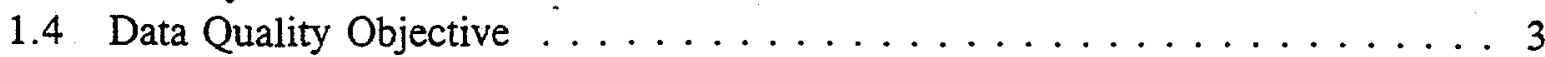

2.0 FLAMMABILITY EQUIPMENT AND TEST PROCEDURES . . . . . . . . 3

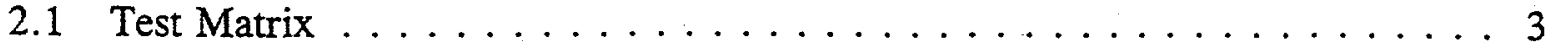

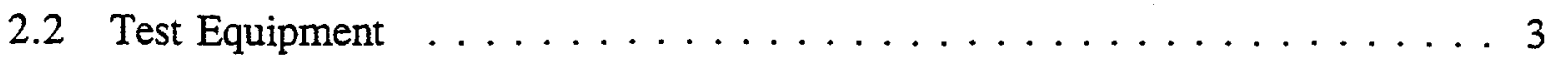

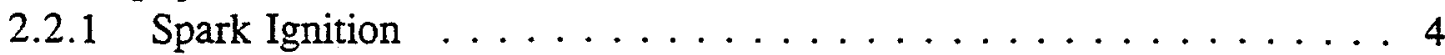

2.2 .2 Pressure Transducers $\ldots \ldots \ldots \ldots \ldots \ldots \ldots \ldots \ldots$

2.2 .3 Temperature Sensor . . . . . . . . . . . . . . 5

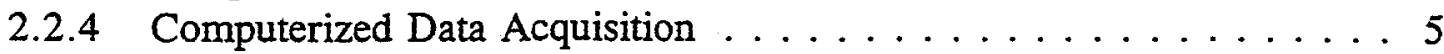

2.3 Equipment Calibrations . . . . . . . . . . . . . . 6

2.3.1 Pressure Calibration . . . . . . . . . . . . . 6

2.3.2 Software Calibration ................. 7

2.3.3 Temperature Calibration $\ldots \ldots \ldots \ldots \ldots \ldots \ldots \ldots \ldots \ldots$

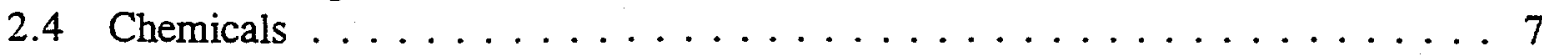

2.5 Calculations . . . . . . . . . . . . . . . . 8

2.5.1 Mixture Composition . . . . . . . . . . . . 8

2.5.2 Estimated Mixture Flammability Limits . . . . . . . . . . . 8

2.6 Preliminary Testing $\ldots \ldots \ldots \ldots \ldots \ldots \ldots \ldots \ldots$

2.7 Standard Test Procedures . . . . . . . . . . . . . . . 11

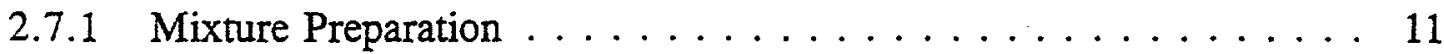

2.7.2 LFL Determination . . . . . . . . . . . . . . . 12

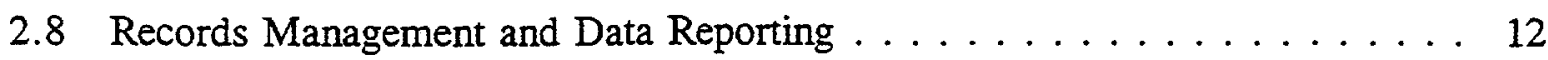

3.0 FLAMMABIITY TEST RESULTS $\ldots \ldots \ldots \ldots \ldots \ldots$

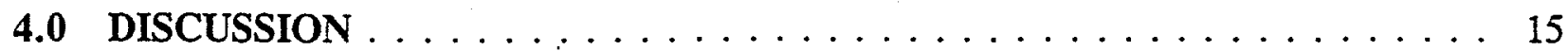

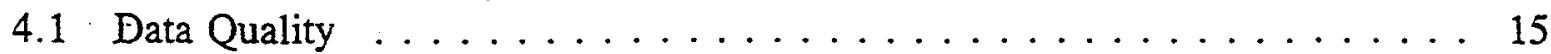

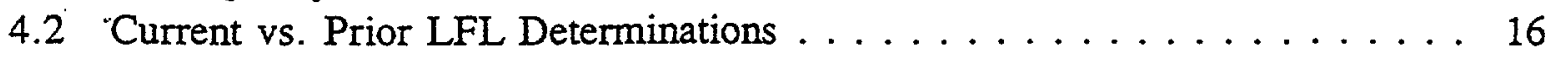

4.3 Estimated LFL Precision . . . . . . . . . . . . . . 17

4.4 Relevance of Prior Predictive Models . . . . . . . . . . . . 17

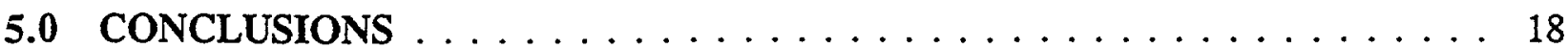

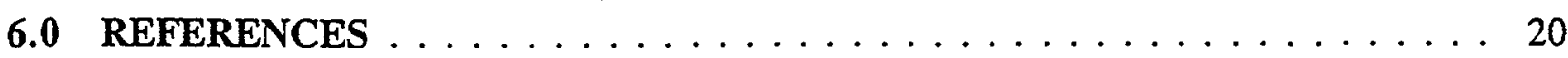




\section{LIST OF ACRONYMS, ABBREVIATIONS, AND DEFINITIONS}

\begin{tabular}{|c|c|}
\hline $\begin{array}{l}\text { AIChE } \\
\text { A/D }\end{array}$ & $\begin{array}{l}\text { American Institute of Chemical Engineers } \\
\text { analog to digital }\end{array}$ \\
\hline ASTM & American Society for Testing and Materials \\
\hline $\mathrm{C}_{\mathrm{i}}$ & Molecular Group Contribution Factor for constituent "i". \\
\hline$C_{i j}$ & atomic (group) factor for atom (group) type " $\mathrm{j} "$ in constituent" $\mathrm{i} "$. \\
\hline CT & carbon tetrachloride $\left(\mathrm{CCl}_{4}\right)$ \\
\hline DCE & 1,2 dichloroethane $\left(\mathrm{ClCH}_{2} \mathrm{CH}_{2} \mathrm{Cl}\right)$ \\
\hline DOE & U.S. Department of Energy \\
\hline equimolar & mixture with an equal number of moles of each constituent. \\
\hline FAMP & Flammability Assessment Methodology Program \\
\hline GC & Gas Chromatography \\
\hline $\mathrm{H}_{2}$ & hydrogen (chemical formula) \\
\hline INEEL & Idaho National Engineering and Environmental Laboratory (formerly INEL) \\
\hline LEL & Lower Explosive Limit \\
\hline LFL & Lower Flammability Limit \\
\hline $\mathrm{L}_{\mathrm{G}}$ & Mixture LFL calculated by the AIChE Group Contribution Method. \\
\hline $\mathrm{L}_{\mathrm{L}}$ & Mixture LFL calculated by the LeChatelier Rule. \\
\hline $\mathrm{L}_{\mathrm{M}}$ & Experimental Mixture LFL \\
\hline LMITCO & Lockheed-Martin Idaho Technologies Co. \\
\hline MEK & 2-butanone, i.e., methyl ethyl ketone $\left(\mathrm{C}_{4} \mathrm{H}_{8} \mathrm{O}\right)$ \\
\hline $\mathbf{n}$ & number of moles \\
\hline$n_{j}$ & number of atoms (or groups) of type " $\mathrm{j} "$ in constituent " $\mathrm{i}$ ". \\
\hline $\mathbf{N}$ & number of constituents in the equimolar mixture. \\
\hline NIOSH & U.S. National Institute for Occupational Safety and Health \\
\hline $\mathrm{NRC}$ & U.S. Nuclear Regulatory Commission \\
\hline $\mathbf{P}$ & pressure \\
\hline$\Delta \mathrm{P}$ & change in pressure or pressure rise \\
\hline $\mathrm{PC}$ & personal computer \\
\hline PRC & Pittsburgh Research Center, a NIOSH governmental research laboratory \\
\hline $\mathrm{R}$ & universal gas constant \\
\hline SOP & Standard Operating Procedures, document issued by PRC in $4 / 97$. \\
\hline $\mathrm{T}$ & temperature \\
\hline & thermocouple \\
\hline Test Plan & FAMP Test Plan \\
\hline Tol & toluene $\left(\mathrm{C}_{7} \mathrm{H}_{8}\right)$ \\
\hline $\begin{array}{l}\text { TRUPACT-II } \\
\mathrm{V}\end{array}$ & Transuranic Package Transporter-II \\
\hline VOC & $\begin{array}{l}\text { test vessel volume } \\
\text { Volatile Organic Compound }\end{array}$ \\
\hline WIPP & $\begin{array}{l}\text { Volatile Urganic Compound } \\
\text { Waste Isolation Pilot Plant }\end{array}$ \\
\hline$x_{i}$ & mole fraction of species " $\mathrm{i}$ " in the mixt \\
\hline
\end{tabular}




\section{LIST OF UNIT OF MEASUURE ABBREVIATIONS}

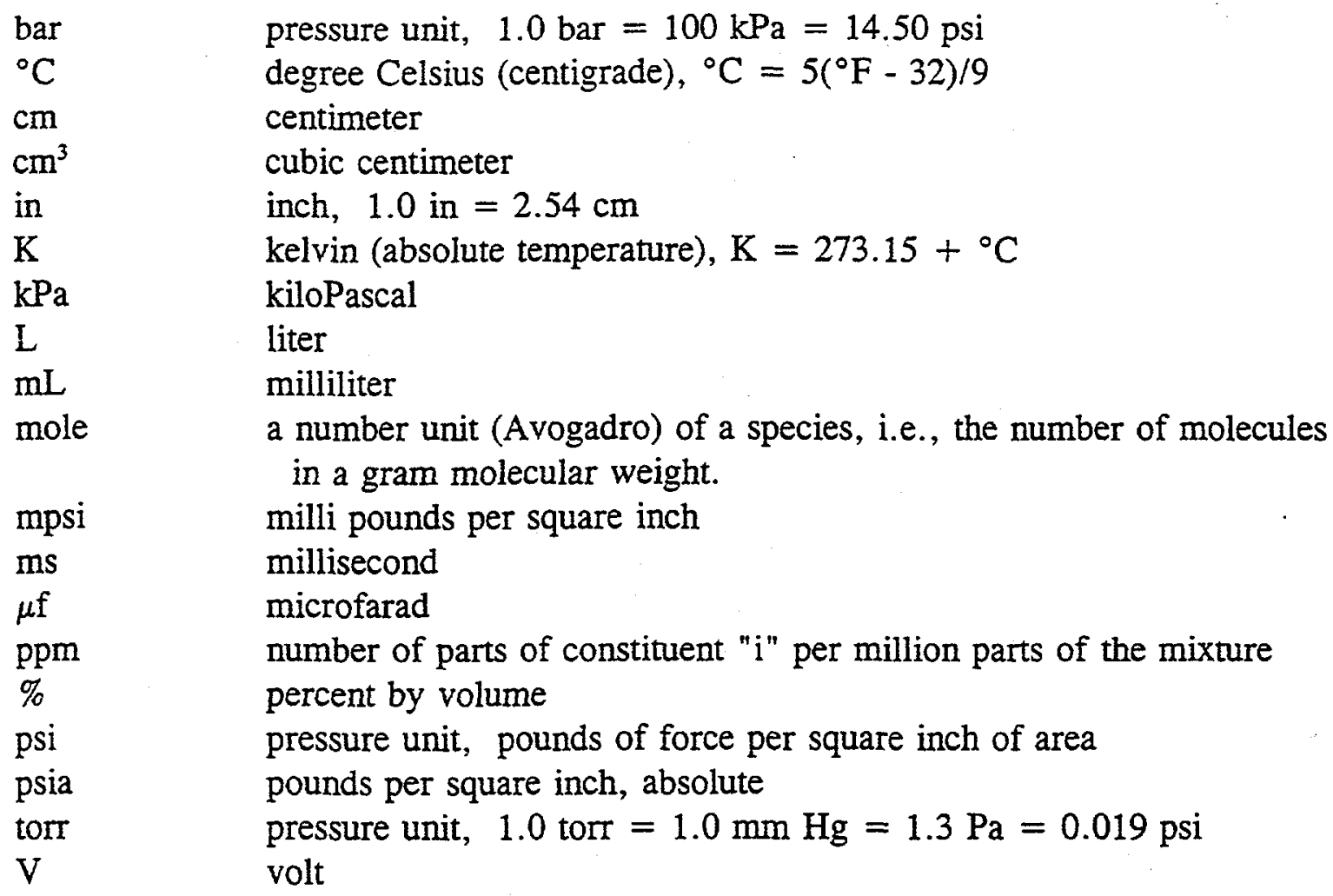

Mention of any company name or product is for identification only and does not constitute endorsement by the Pittsburgh Research Center, NIOSH. 


\title{
MEASUREMENT of the LOWER FLAMMABILITY LIMITS of MIXTURES of VOLATILE ORGANIC COMPOUNDS plus HYDROGEN in AIR
}

\author{
by Isaac A. Zlochower ${ }^{1}$, Kenneth L. Cashdollar ${ }^{2}$, and Gregory M. Green ${ }^{3}$
}

Pittsburgh Research Center, National Institute for Occupational Safety and Health, Centers for Disease Control and Prevention, U.S. Department of Health and Human Services Pittsburgh, PA

\subsection{INTRODUCTION}

This report describes the flammability testing, at ambient temperature, of 40 specified equimolar (equal moles) volatile organic compound (VOC) mixtures, with and without hydrogen $\left(\mathrm{H}_{2}\right)$. This work was conducted by the Pittsburgh Research Center ${ }^{4}(\mathrm{PRC})$, National Institute of Occupational Safety and Health (NIOSH), in fulfillment of a contract with the Lockheed Martin Idaho Technologies Company (LMITCO). The lower flammability limits (LFL), also known as the lower explosive limits (LEL), were determined for these mixtures.

\subsection{BACKGROUND}

The determination of the hydrogen, methane, and VOC concentrations that are present during a 2 month storage period in sealed shipping containers is a major U.S. Nuclear Regulatory Commission (NRC) requirement for the proposed use of the Transuranic Package Transporter-II (TRUPACT-II) to ship transuranic nuclear waste from various U.S. Department of Energy (DOE) sites to the Waste Isolation Pilot Plant (WIPP) in New Mexico. It is desirable, therefore, to establish a reliable data base for such mixtures, which will allow the formulation of a realistic, yet conservative, estimate of the LFL of such mixtures. It is impractical to establish a flammability data base for all possible VOCs present in the transuranic waste. It should suffice, however, to establish the LFLs for specific mixtures of representative VOCs that are present in the waste.

${ }^{1}$ Research Chemist at PRC

${ }^{2}$ Supervisory Research Physicist at PRC

${ }^{3}$ Physical Science Technician at PRC

${ }^{4}$ Formerly part of the Bureau of Mines in the U.S. Department of the Interior before its transfer to NIOSH in 1996 
The Flammability Assessment Methodology Program (FAMP) Test Plan [1] selected 4 VOCs to represent the different types of organic compounds present in transuranic waste, together with $\mathrm{H}_{2}$. The 4 VOCs were toluene (Tol), to represent the aromatic hydrocarbon VOCs; 2-butanone (MEK), to represent the oxygenated hydrocarbons; 1,2 dichloroethane (DCE), to represent chlorinated hydrocarbons; and carbon tetrachloride (CT), to represent nonflammable VOCs. The VOCs chosen also represented a range of LFLs, from near $1 \%$ for Tol to near $2 \%$ for MEK to near $5 \%$ for DCE. The mixture compositions specified in the Test Plan included all the possible equimolar combinations of the VOCs, with and without $\mathrm{H}_{2}$. In addition, two blank tests, consisting of air alone, were specified for statistical control purposes. Seven of the VOC test mixtures were replicates of previous tests in the series. These were intended to provide a measure of the reproducibility of the LFL measurements. Thus, a total of $\mathbf{4 0}$ mixtures were to be run in the randomized order specified in the Test Plan, for statistical reliability purposes. This was done at PRC in a relatively large laboratory chamber [2] that is the standard PRC test vessel for gas and/or dust explosibility measurements.

\subsection{OBJECTIVES}

The direct objective of this investigation is the determination of the LFLs of the specified mixtures in a reliable fashion. The ultimate objective is to produce a reliable flammability data base that can be used to develop and calibrate methods of calculating mixture LFLs. Such methods can then be used to calculate the LFL of VOC mixtures that are found in container headspace sampling. Containers whose head-space vapors are at concentrations well below their calculated LFL can then be considered nonflammable.

\subsection{ACTIVITY}

The LFLs of the 40 specified mixtures have been determined at PRC in a 19-L chamber used for explosibility measurements. The measured partial pressures of the components were used to determine the mixture composition and concentration in air. The mixture was ignited by energizing a suitable spark circuit, and the resulting explosion pressure was then monitored to determine the maximum pressure generated. The data collection from the point of ignition was computer controlled. A pressure rise criterion was used to establish flammability, and at least 4 concentrations giving rise to pressures above and below the criterion were tested. 


\subsection{DATA QUALITY OBJECTIVE}

The required overall data quality objective was to keep the error in the LFL determination to within $5 \%$. Replicate mixtures were included in the experimental design to assess the experimental error.

\subsection{FLAMMABLITY EQUIPMENT AND TEST PROCEDURES}

All flammability tests were conducted at PRC using the 19-L explosion chamber. Gas/vapor mixtures were prepared by the partial pressure method. Ignition was attempted using a 41-J energy spark, and the resulting pressure trace was monitored to determine flammability or nonflammability for each test. All of the flammability tests were conducted at ambient temperature. The test procedures will be described in this section and are also described in the SOP document.[3]

\subsection{TEST MATRIX}

Table 2.1 lists the specified order of tests for the 40 mixtures, based on a factorial experimental design. The first column lists the order for the experimental tests; this is the number that will be used to refer to individual mixtures in the remainder of this report. The second column lists the "Test Mixture" number. The next five columns list the amounts of the four VOCs and hydrogen in the various test mixtures.

\subsection{TEST EQUTPMENT}

Figure 2.2 shows schematic diagrams (horizontal and vertical cross sections) of the explosibility chamber that was used to determine the LFLs of the 40 mixtures. It is a nearly spherical vessel made of $13-\mathrm{mm}(1 / 2-$ in) thick stainless steel (type 304) with a pressure rating of 21 bar ( $300 \mathrm{psi}$ ). The approximate dimensions are $35 \mathrm{~cm}$ in height, $30 \mathrm{~cm}$ in diameter, and $191 / 2 \mathrm{~L}$ in volume. The chamber has sapphire viewing windows on top and on the sides. There are ports with ball valves for connection to a vacuum pump, exhaust, and a sensitive pressure sensor. There are ports with needle valves for connection to sources of compressed air and hydrogen. There is a solenoid controlled port on the bottom for the rapid introduction "of compressed air. There are central ports for the spark electrodes, and a port on the lid for a thermocouple. There are ports for the pressure transducers that monitor the explosion pressure. There is also a port with a swage fitting that includes a rubber septum. The latter is the means of introducing the VOC liquids into the chamber. Glass hypodermic syringes with a Teflon tipped plunger and a built-in metal valve are used to control the amount and vapor pressure of the injected liquids. 
HORIZONTAL SECTION

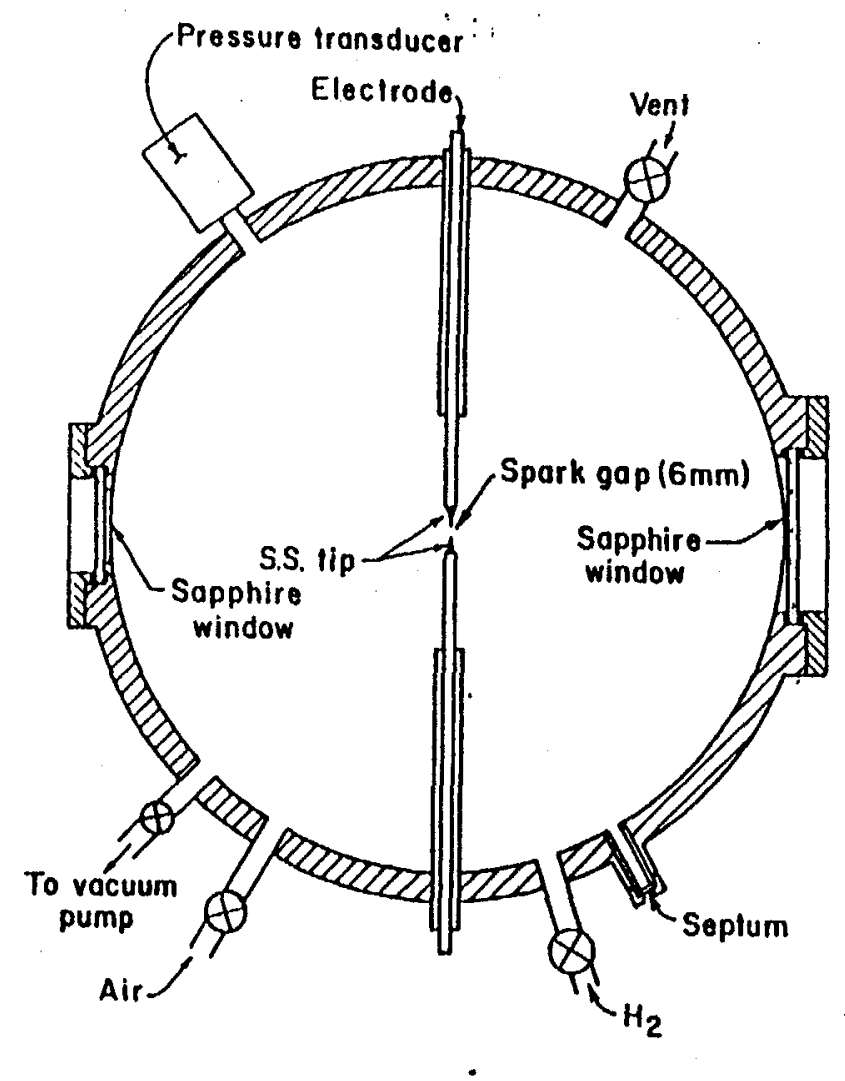

VERTICAL SECTION

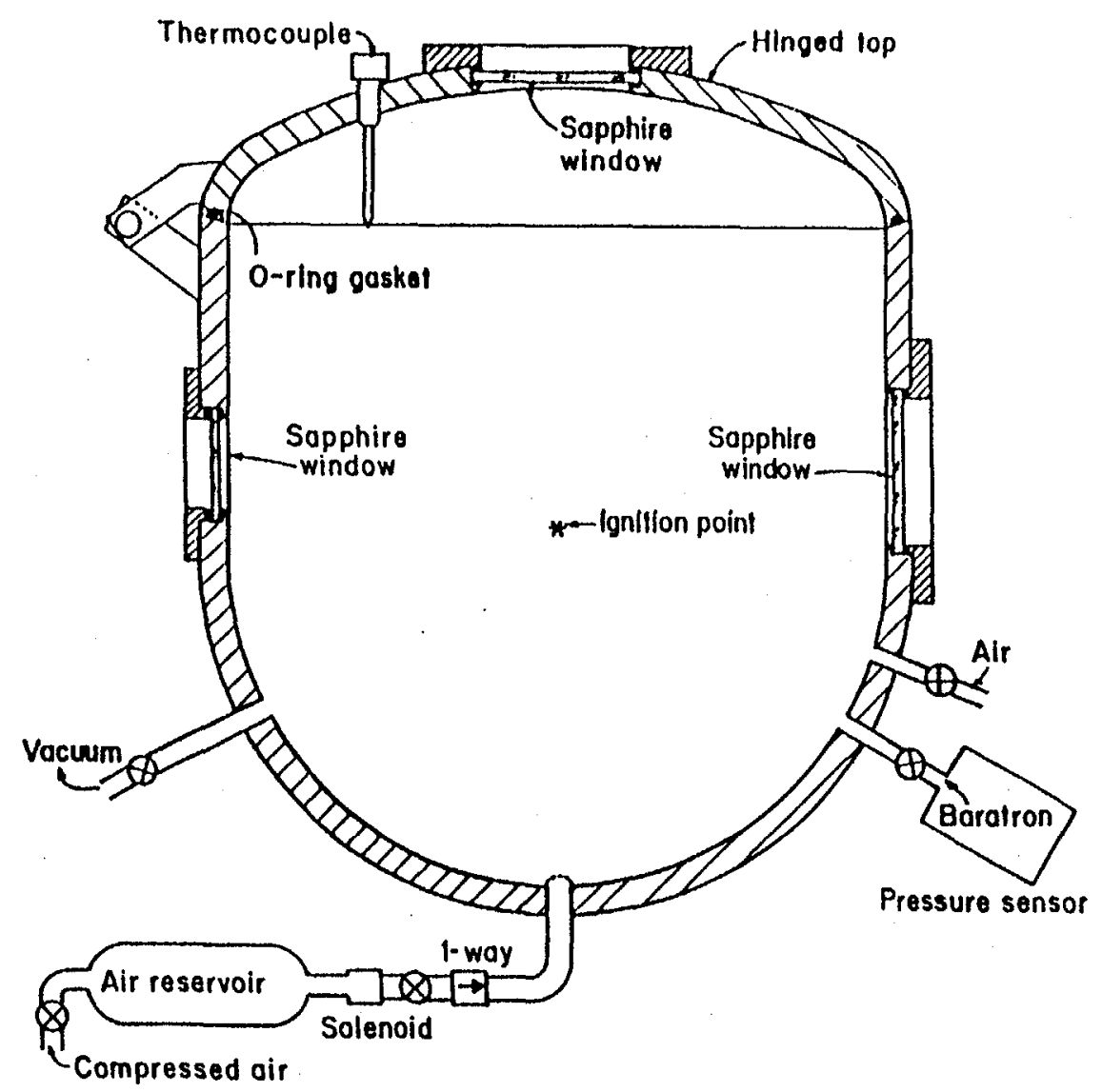

Figure 2.2 Flammability Test Chamber, with horizontal and vertical cross sections. 


\subsubsection{Spark Ignition}

The electrodes used for spark ignition are made of $3-\mathrm{mm}(1 / \mathrm{s}-\mathrm{in})$ diameter brass rods that are drilled at the ends and soldered to accommodate phonographic needles. The rods are inserted in ceramic sleeves through opposing ports (front and back) that are at chamber halfheight. The needle tips are centered in the chamber with a spark gap of $6 \mathrm{~mm}(1 / 4 \mathrm{in})$. A 900- $\mu$ f capacitor bank is charged to $300 \mathrm{~V}$ and then discharged through a transformer to create a high-voltage spark discharge between the electrode tips, with a total discharge time of about $100 \mathrm{~ms}$. The stored electrical energy is $41 \mathrm{~J}$, but circuit losses probably result in a lower electrical energy delivered to the spark gap. The measured pressure pulse due to the rapid heating (by the spark) of the air volume in the immediate vicinity of the electrode gap is $\sim 4 \mathrm{mpsi}$. The corresponding delivered thermal energy $(2.5 \mathrm{~V} \Delta \mathrm{P})$ is about $1 \mathrm{~J}$. A previously used 380- $\mu \mathrm{f}$ capacitor, in contrast, gave a pressure pulse of $2 \mathrm{mpsi}$, which corresponds to about $0.5 \mathrm{~J}$ of thermal energy. In some preliminary tests, the lower energy spark had been shown to have adequate ignition energy to reproduce the LFL values of toluene and MEK that are listed in the basic reviews of flammability limits by Coward and Jones [4], Zabetakis [3], and Kuchta [ 6 , but only the higher energy spark was used in the test series.

\subsubsection{Pressure Transducers}

The accurate measurement of the vapor pressures of the VOC components and hydrogen required the use of a sensitive and stable pressure sensor. It was anticipated that component pressures somewhat below 5 torr $(0.1$ psia) would be needed for some mixtures. Achievement of an accuracy of several percent of the measurement (to keep the overall error within $5 \%$ ) required a sensor that was accurate to 0.1 torr $(2 \mathrm{mpsi}$ ). The temperature controlled capacitance manometer from MKS instruments, Inc. ("Baratron" model 390HA10000) met these requirements in conjunction with a signal conditioner and electronic readout unit from the same manufacturer. At a full-scale range of $0-10,000$ torr $(0-193.37 \mathrm{psia})$, this sensor had a resolution of 1 torr $(0.01 \mathrm{psia})$. However, it was normally used in the more sensitive, but limited, range of $0-1000$ torr with a resolution of 0.1 torr. Using the 0 -19.337. psia range, the resolution was 0.001 psia. The meter provided a selection of pressure ranges and units. This sensor was rarely used to measure explosion pressures, in order to avoid the possible effects of a rapid pressure pulse and explosion products.

The explosion pressures were measured, instead, using strain gauge transducers (model 218) made by Viatran Corp. Initially the two sensors used (for redundancy) each had a pressure range of 0-100 psia. One of the Viatran sensors, however, began to deviate slightly from the readings given by the other and from the Baratron sensor in the middle of the LFL tests. Therefore, it was replaced by another Viatran sensor having a range of 
0-50 psia. The latter gave good agreement with the remaining 0-100 psia transducer, but went over-range during strong explosions. The pressure measurements at concentrations close to the LFL value, however, remain the average of the outputs of the two Viatran transducers. A summary of the pressure transducer specifications is listed in table 2.2.2.

\subsubsection{Temperature Sensor}

The vapor space temperature in the chamber during the addition of each mixture component, and during the explosions, was monitored by a Chromel-Alumel (type $\mathrm{K}$ ) thermocouple that was inserted into the chamber through the lid. The thermocouple tip was $9 \mathrm{~cm}$ from the top and the same distance from the central vertical axis of the chamber. The position of the tip was appropriate for sensing the temperature of a rising, expanding small "fireball" that is initially produced by the central spark ignition. The wire diameter of the thermocouple was $5 \mathrm{mil}(130 \mu \mathrm{m})$. A thermocouple of this size can survive the explosions, and is fast enough to respond qualitatively to the rapid temperature rise from an explosion. It was, therefore, able to give qualitative data on flame propagation and temperature, but was not fast enough to allow the monitoring of the actual peak explosion temperature. The thermocouple was connected to a temperature compensated digital meter with a direct temperature display (readable to $0.1^{\circ} \mathrm{C}$ ). The specifications for the type $\mathrm{K}$ thermocouple are also listed in table 2.2.2.

\subsubsection{Computerized Data Acquisition}

The two Viatran pressure transducers and the Baratron pressure transducer were connected to a high speed analog-to-digital (A/D) data acquisition board (model DT 2821 from Data Translation, Inc.). Details on the instrumentation settings and resolution are listed in the lower half of Table 2.2.2. The Baratron sensor was normally isolated from the explosion, using a ball valve. It was, occasionally, left open when only a weak explosion was expected, based on earlier experimental runs.

The thermocouple was connected to a calibrated amplifier via type $\mathrm{K}$ thermocouple extender wire and a temperature compensator, and then to the $\mathrm{A} / \mathrm{D}$ board. The gain setting (2) normally used corresponded to a maximum readable temperature of $1230^{\circ} \mathrm{C}$, with a resolution of $0.6^{\circ} \mathrm{C}$ (see Table 2.2.4). A higher gain setting of 4 would have improved the resolution, but its $615^{\circ} \mathrm{C}$ temperature limit would have been exceeded during strong explosions.

The A/D data acquisition board was controlled by a 80486 microprocessor based PC running at $33 \mathrm{MHz}$. The custom program that controlled the data acquisition, analysis, and 
Table 2.2.2 - Instrumentation

\begin{tabular}{|c|c|c|c|c|c|c|}
\hline & \multicolumn{2}{|c|}{ Baratron } & $\begin{array}{c}\text { Viatran } \\
\mathrm{P} 1 \\
\end{array}$ & $\begin{array}{c}\text { Viatran } \\
\text { P2 }\end{array}$ & \multicolumn{2}{|c|}{$\begin{array}{c}\text { Thermocouple } \\
\text { type K }\end{array}$} \\
\hline Scale & $0-1000$ Torr & $0-10,000$ Torr & $0-50$ psia & $0-100$ psia & $-270^{\circ} \mathrm{C}$ & $70^{\circ} \mathrm{C}$ \\
\hline Resolution/Accuracy & $\begin{array}{l}0.002 \text { psi } \\
0.1 \text { Torr }\end{array}$ & $\begin{array}{c}0.04 \mathrm{psi} \\
2 \text { Torr } \\
\end{array}$ & $0.05 \mathrm{psi}$ & $0.1 \mathrm{psi}$ & & \\
\hline Gain (A/D board) & 1 & 4 & 2 & 2 & 2 & 4 \\
\hline Calibration & $1934 \mathrm{mpsi} / \mathrm{V}$ & $19.34 \mathrm{psi} / \mathrm{V}$ & $-20 \mathrm{psi} / \mathrm{V}$ & $-20 \mathrm{psi} / \mathrm{V}$ & eqn & eqn \\
\hline Maximum & $\begin{array}{c}19340 \mathrm{mpsia} \\
1000 \text { Torr }\end{array}$ & $\begin{array}{l}48 \text { psia } \\
2500 \text { Torr }\end{array}$ & 50 psia & 100 psia & $1230^{\circ} \mathrm{C}$ & $600^{\circ} \mathrm{C}$ \\
\hline A/D Resolution & $9 \mathrm{mpsi}$ & $0.02 \mathrm{psi}$ & $0.02 \mathrm{psi}$ & $0.05 \mathrm{psi}$ & $0.6^{\circ} \mathrm{C}$ & $0.3^{\circ} \mathrm{C}$ \\
\hline
\end{tabular}


Table 2.1. - Test Matrix for Mixtures of Volatile Organic Compounds (VOCs) and $\mathrm{H}_{2}$

\begin{tabular}{|c|c|c|c|c|c|c|c|}
\hline \multirow{2}{*}{$\begin{array}{l}\text { Experimental } \\
\text { order }\end{array}$} & \multirow{2}{*}{$\begin{array}{l}\text { Test } \\
\text { mixture }\end{array}$} & \multicolumn{5}{|c|}{ Fuel Makeup in Test Mixture, mole \% } & \multirow[t]{2}{*}{ Comment } \\
\hline & & DCE & MEK & Fal & $\mathrm{H}_{2}$ & CT & \\
\hline 01 & 12 & 33 & 0 & 33 & 33 & 0 & \\
\hline 02 & 30 & 0 & 33 & 0 & 33 & 33 & \\
\hline 03 & 33 & 33 & 0 & 33 & 0 & 33 & \\
\hline 04 & 3 & 50 & 50 & 0 & 0 & 0 & · \\
\hline 05 & 25 & 0 & 0 & 33 & 33 & 33 & \\
\hline 06 & 19 & 0 & 50 & 50 & 0 & 0 & \\
\hline 07 & 32 & 0 & 0 & 0 & 0 & 0 & Air blank \\
\hline 08 (2) & 36 & 0 & 33 & 0 & 33 & 33 & \\
\hline 09 & 6 & 33 & 33 & 0 & 33 & 0 & \\
\hline 10 & 1 & 20 & 20 & 20 & 20 & 20 & \\
\hline 11 & 21 & 0 & 25 & 25 & 25 & 25 & \\
\hline 12 & 16 & 50 & 0 & 0 & 0 & 50 & \\
\hline 13 & 5 & 25 & 25 & 25 & 25 & 0 & \\
\hline 14 & 8 & 33 & 33 & 0 & 0 & 33 & \\
\hline $15 \quad(7)$ & 37 & 0 & 0 & 0 & 0 & 0 & Air blank \\
\hline 16 (4) & 38 & 50 & 50 & 0 & 0 & 0 & \\
\hline 17 & 7 & 25 & 25 & 0 & 25 & 25 & \\
\hline 18 & 23 & 0 & 0 & 50 & 0 & 50 & \\
\hline 19 & 22 & 0 & 0 & 100 & 0 & 0 & \\
\hline 20 & 34 & 0 & 33 & 33 & 0 & 33 & \\
\hline $21 \quad \therefore$ & 17 & 0 & 100 & 0 & 0 & 0 & \\
\hline 22 & 20 & 0 & 50 & 0 & 50 & 0 & \\
\hline $23(13)$ & 40 & 25 & 25 & 25 & 25 & 0 & \\
\hline 24 & 35 & 33 & 0 & 0 & 33 & 33 & \\
\hline 25 & 24 & 0 & 0 & 50 & 50 & 0 & \\
\hline $26(24)$ & 15 & 33 & 0 & 0 & 33 & 33 & \\
\hline 27 & 26 & 0 & 0 & 0 & 100 & 0 & \\
\hline 28 & 27 & 0 & 0 & 0 & 50 & 50 & \\
\hline
\end{tabular}




\begin{tabular}{|c|c|c|c|c|c|c|c|}
\hline \multirow{2}{*}{$\begin{array}{l}\text { Experimental } \\
\text { order }\end{array}$} & \multirow{2}{*}{$\begin{array}{l}\text { Test } \\
\text { mixture }\end{array}$} & \multicolumn{5}{|c|}{ Fuel Makeup in Test Mixture, mole \% } & \multirow{2}{*}{ Comment } \\
\hline & & DCE & MEK & Tol & $\mathrm{H}_{2}$ & CT & \\
\hline 29 & 29 & 0 & 33 & 33 & 33 & 0 & \\
\hline 30 & 18 & 0 & 50 & 0 & 0 & 50 & \\
\hline 31 & 2 & 100 & 0 & 0 & 0 & 0 & \\
\hline 32 & 13 & 25 & 0 & 25 & 25 & 25 & \\
\hline $33(25)$ & 39 & 0 & 0 & 50 & 50 & 0 & \\
\hline $34(20)$ & 28 & 0 & 33 & 33 & 0 & 33 & \\
\hline 35 & 9 & 25 & 25 & 25 & 0 & 25 & \\
\hline 36 & 14 & 50 & 0 & 0 & 50 & 0 & \\
\hline 37 & 10 & 50 & 0 & 50 & 0 & 0 & \\
\hline 38 & 4 & 33 & 33 & 33 & 0 & 0 & \\
\hline $39 \quad(3)$ & 11 & 33 & 0 & 33 & 0 & 33 & \\
\hline 40 & 31 & 0 & 0 & 0 & 0 & 100 & NF \\
\hline
\end{tabular}

DCE $=1,2$ dichloroethane, $M E K=2$-butanone (methyl ethyl ketone)

Tol $=$ toluene, $C T=$ carbon tetrachloride, $\mathrm{H}_{2}=$ hydrogen

The number in parentheses after 'experimental order number' denotes the previous mixture no. that this mixture duplicated. 
display was written by C. E. Lucci ${ }^{5}$, who has also maintained the software. The program displays the absolute pressure, pressure rise, rate of pressure rise $(\mathrm{dP} / \mathrm{dt})$, and temperature data versus time. The calibration data for the various instrumentation can be entered into the program so that the displays are in engineering units. It also allows scale changes, peak search start and end points, and data smoothing. The PC program provides a data input form ("header" screen), data graphs from each instrument, and a data summary output.

\subsection{EQUIPMENT CALIBRATIONS}

The required calibrations were done at the start of the test series, and/or on a daily basis, as specified in the report "Experimental Apparatus and Procedure for Vapor Explosibility Testing in the 19-L Chamber" issued by PRC in April 1997 for this project [3].

\subsubsection{Pressure Calibrations}

All of the pressure transducers were calibrated on a daily basis. The two Viatran transducers were calibrated using built-in internal shunt resistors. The chamber was first evacuated and the "zero" pressure readings were taken from the voltmeter output of the Viatran sensors. The shunt calibration leads were then connected and the voltage output of the sensors was read. After subtracting the "zero" readings, these calibration voltages were used with the manufacturer's listed calibration pressure to give the $p s i / V$ calibration values for the two transducers. The calibration data were then entered into the PC data acquisition system daily. The 100-psia transducer's calibration value was stable at $19.98 \pm 0.01 \mathrm{psi} / \mathrm{V}$ over the course of the tests. The 50-psia transducer's calibration was stable at $10.02 \pm 0.02 \mathrm{psi} / \mathrm{V}$.

The Baratron system was calibrated by the manufacturer prior to starting the LFL tests. The accuracy was within 0.1 torr for the $0-1000$ torr range, and within 2 torr for the $0-10,000$ torr range. The read-out unit was also calibrated on a daily basis, using the manufacturer's recommended procedure. The null value of $0.000 \mathrm{~V}$ was maintained throughout the tests. The full-scale setting often needed adjustment, however, to $10.000 \mathrm{~V}$. The manufacturer's system check value of $9.963 \mathrm{~V}$ was maintained to within several millivolts after adjusting the full-scale setting.

These measured calibration values for the three pressure transducers were entered on a separate calibration sheet on a daily basis, and then entered into the PC.

\footnotetext{
${ }^{5}$ Research Physicist at PRC
} 


\subsubsection{Software Calibration}

The software used to acquire the explosion pressure and temperature data was developed at PRC for use in explosion studies. The resolution and accuracy of the software controlled data acquisition for pressures was determined before the start of the LFL tests by establishing a series of nine fixed pressures in the chamber ranging from 1 to $50 \mathrm{psia}$, and comparing the digital meter and PC readouts for all the sensors used in the chamber. The results of this calibration experiment are in Table 2.3.2.

\subsubsection{Temperature Calibration}

The digital temperature readout was used to measure the chamber temperature during VOC addition. The PC output was only used to give a qualitative estimate of the peak temperature of the post-ignition combustion gases. The temperatures given by the PC output were initially calibrated against the Omega digital readout and a sensitive mercury thermometer by immersing the thermocouple in ambient temperature water, cold water, and ice water. The temperatures measured in the three ways agreed to within several tenths of a degree. During the course of the tests, however, the agreement between the PC output and the Omega digital readout was not maintained this closely, probably due to the effect of fluctuations in ambient temperature on the amplifier (see Table 2.3.2). It was considered impractical to recalibrate the PC temperature output on a regular basis since the thermocouple was cemented in place inside the chamber. The PC temperature output, therefore, should be treated as relative rather than absolute data, with more significance given to the measured explosion temperature rise than on the absolute initial starting temperature.

\subsection{CHEMICALS}

All VOCs and gases used for these tests were supplied as high purity materials (>99\%) by the manufacturer. The cylinders of high grade air that were used in the test program had very low ppm levels of organic and carbon monoxide impurities. The oxygen content was also consistent with that of standard dry air $(20.96 \%)$. The hydrogen cylinder that was used contained research grade hydrogen that is over $99.8 \% \mathrm{H}_{2}$. The minor impurities are nitrogen, oxygen, and carbon dioxide. The toluene (Tol), 2-butanone (MEK), 1,2 dichloroethane (DCE), and carbon tetrachloride (CT) VOCs that were used in the flammability tests were anhydrous, high purity chemicals that had been packaged under nitrogen in sealed glass containers by a major fine chemical supplier (Aldrich Chemical Co.). The toluene and 1,2 dichloroethane were $99.8 \%$ pure with $50 \mathrm{ppm}$ of water and 3-5 ppm of residue. The 2 -butanone was over $99.5 \%$ pure. It had been redistilled in glass and sealed under nitrogen. The carbon tetrachloride was over $99 \%$ pure, with $50 \mathrm{ppm}$ water and $3 \mathrm{ppm}$ 
Table 2.3.2 - Software and Sensor Calibrations

\begin{tabular}{|c|c|c|c|c|c|c|c|c|}
\hline Run & $\begin{array}{c}\text { Brtin } \\
\text { psi : }\end{array}$ & $\begin{array}{c}\text { B.PC } \\
\text { psi }\end{array}$ & $\begin{array}{c}\text { Vtrn,P1 } \\
\text { psi }\end{array}$ & $\begin{array}{c}\mathrm{V} \cdot \mathrm{PC} \\
\mathrm{psi}\end{array}$ & $\begin{array}{c}\text { Vtrn,P2 } \\
\text { psi }\end{array}$ & $\begin{array}{l}\text { V.PC } \\
\text { psi }\end{array}$ & $\begin{array}{l}\text { Temp. } \\
{ }^{\circ} \mathrm{C}\end{array}$ & $\begin{array}{c}\text { T.PC } \\
{ }^{\circ} \mathrm{C}\end{array}$ \\
\hline 97.5126 & 1.000 & 1.0 & 0.97 & 1.0 & 0.97 & 1.0 & 22.7 & 23.7 \\
\hline 97.5127 & 5.000 & 5.0 & 4.96 & 5.0 & 4.96 & 5.0 & 23.4 & 24.7 \\
\hline 97.5128 & 10.000 & 10.0 & 9.95 & 10.0 & 9.95 & 10.0 & 23.4 & 24.7 \\
\hline 97.5129 & 14.500 & 14.5 & 14.42 & 14.5 & 14.43 & 14.5 & 23.2 & 24.0 \\
\hline 97.5130 & 15.500 & 15.5 & 15.40 & 15.4 & 15.41 & 15.4 & 23.5 & 23.8 \\
\hline 97.5131 & 20.00 & 20.0 & 19.91 & 20.0 & 19.91 & 19.9 & 23.8 & 23.9 \\
\hline 97.5132 & 30.00 & 30.0 & 29.89 & 29.9 & 29.88 & 29.9 & 23.4 & 23.1 \\
\hline 97.5133 & 40.00 & 40.0 & 39.89 & 39.9 & 39.83 & 39.8 & 23.4 & 23.4 \\
\hline 97.5134 & 50.00 & & 49.86 & 49.9 & 49.80 & 49.8 & 23.3 & 23.9 \\
\hline
\end{tabular}

Note: The above data were obtained with the following sensors, readout devices, and PC A/D program settings:

In the table, "Brtm" denotes the Baratron pressure sensor and "B.PC" denotes the PC readout for the Baratron. The Baratron $390 \mathrm{HA}-10000$ pressure sensor and $2700 \cdot 4$ readout were both calibrated by the manufacturer, MKS. The RX1 range $(0.193 .37$ psia) was used for $P \geq 20$ psia, the $R X .1$ range was used for $P<20$ psia. The $P C$ output from the Baratron was generated using a calibration factor of 19.34 (psi/v), RX1 Baratron setting, and an $A / D$ gain $=4$.

In the table, "Vtrn" denotes a Viatran pressure transducer and "V.PC" denotes the PC readout for a Viatran transducer. The Viatran model 218 pressure sensors read 0. 100 psia. They were calibrated by measuring the internal (shunt) voltage that corresponded to the specific calibration pressure for the unit. The PC outputs for the P1 and $\mathrm{P} 2$ units were generated for the above calibration runs using calibration factors of 19.98 and 19.99 psilv, respectively, at a gain of 2 .

The temperature data were generated from a type $K$ thermocouple (TC) that was situated near the top of the chamber. The readout device was a type $K$ digital TC meter from Omega. The PC output ("T.PC" in the table) was generated at a gain of 2 . This setting provides a range of $0.1230^{\circ} \mathrm{C}$ with an $\mathrm{A} / \mathrm{D}$ resolution of $0.6^{\circ} \mathrm{C}$. 
residue. The emphasis in ordering these materials was placed on obtaining dry, high purity chemicals in a positively sealed container. MSDS sheets on the above chemicals were obtained from Aldrich Chem. Co, and impervious polyethylene gloves were worn when handling the VOC liquids.

Appropriate portions of the above VOC liquids were transferred to labelled $50-\mathrm{cm}^{3}$ glass bottles that had an inert, closable septum seal ("mininert" valve), via dedicated, labelled syringes. The object was to provide a more easily handled VOC container, and to be consistent with good chemical practice.

\subsection{CALCULATIONS}

\subsubsection{Mixture Composition}

The preparation of the equimolar gaseous mixtures of VOCs is based on adding a sufficient amount of the individual VOC liquids to give the same number of moles of vapor in the 19- $\mathrm{L}$ test chamber for each component. The number of moles of each component is determined from the component vapor pressure, using the ideal gas law $\left(n_{i}=P_{i} V / R T_{i}\right.$, where $n_{i}$ is the number of moles of component "i", $P_{i}$ is its vapor pressure, $T_{i}$ is its absolute temperature, $\mathrm{V}$ is the chamber volume, and $\mathrm{R}$ is the universal gas constant). If hydrogen $\left(\mathrm{H}_{2}\right)$ is absent, the total gas mixture in the chamber consists of the VOC mixture and air. The mole fraction of VOC component in the gas mixture is $n_{i} / n_{i}$, where $n$ is the number of moles, the subscript " $\mathrm{i}$ " refers to the VOC component, and the subscript " $\mathrm{t}$ " refers to the total mixture of VOC and air. From the ideal gas law, $n_{i} / n_{l}=\left(P_{i} / P\right)\left(T_{l} / T_{i}\right)$, where $T_{i}$ is the absolute temperature in kelvins after the addition of the VOC component and $T_{t}$ is the absolute temperature at the time the chamber pressure $(P)$ has stabilized after the air addition. ( $T_{i}$ is expected to be approximately the same for each component addition, and was normally taken as the average VOC component temperature.) In the presence of hydrogen, the mole fraction of $\mathrm{H}_{2}\left(\mathrm{n}_{\mathrm{Fi}_{2}} / \mathrm{n}_{\mathrm{l}}\right)$ is used, in addition to $\mathrm{n}_{\mathrm{i}} / \mathrm{n}_{\mathrm{q}}$.

\subsubsection{Estimated Mixture Flammability Limits}

In order to estimate the expected LFLs for the mixtures as a starting point for the experimental tests, the LeChatelier Rule and the Group Contribution Methods were both used in calculating LFLs for the equimolar fuel mixtures. Both methods are described in the Test Plan $[1, p .5-1]$. The first was developed by the eminent French physical chemist, LeChatelier, a century ago $[6, p .14]$. The second was published by the American Institute of Chemical Engineers (AIChE) several years ago [7], and elaborated in the Test Plan [I]. 
The LeChatelier rule is given by:

$$
L_{L}=\frac{1}{\sum x_{i} / L_{i}}
$$

where $L_{L}$ is the mixture LFL in percent, $x_{i}$ is the mole fraction of fuel component " $i$ " in the mixture, and $L_{i}$ is the experimental LFL, in percent, for the pure component " $i$." The sum $(\Sigma)$ is taken over all the fuel components. For an equimolar mixture, $x_{i}=1 / N$, where $N$ is the number of components in the mixture, and $\mathrm{L}_{\mathrm{L}}=\mathrm{N} / \mathrm{L}\left(1 / \mathrm{L}_{\mathrm{i}}\right)$. For a binary mixture, $\mathrm{N}=2$ and $\mathrm{L}_{\mathrm{L}}=2 /\left(1 / \mathrm{L}_{1}+1 / \mathrm{L}_{2}\right)$. For a ternary mixture, $\mathrm{N}=3$ and $\mathrm{L}_{\mathrm{L}}=3 /\left(1 / \mathrm{L}_{1}+1 / \mathrm{L}_{2}+1 / \mathrm{L}_{3}\right)$. This equation has some theoretical justification for an ideal mixture, but it was designed for mixtures of fuel components - not for nonflammable components such as carbon tetrachloride.

The Group Contribution method is, in contrast, strictly empirical, but has the flexibility to accommodate nonflammable components. The LFL equation for mixtures using the Group Contribution Method is:

$$
L_{G}=\frac{100}{\sum x_{i} C_{i}}
$$

where $\mathrm{C}_{\mathrm{i}}$ is the "molecular" contribution from component " $\mathrm{i}$ " in the mixture. For equimolar mixtures, $x_{i}=1 / N$ and $L_{G}=100 \times N / \sum C_{i}$. This method is based on a factorization of the experimental LFL data on individual molecular species into additive "atomic" contributions $\left(\mathrm{C}_{\mathrm{ij}}\right)$. Thus $\mathrm{C}, \mathrm{H}, \mathrm{O}$, and $\mathrm{Cl}$ have calculated atomic contributions of $9.10,2.17,-2.68$, and -4.38 , respectively. The "molecular" contribution $\left(C_{i}\right)$ is given by $C_{i}=\Sigma n_{j} C_{i j}$, where $n_{j}$ is the number of atoms of each type "j" in the molecule. Thus, toluene $\left(\mathrm{C}_{7} \mathrm{H}_{8}\right)$ makes a total contribution of $7(9.10)+8(2.17)=81.06$, MEK $\left(\mathrm{C}_{4} \mathrm{H}_{8} \mathrm{O}\right)$ gives $51.08, \mathrm{DCE}\left(\mathrm{C}_{2} \mathrm{H}_{4} \mathrm{Cl}_{2}\right)$ gives 18.12 , and $\mathrm{CT}\left(\mathrm{CCl}_{4}\right)$ gives -8.42 . The negative value for $\mathrm{CT}$ indicates that it is nonflammable, as found experimentally. For $\mathrm{H}_{2}, \mathrm{C}_{\mathrm{i}}$ was not calculated [I] as $2 \times 2.17$, but was taken directly from the experimental LFL of $5 \%$, i.e., $\mathrm{C}=100 / 5.0=20$.

\section{$\therefore \quad 2.6$ PRELIMINARY TESTING}

The function of the initial testing was to qualify the chamber, sensors, and test procedures for the actual test series. It also served to establish an appropriate explosion pressure rise criterion for the flammability of a mixture and its concentration limits. This was done by testing the individual components. Normally, the boundary between flammable and nonflammable concentrations of a fuel component (LFL) is characterized by a steep rise in explosion pressure from very low values. A specific pressure criterion is, consequently, immaterial for such components. For hydrogen, however, only a gradual increase in 
pressure occurs from about $4 \%$ until a concentration of over $8 \% \mathrm{H}_{2}$ is reached. A specific pressure criterion is, therefore, needed to determine the LFL of hydrogen. The pressure rise criterion of 0.5 psi that was selected was designed to give the $5 \%$ LFL value accepted by $\mathrm{NRC}$ for $\mathrm{H}_{2}$ [8][9]. Using this criterion, the LFL values of toluene, and MEK agreed well with the literature values [4]. This provided a verification of the test equipment and procedures.

An important function of the initial chamber tests was to ascertain that the system was leak-tight. All the initial leak sources were identified and corrected, and a simple design for the VOC injection (septum) port provided adequate protection against leaks. The septum consisted of the rubber stopper used to seal evacuated test tubes ("Vacutainers"). The septum was secured in a swaged pipe fitting. This arrangement was leak-tight as long as the septum (stopper) had not been punctured too often. The stoppers were changed regularly to help insure that leakage through an incompletely sealed needle puncture would not occur.

Initially, an internal non-sparking fan was used to insure mixture uniformity. However, it was found that the toluene vapor pressure in the chamber declined with time, presumably due to absorption in the motor windings and/or the insulated (vinyl) electrical leads. The fan was, therefore, removed and mixing was accomplished via a blast of pressurized air from the solenoid controlled air disperser nozzle on the bottom of the chamber. The final air addition that brought the VOC concentrations to the desired level was accomplished by the manual addition of air via a needle valve. This addition was completed within 1 minute of the air blast to help insure that adequate mixing was still occurring in the chamber. Samples of the gas mixtures were initially collected for GC analysis to confirm that the air-blast mixing was adequate.

Preliminary tests on the LFLs of toluene and MEK had used a stored spark energy of $17 \mathrm{~J}(380 \mu \mathrm{f}$ at $300 \mathrm{~V})$. The LFLs so determined were in agreement with the reported values from closed flammability tubes [4]. Despite the seeming adequacy of the spark energy used, it was deemed advisable to use an even more energetic spark (41 J stored energy from a $900 \mu \mathrm{f}$ capacitor bank at $300 \mathrm{~V}$ ) for the test series, in order to help insure that the more difficult to ignite components (DCE) and mixtures (those with DCE or CT) would not be ignition. limited. Switching to the higher capacitance spark did not reduce the LFL for MEK. There was, therefore, no indication that the more energetic spark was "overdriving" the chamber mixture, nor was there any expectation that the actual thermal energy deposited in the chamber by the spark (about $1 \mathrm{~J}$ ) could possibly do so. 


\subsection{STANDARD TEST PROCEDURES}

\subsubsection{Mixture Preparation}

The outline of the test methodology used to ascertain the LFLs of the 40 specified mixtures is given in the Test Plan $[1, p .4-3]$. The justification and the details of the procedures adopted are given below.

The chamber had been cleaned, sealed, and filled with cylinder (dry) air overnight, after having the septum changed (if needed). At the start of the daily testing, the chamber was evacuated, and the pressure transducers were calibrated according to the procedures listed in section 2.3.1. These pressure transducer calibrations were entered onto individual calibration sheets each day, and also entered into the PC data acquisition program (data channel calibration).

With the vacuum pump isolated from the chamber and shut down, the Baratron pressure reading was monitored for at least several minutes to confirm that there was no air leak. The VOC liquids needed for the test were drawn from the appropriate $50-\mathrm{cm}^{3}$ bottles by dedicated gas-tight syringes equipped with integral metal valves. After recording the initial chamber pressure, the first VOC was metered into the chamber by careful liquid injection from the appropriate syringe to achieve the desired component pressure. Normally, toluene, if present in the mixture, was the first liquid, since it had the lowest vapor pressure of all the VOC liquids. However, MEK had a tendency to give a non-steady (slightly decreasing) vapor pressure due to possible absorption inside the chamber. It was, therefore, injected first, and care was taken to insure that the desired steady-state vapor pressure reading was attained. This injection was followed by that of Tol, DCE, CT, $\mathrm{H}_{2}$, and air, in that order. The temperature inside the chamber (after each component addition) was read from the digital thermocouple meter together with the chamber pressure reading from the Baratron meter. Initially, the desired component pressures were calculated by assuming a final pressure (e.g., 14.5 psia), which was then multiplied by the desired mole fraction of the component (e.g., a desired mixture containing $1.00 \%$ of each designated component would require a component pressure of $0.145 \mathrm{psi}$ ). To obtain the actual concentration of a component, measurements of the stable vapor pressure reading of that component, its associated temperature, and the actual final mixture pressure (with its associated temperature) were required. Thus, corrections for the ratio of the actual component and final pressures, and for the ratio of the absolute final and component temperatures were needed to arrive at the true concentrations, as specified in section 2.5.1.

The fact that the chamber temperature can change with addition of components is due primarily to heating by the "adiabatic compression" of the chamber contents from the rush of incoming gas. This effect was most noted with the substantial air addition, particularly when 
added initially at a high velocity. The temperature quickly decreased from its peak value, then fell slowly over time. It would be too time consuming to wait for the temperature to reach a true equilibrium value. Instead, the chamber pressure was read when it appeared to have reached a steady-state value, and the corresponding temperature was noted and used to correct the calculated concentrations.

\subsubsection{LFL Determination}

First, the estimated or expected lower flammability limits (LFL) of the various test mixtures were calculated using the LeChatelier and/or Group Contribution Method, as outlined in section 2.5.2. The LeChatelier calculation used the values for the LFL of the pure components that were determined during the preliminary testing, as described in section 2.6. Thus, Tol, MEK, and $\mathrm{H}_{2}$ were considered to have LFLs of $1.2,2.0$, and $5.0 \%$, respectively, for the purpose of making LFL estimates. The LFL of DCE was considered uncertain since the literature showed values ranging from 5.4 to $6.2 \%$. It was found that the two LFL calculation methods generally agreed to within the first decimal place, and an average of the two calculated values was taken as the starting point in making the mixture concentrations for flammability testing. For mixtures containing the nonflammable carbon tetrachloride (CT), only the Group Contribution calculation was available.

The second concentration prepared for a given mixture differed from the first by approximately $10 \%$. The objective was to achieve a flammable concentration (a "go") if the first was nonflammable (a "no go"), or the reverse. Subsequent tests were aimed at determining the LFL to within the first decimal place, if possible. The objective was to achieve at least two "no go's" slightly below the LFL and at least two "go's" slightly above the LFL in order to determine the LFL to within $\pm 3 \%$. The LFL criterion used for these measurements was a pressure rise of $0.5 \mathrm{psi}$. Temperature rise measurements and visual observations of the flame propagation were found to correlate well with the pressure rise measurements. The flammability data (pressure versus concentration) for each mixture were plotted, and the best estimated LFL value (in \% by volume) was determined and then rounded to the nearest $0.05 \%$.

\subsection{RECORDS MANAGEMENT AND DATA REPORTING}

The primary data record for this program was a numbered, bound, and signed laboratory (black) notebook. A second such (green) book was used as a workbook where detailed data on pressure and temperature readings versus time were kept, both for actual tests and calibrations. This workbook also contained all calculations needed for the tests and calibrations. The black laboratory notebook provides the summary data on the experimental conditions and results, in tabular form. It also contains a summary of other relevant data 


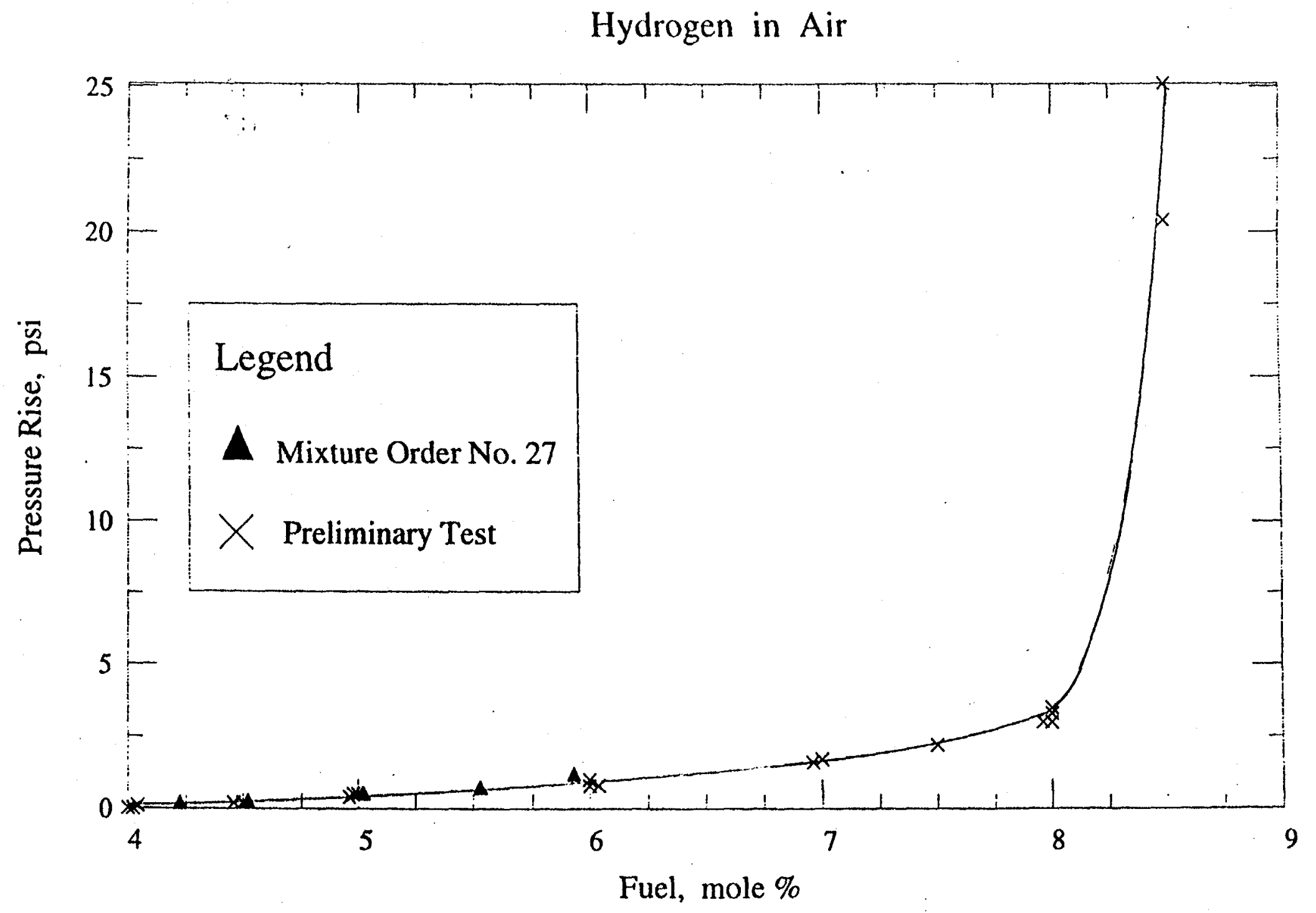

Figure 3.1.1a Flammability data ( $\triangle$ 's) for Mixture Order Number $27\left(\mathrm{H}_{2}\right)$, compared to preliminary $\mathrm{H}_{2}$ data (x's) 
such as calibration results, and brief comments on the tests. The notebook pages were signed by the person entering the data during the tests, and any corrections to data entries were initialed by him. The laboratory notebook data was regularly reviewed and initialed by the project manager at PRC. He also reviewed the computer generated data, and based his data corrections on a re-analysis of the computer data. A signature page preceding the start of the official test program was provided in the notebook where all personnel conducting and reviewing the tests attested that they read, understood, and proposed to follow the procedures and requirements specified in the SOP [3] and Test Plan [1] documents.

The protection of the computer acquired data was insured by daily backup of the data on the PC's hard drive to standard $3 \frac{1 / 2}{2}$ in magnetic data disks. The printed output of the data acquisition and display program for the flammability tests is available at PRC, in addition to copies of the computer acquired data and the executable program on data disks and/or transferable computer files. The computer generated data files will be transferred to LMITCO for permanent storage.

Traceability of the VOC or the VOC mixture used in a flammability test was maintained by careful and prompt labelling of the $50-\mathrm{mL}$ bottles that were used as the VOC reservoirs for the series of flammability tests. The labels identified the bottle, the VOC liquid, and the specific reagent bottle that was used as the source of the VOC. The latter is needed since the VOC liquids were primarily supplied as several $100-\mathrm{mL}$ bottles of each material. The 1-L toluene (Tol) reagent bottle was labelled "T1", the $100-\mathrm{mL}$ bottles of 2-butanone (MEK) were labelled "B1" and "B2", the 100-mL bottles of carbon tetrachloride (CT) were " $\mathrm{C} 1$ " and "C2", and the 100-mL bottles of 1,2 dichloroethane (DCE) were "D1" and "D2". The 50-mL bottles containing a single component were labelled "\#1 Tol-T1", "\#1 MEK-B1", "\#1 CT-C1", and "\#1 DCE-D1" for toluene, MEK, CT, and DCE, respectively. As additional bottles were required, they were numbered as \#2 Tol-T1, etc. The syringes used to transfer the VOC components to the $50-\mathrm{mL}$ bottles, and to inject the mixtures into the chamber were labelled so as to avoid cross-contamination. The laboratory notebook recorded the identity of the 50-mL containers used as the VOC sources for each test. It also provided the FAMP Test Plan designated experimental order and test mixture numbers for each mixture tested.

\subsection{FLAMMABILITY TEST RESULTS}

Example graphs of the flammability test data for some of the specified mixtures are shown in figures 3.1.1 to 3.1.7. They illustrate the cases of some inherent uncertainty in LFL determinations and the agreement achieved in replicate mixtures.

Figure 3.1.1a shows the flammability data for hydrogen (data $\triangle$ 's for mixture order no. 27) compared to the preliminary (see section 2.6 ) hydrogen data ( $x$ 's). The vertical axis 
shows the explosion pressure rise in psi and the horizontal axis shows the fuel $\left(\mathrm{H}_{2}\right)$ concentration. There is good agreement between the preliminary and final data sets. This plot shows the gradual increase in explosion pressure over the 4 to $8 \% \mathrm{H}_{2}$ concentration range. A concentration of over $8 \%$ is needed in order to get a substantial overpressure and sensitivity to concentration. This implies that the LFL is sensitive to the precise value of the pressure rise criterion. The hydrogen data are shown on an expanded scale in figure 3.1.1b. The dotted horizontal line in the graph shows the pressure rise criterion of $0.5 \mathrm{psi}$ chosen during preliminary testing (see section 2.6) in order to best match the NRC value of $5 \%$ as the LFL of $\mathrm{H}_{2}[8,9]$.

Figure 3.1.2 shows the flammability data (mixture order no. 28) for the binary mixture of $\mathrm{H}_{2}$ with $\mathrm{CT}\left(\mathrm{CCl}_{4}\right)$. In this case, the horizontal axis shows the total mixture concentration $\left(\mathrm{H}_{2}\right.$ plus $\left.\mathrm{CT}\right)$. For this graph and the following graphs, the total $\mathrm{H}_{2}$ and VOC concentration is denoted as "fuel, " even though the CT is actually nonflammable. This plot shows an even more gradual increase in pressure with concentration. The best estimate of the LFL for this mixture is $10.8 \pm 0.8 \%$, i.e., the decimal value is quite uncertain. It should be noted that this mixture combines the lightest, most diffusible molecule $\left(\mathrm{H}_{2}\right)$ with the heaviest of the VOCs $\left(\mathrm{CCl}_{4}\right)$.

Figure 3.1.3 shows a less gradual increase in explosion pressure with concentration for mixture order no. 36, a binary mixture of $\mathrm{H}_{2}$ with DCE $\left(\mathrm{ClC}_{2} \mathrm{H}_{4} \mathrm{Cl}\right)$. Here the LFL can be specified as $5.35 \% \pm 0.2 \%$.

Figure 3.1.4 shows the reasonable agreement of the replicate mixtures (order numbers 24 and 26) containing $\mathrm{H}_{2}$, DCE, and CT, despite the exhibited gradual rise in explosion pressure with concentration. The measured LFLs of these mixtures, 10.1 and $9.7 \%$, respectively, still agree within the uncertainty in the measurements.

These four data graphs (figures 3.1.1, 3.1.2, 3.1.3, and 3.1.4) show that pure hydrogen and some hydrogen mixtures have a fairly large uncertainty in LFL values, depending on the pressure criterion chosen, due to the gradual increase of pressure with concentration. These are mixtures where hydrogen has a dominant effect. The other hydrogen containing mixtures and the pure VOC mixtures show a sharp discontinuity at the flammability boundary and therefore have more well-defined LFL values. These are mixtures where there is no hydrogen or where the fuel is dominated by VOCs with a lower LFL than hydrogen.

Figure 3.1.5 shows the excellent agreement of the replicate mixtures 13 and 23 , which contain Tol, MEK, and DCE in addition to $\mathrm{H}_{2}$. Note the relatively sharp rise in explosion pressure above $2.40 \%$. The pressure is near zero at $2.35 \%$ fuel, then rises to slightly over 1 psi at $2.4 \%$, and then increases rapidly to 45 psi $2.5 \%$ fuel. 


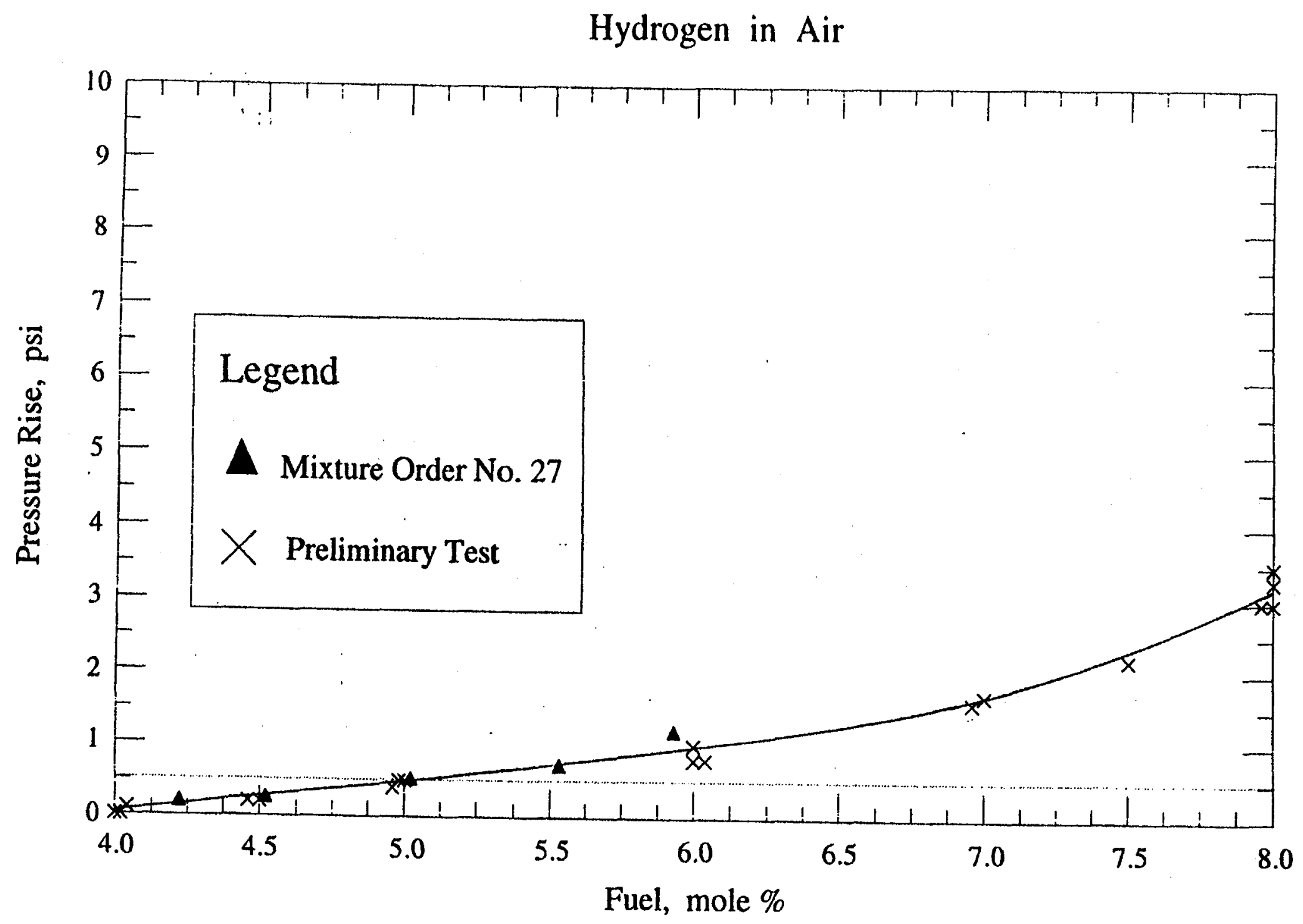

Figure 3.1.1b Expanded scale flammability data for $\mathrm{H}_{2}$, with Mixture Number 27 ( $\mathrm{A}$ 's) compared to preliminary data ( $x$ 's) 
Mixture Order No. 36 (DCE, H2)

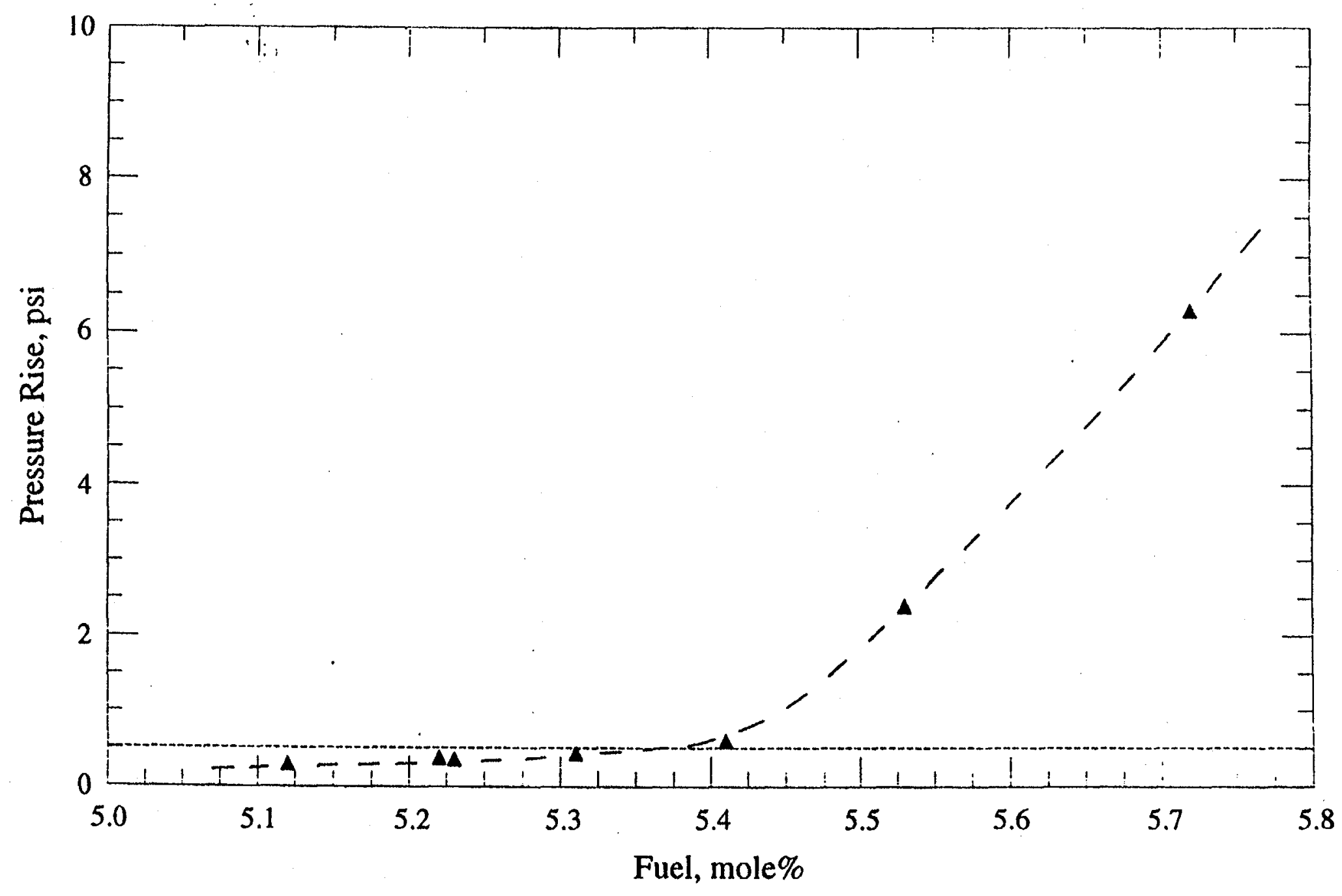

Figure 3.1.3 Flammability data for Mixture Order Number $36\left(\mathrm{H}_{2}\right.$ and DCE) 


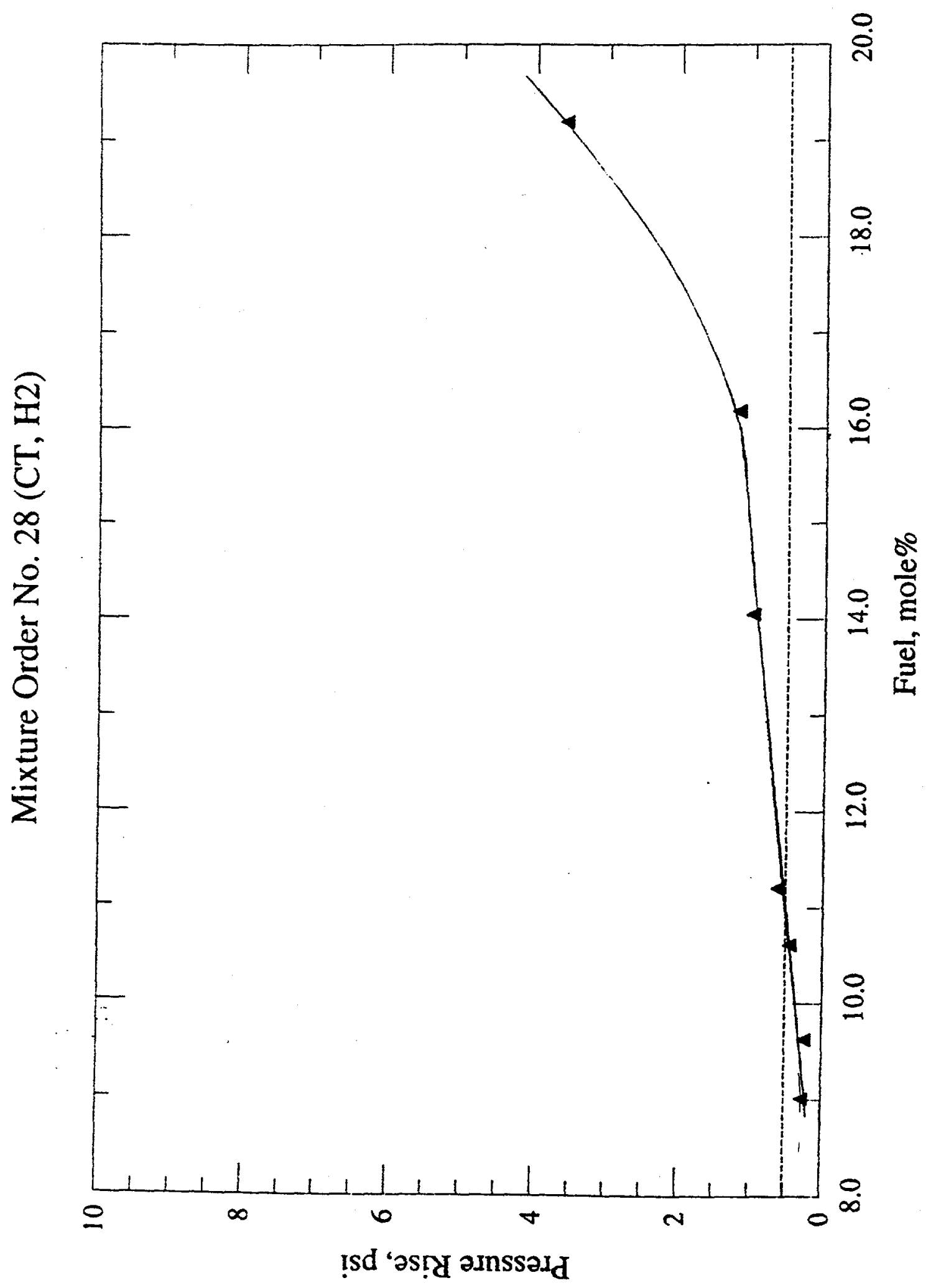

仓

்ֻ 


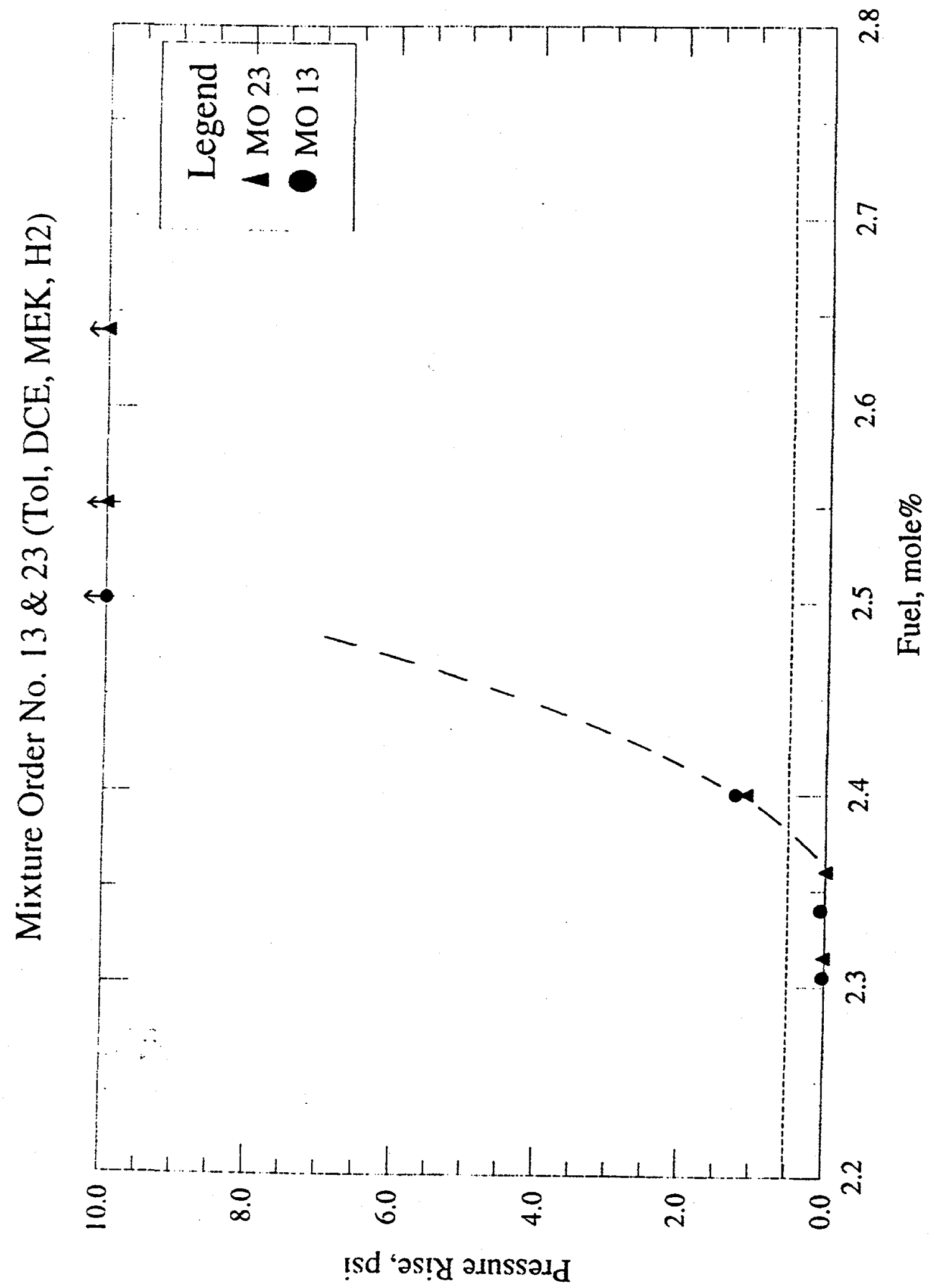

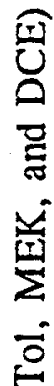

$\Xi$

กิ

छั

$\because$

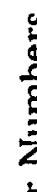

อั

莺

논

폻

录

奋 


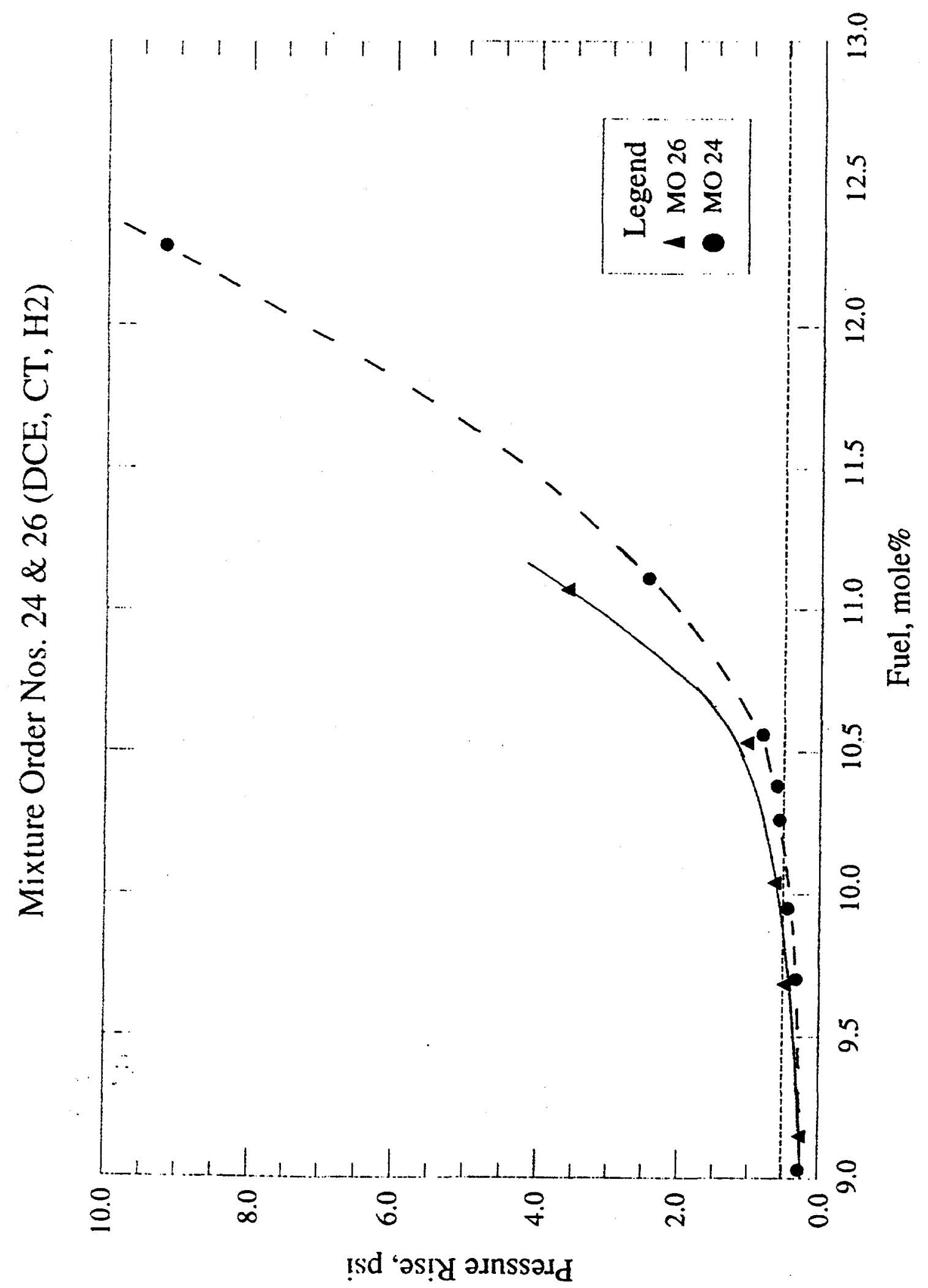

U

تัن 


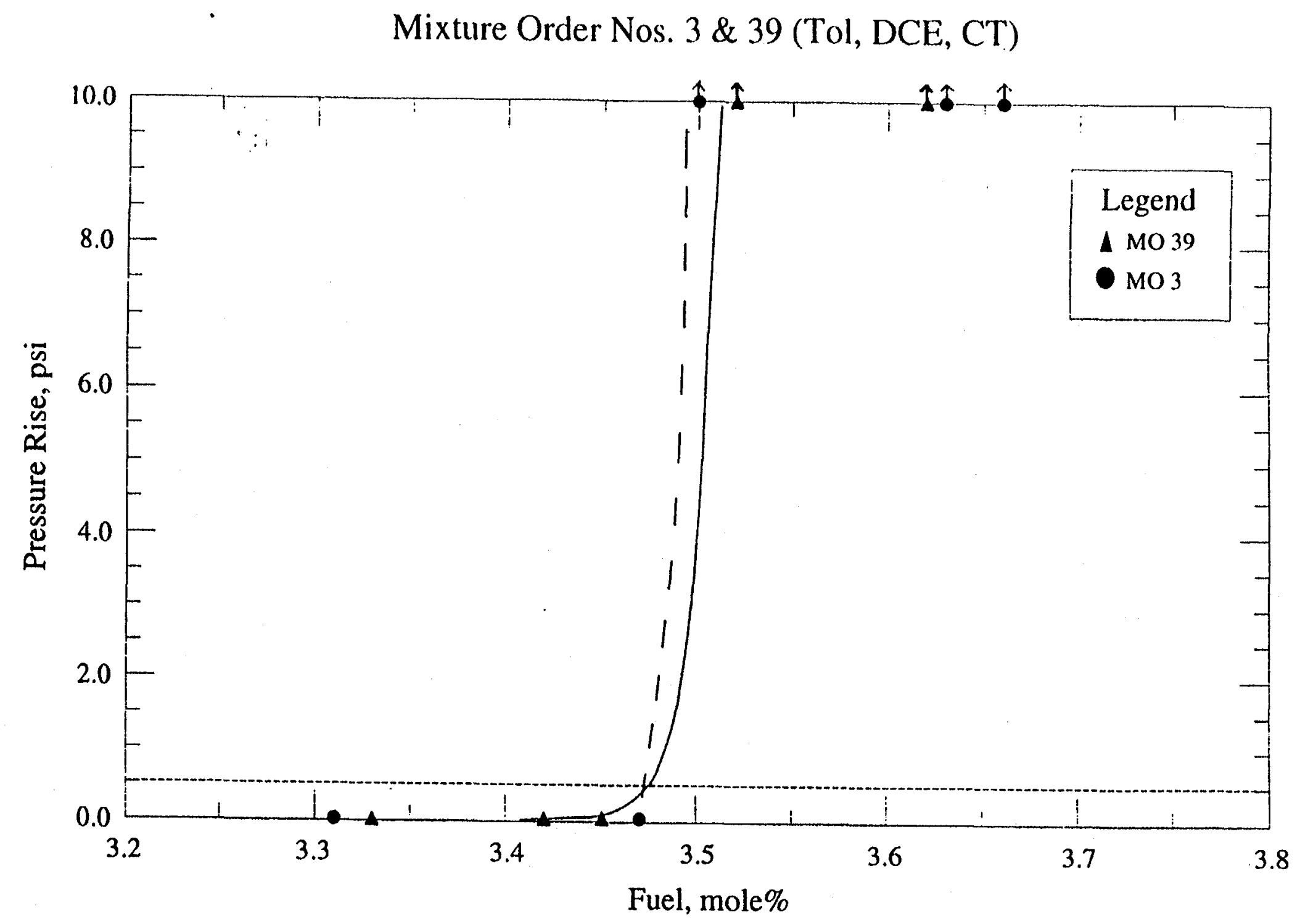

Figure 3.1.6 Flammability data for Mixture Order Numbers 3 and 39 (Tol, DCE, and CT) 
Figure 3.1.6 shows the excellent agreement and sharp rise in explosion pressure near $3.5 \%$ for mixtures 3 and 39 (Tol, DCE, and CT). The pressure rises from near zero at $3.45 \%$ fuel to over 50 psi at $3.5 \%$ fuel. Such pressure rise sensitivity to concentration at the LFL value is characteristic of all the non-hydrogen containing mixtures studied. For both mixtures, the measured LFL is between 3.45 and $3.50 \% \mathrm{H}_{2}$, although the LFL values reported in table 3.0 are rounded to the nearest $0.5 \%$.

Figure 3.1.7 illustrates a less perfect agreement of replicate mixtures (mixture order numbers 20 and 34). The measured LFLs are $2.35 \pm 0.05 \%$ for mixture 20 and $2.45 \pm 0.05 \%$ for mixture 34. Nonetheless, the difference in LFLs of the replicate determinations is $0.1 \%$ absolute, or a relative error of $\sim 4 \%$.

A summary of the measured LFL values for the mixtures shown in the preceding graphs and for the other mixtures is listed in table 3.0.

\subsection{DISCUSSION}

\subsection{DATA QUALITY}

The data quality requirements for this project are necessitated by the desire to use the LFL determinations reported here as the flammability data base for calculating the LFLs of arbitrary mixtures of the prescribed VOC components and $\mathrm{H}_{2}$. The data developed for this project must, therefore, be compared with prior LFL determinations, in addition to some self consistency checks using replicate mixtures. The relative precision of the earlier reported LFL limits $[4,5,6]$ is generally about $10 \%$ of the LFL value at an LFL of about $1 \%$ by volume [6]. That is, the LFL would be $1.0 \% \pm 0.1 \%$. For LFL values near $10 \%$ by volume, the relative precision is generally about $5 \%$ of the LFL value [6] (i.e, the LFL would be $10.0 \% \pm 0.5 \%$ ). It was considered desirable for this project, however, to achieve a relative precision of $\leq 5 \%$ of the LFL value [ 1$]$ for all the measured LFL values.

In making comparisons with earlier LFL data, it must be remembered that the bulk of the earlier data were determined in vessels of a radically different geometry, and a qualitatively different flammability criterion was used. Most of the earlier determinations were made in U.S. Bureau of Mines type flammability tubes that were $5 \mathrm{~cm}(2$ in) in diameter and $150 \mathrm{~cm}$ (60 in) long [4]. Commonly, the fuel-air vapor mixture was ignited by a spark at the open end (bottom), and the flame propagated towards the closed top. The mixture was considered flammable if the flame propagated at least substantially (e.g., $100 \mathrm{~cm}$ ) to the top. For some fuels, such propagation could occur as a small "fireball" or, even, small cells (e.g., $\mathrm{H}_{2}$ ), that rose to the top (or $100 \mathrm{~cm}$ ) and disappeared. There was no downward subsequent propagation in these cases, and very little of the mixture was burned. Had the experiment been conducted in a closed vessel, very little pressure would have, 
TABLE 3.0. - LFL Data for Mixtures of Volatile Organic Compounds (VOCs) plus Hydrogen in Air

\begin{tabular}{|c|c|c|c|c|c|c|c|}
\hline \multirow{2}{*}{$\begin{array}{l}\text { Experimental } \\
\text { order }\end{array}$} & \multirow{2}{*}{$\begin{array}{l}\text { Fest } \\
\text { mixture }\end{array}$} & \multicolumn{5}{|c|}{ Fuel Makeup in Fest Mixture, male \% } & \multirow{2}{*}{$\begin{array}{l}\text { Exp. } \\
\text { LFL, } \\
y\end{array}$} \\
\hline & & DCE & MEK & Fol & $\mathrm{H}_{2}$ & $\mathrm{CT}$ & \\
\hline 01 & 12 & 33 & 0 & 33 & 33 & 0 & $2.65 \pm 0.05$ \\
\hline 02 & 30 & 0 & 33 & 0 & 33 & 33 & $5.20 \pm 0.10$ \\
\hline 03 & 33 & 33 & $\underline{0}$ & 33 & 0 & 33 & $3.45 \pm 0.10$ \\
\hline 04 & 3 & 50 & 50 & 0 & 0 & 0. & $2.65 \pm 0.05$ \\
\hline 05 & 25 & 0 & 0 & 33 & 33 & 33 & $3.65 \pm 0.10$ \\
\hline 06 & 19 & 0 & 50 & 50 & 0 & 0 & $1.45 \pm 0.05$ \\
\hline 07 & 32 & 0 & 0 & 0 & 0 & 0 & NA \\
\hline $08 \quad(2)$ & 36 & 0 & 33 & 0 & 33 & 33 & $5.20 \pm 0.07$ \\
\hline 09 & 6 & 33 & 33 & 0 & 33 & 0 & $3.40 \pm 0.07$ \\
\hline 10 & 1 & 20 & 20 & 20 & 20 & 20 & $3.40 \pm 0.10$ \\
\hline 11 & 21 & 0 & 25 & 25 & 25 & 25 & $2.90 \pm 0.05$ \\
\hline 12 & 16 & 50 & 0 & 0 & 0 & 50 & $*$ \\
\hline 13 & 5 & 25 & 25 & 25 & 25 & 0 & $2.40 \pm 0.05$ \\
\hline 14 & 8 & 33 & 33 & 0 & 0 & 33 & $4.85 \pm 0.10$ \\
\hline $15 \quad(7)$ & 37 & 0 & 0 & 0 & 0 & 0 & NA \\
\hline $16 \quad$ (4) & 38 & 50 & 50 & 0 & 0 & 0 & $2.70 \pm 0.05$ \\
\hline 17 & 7 & 25 & 25 & 0 & 25 & 25 & $5.15 \pm 0.05$ \\
\hline 18 & 23 & 0 & 0 & 50 & 0 & 50 & $2.90 \pm 0.05$ \\
\hline 19 & 22 & 0 & 0 & 100 & 0 & 0 & $1.20 \pm 0.03$ \\
\hline $20 \quad \therefore$ & 34 & 0 & 33 & 33 & 0 & 33 & $2.35 \pm 0.05$ \\
\hline 21 & 17 & 0 & 100 & 0 & 0 & 0 & $1.95 \pm 0.03$ \\
\hline 22 & 20 & 0 & 50 & 0 & 50 & 0 & $3.15 \pm 0.07$ \\
\hline 23 (13) & 40 & 25 & 25 & 25 & 25 & 0 & $2.40 \pm 0.10$ \\
\hline 24 & 35 & 33 & 0 & 0 & 33 & 33 & $10.10 \pm 0.50$ \\
\hline 25 & 24 & 0 & 0 & 50 & 50 & 0 & $2.05 \pm 0.03$ \\
\hline 26 (24) & 15 & 33 & 0 & 0 & 33 & 33 & $9.70 \pm 0.50$ \\
\hline 27 & 26 & 0 & 0 & 0 & 100 & 0 & $5.00 \pm 0.40$ \\
\hline
\end{tabular}


Mixture Order Nos. $20 \& 34$ (MEK, Tol, CT)

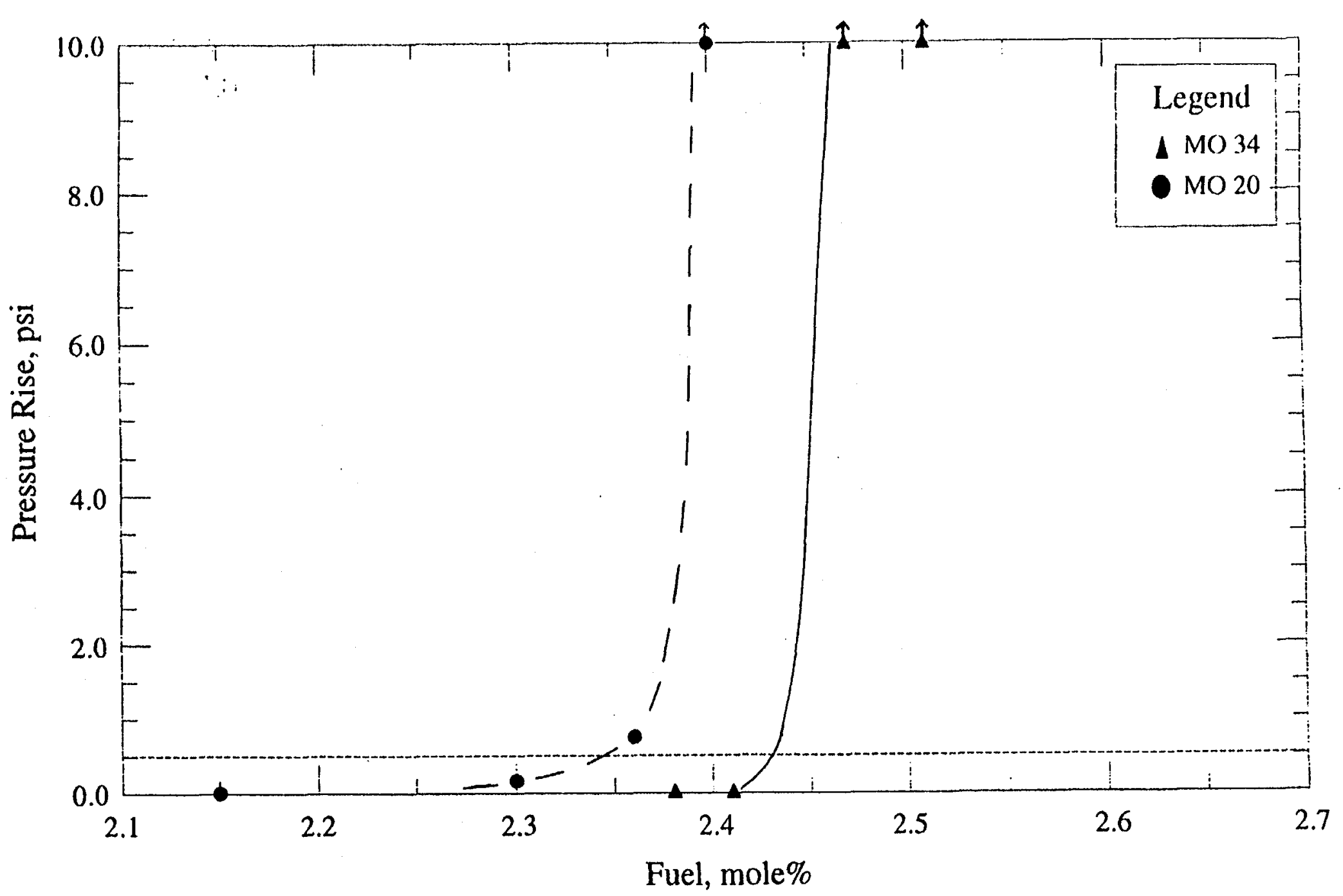

Figure 3.1.7 Flammability data for Mixture Order Numbers 20 and 34 (Tol, MEK, and CT) 
consequently, developed, and there would not have been a sharp change in pressure with mixture concentration at the LFL.

Wall effects, that is, cooling and deactivation of the free radical chain carriers characterizing combustion reactions, can be important in a tube geometry. The $5-\mathrm{cm}$ tube diameter was recommended as the minimum i.d. for flammability measurements, in order to minimize wall effects [4]. It was recognized, however, that this diameter is not adequate for all fuels. The halogen containing fuels are known to exhibit strong wall effects [5], and required both a higher energy spark and a greater lateral diameter in order to approach a "true" (apparatus independent) LFL determination [6].

For the present project, it was considered desirable to conduct flammability tests in a relatively large laboratory chamber, that could serve as a model for the actual shipping packages (TRUPACT II). The 19-L flammability chamber used at PRC was, thus, more suitable than the flammability tubes (3-L volume) described above. The lateral dimension of $30 \mathrm{~cm}$ would minimize wall effects, a stronger spark could be used without fear of "overdriving" the system, and a pressure criterion would be more consistent with the actual safety concern involving the shipment of materials with, possibly, flammable vapors.

The actual pressure criterion used to assess flammability is rather arbitrary. If based on the pressure rating of the specific transportation vessel, it would not have broader application to assessing mixture flammability. Instead, a pressure rise criterion $(0.5 \mathrm{psi})$ was chosen that was consistent with the NRC listed $5 \%$ LFL for $\mathrm{H}_{2}$ in air $[8,9]$. It was also consistent with the visual observations of a rising "fireball" that reached the top of the chamber and lingered momentarily. Finally, it was correlated with the sensing of a definite temperature increase $\left(1^{\circ} \mathrm{C}\right)$ by the 5 mil thermocouple located near the top of the chamber. Additional PRC data on the flammability of $\mathrm{H}_{2}$ in larger, closed vessels have been published previously [10][11].

\subsection{CURRENT vs. PRIOR LFL DETERMINATIONS}

The flammability tube data referenced by Coward and Jones [4] give an average LFL of $1.3 \% \pm 0.1 \%$ for toluene and $2.0 \% \pm 0.1 \%$ for MEK. These values are consistent with the values determined in the PRC 19-L flammability apparatus. The preliminary tests (sec. 2.6) gave LFL values of $1.19 \%$ for toluene and $1.95 \%$ for MEK. In the actual test series, the LFL values were $1.20 \%$ for toluene (mixture no. 19) and $1.95 \%$ for MEK (mixture no. 21). In contrast, there is no consistent set of values for DCE in the prior literature; LFL values of $6.2 \%$ [4] to $5.4 \%$ [12] are reported. The variability in these values is probably a reflection of wall effects and ignition limitation. The $4.85 \% \mathrm{LFL}$ value (mixture no. 31) determined in the PRC apparatus is considered more reliable than the prior range of values, for reasons discussed in section 4.1 , and is certainly more conservative. 


\begin{tabular}{|c|c|c|c|c|c|c|c|}
\hline \multirow{2}{*}{$\begin{array}{l}\text { Experimental } \\
\text { order }\end{array}$} & \multirow{2}{*}{$\begin{array}{l}\text { Test } \\
\text { mixture }\end{array}$} & \multicolumn{5}{|c|}{ Fuel Makeup in Test Mixture, mole \% } & \multirow{2}{*}{$\begin{array}{c}\text { Exp. } \\
\text { LFL, } \\
y\end{array}$} \\
\hline & & DCE & MEK & Tol & $\mathrm{H}_{2}$ & $C T$ & \\
\hline 28 & 27 & 0 & 0 & 0 & 50 & 50 & $10.80 \pm 0.80$ \\
\hline 29 & 29 & 0 & 33 & 33 & 33 & 0 & $2.00 \pm 0.05$ \\
\hline 30 & 18 & 0 & 50 & 0 & 0 & 50 & $4.65 \pm 0.03$ \\
\hline 31 & 2 & 100 & 0 & 0 & 0 & 0 & $4.85 \pm 0.05$ \\
\hline 32 & 13 & 25 & 0 & 25 & 25 & 25 & $3.95 \pm 0.05$ \\
\hline $33(25)$ & 39 & 0 & 0 & 50 & 50 & 0 & $2.05 \pm 0.03$ \\
\hline $34(20)$ & 28 & 0 & 33 & 33 & 0 & 33 & $2.45 \pm 0.05$ \\
\hline 35 & 9 & 25 & 25 & 25 & 0 & 25 & $2.80 \pm 0.05$ \\
\hline 36 & 14 & 50 & 0 & 0 & 50 & 0 & $5.35 \pm 0.20$ \\
\hline 37 & 10 & 50 & 0 & 50 & 0 & 0 & $2.05 \pm 0.03$ \\
\hline 38 & 4 & 33 & 33 & 33 & 0 & 0 & $1.95 \pm 0.03$ \\
\hline 39 & 11 & 33 & 0 & 33 & 0 & 33 & $3.50 \pm 0.05$ \\
\hline 40 & 31 & 0 & 0 & 0 & 0 & 100 & NF \\
\hline
\end{tabular}

$\mathrm{DCE}=1,2$ dichloroethane, $\mathrm{MEK}=2$-butanone (methyl ethyl ketone)

Tol $=$ toluene, $C T=$ carbon tetrachloride, $\mathrm{H}_{2}=$ hydrogen

LFL data are rounded to the nearest $0.05 \%$

* * LFL not measured for \#12 because vapor condensed

Number in parentheses after 'experimental order number' denotes the previous mixture no. that this mixture duplicated

NF $=$ nonflammable 


\subsection{ESTIMATED LFL PRECISION}

The direct test of the precision of the LFL values reported here are the replicates runs for seven mixtures (mixtures numbers $2 \& 8,3 \& 39,4 \& 16,13 \& 23,20 \& 34,24 \& 26$, and $25 \& 33$ are replicate pairs). The greatest LFL variations ( $\sim 4 \%$ of the LFL value) were observed for the $20 \& 34$ and $24 \& 26$ pairs. These results are still consistent with the data quality objective ( $\leq 5 \%$ error) in the Test Plan.

The estimated precision of the LFL determinations listed in the last column of Table 3.0 is based on the number of data points in the near vicinity of the LFL value, and how close they are to the LFL. The listed precision considers the possibility of an error in the data points closest to the LFL. It also considers the effect of using a range of pressure rise values (pressure criterion $=0.5 \pm 0.2 \mathrm{psi}$ ) for the flammability criterion. That is, an estimate is made of the sensitivity of the LFL to the choice of a specific pressure criterion. The precision listed for the LFL values in table 3.0 is, thus, a conservative value. Solely in terms of repeatability, the precision shown in table 3.0 for the replicated LFLs would be smaller than the estimated uncertainty listed in the table for those mixtures with relatively insensitive explosion pressures near the LFL, as illustrated by figures 3.1.1 and 3.1.4. The greatest relative uncertainties listed in table 3.0 are $8 \%$ for mixture order no. 27 (pure $\mathrm{H}_{2}$ ), $-7 \%$ for mixture $28\left(1: 1 \mathrm{H}_{2}: \mathrm{CT}\right)$, and $-5 \%$ for mixtures $24 \& 26\left(1: 1: 1 \mathrm{DCE}: \mathrm{CT}: \mathrm{H}_{2}\right)$. These mixtures are shown as figures 3.1.1, 3.1.2, and 3.1.4, respectively. It will be seen that the uncertainty is associated with the relative insensitivity of explosion pressure to concentration near the LFL value, as noted above. These are mixtures that are dominated by the flammability characteristics of hydrogen. The LFL value of $10.8 \%$ that was determined for the $\mathrm{H}_{2}$-CT mixture (no. 28) and the LFL values of $\sim 10 \%$ for the DCE-CT- $\mathrm{H}_{2}$ mixtures (no. $24 \& 26$ ) are, thus, dependent on the $\mathrm{H}_{2}$ pressure criterion. The mixture no. 36 (1:1 DCE: $\mathrm{H}_{2}$ ) has an LFL of $5.35 \pm 0.2 \%$, with a relative uncertainty of $3.7 \%$ (figure 3-1.3). It shows a marked increase in sensitivity to concentration changes above the LFL value. The remaining mixtures are much less dependent on the pressure rise criterion, since they show a relatively steep rise in pressure above the LFL. The mixtures showing a relative insensitivity of explosion pressure to mixture concentration are, thus, $\mathrm{H}_{2}$ and mixtures of $\mathrm{H}_{2}$ and the heaviest VOCs, particularly, $\mathrm{CCl}_{4} . \mathrm{H}_{2}$ is expected to dominate such equimolar mixtures due to selective enrichment at the flame fronts arising from the great difference in diffusibility. It is not surprising, then, that the flammability behavior of these mixtures near the flammability limit more closely resembles that of pure $\mathrm{H}_{2}$.

\subsection{RELEVANCE OF PRIOR PREDICTIVE MODELS}

The use of the LeChatelier rule and the AIChE Group Contribution method in calculating LFLs of mixtures was described in section 2.5.2. The limitation of the simple 
LeChatelier formula to flammable components was mentioned. The Group Contribution method can accommodate nonflammable components, but it is even more dependent on the availability of an extensive and accurate LFL data base. Thus, the uncertainties in the literature values for the flammability of halogen containing compounds introduces a corresponding error in the group contribution of such molecules in a mixture of VOCs. The LFL value of $4.85 \%$ for 1,2 dichloroethane $\left(\mathrm{ClCH}_{2} \mathrm{CH}_{2} \mathrm{Cl}\right)$ that was determined in our apparatus can be used directly in the LeChatelier formula for mixtures with DCE, and can also be used to derive a more consistent group contribution factor for DCE. The determination of the LFLs of additional halogen containing compounds such as methyl chloride $\left(\mathrm{CH}_{3} \mathrm{Cl}\right)$, methylene chloride $\left(\mathrm{CH}_{2} \mathrm{Cl}_{2}\right)$, and ethyl chloride $\left(\mathrm{CH}_{3} \mathrm{CH}_{2} \mathrm{Cl}\right)$ would be needed, however, to put the Group Contribution Method calculation on a more solid basis.

The calculation of LFLs for mixtures containing hydrogen present another difficulty. Hydrogen is a uniquely diffusible and reactive fuel. It gives rise to cellular flamelets at low concentrations, resulting in low explosion pressures that show little sensitivity to concentration changes. Moreover, its true concentration at the flame fronts can be considerably greater than its overall concentration in a uniform mixture, as mentioned in section 4.3. The contribution from $\mathrm{H}_{2}$ to the $\mathrm{LFL}$ of the mixture is, therefore, greater than that given by its nominal concentration. This discrepancy, normally reflected as a measured LFL for the mixture that is closer to the LFL of pure $\mathrm{H}_{2}$ than predicted, is greatest when the other molecules are much heavier and slower than $\mathrm{H}_{2}$. Thus, combinations of $\mathrm{H}_{2}$ and the halogenated VOCs (DCE and CT) will feature LFLs that are closer to the value of $\mathrm{H}_{2}(5 \%)$ than would be expected on the basis of the proportion of $\mathrm{H}_{2}$ in the mixture. The most dramatic example is that of the binary $\mathrm{H}_{2}-\mathrm{CT}$ mixture (mixture no. 28), whose measured LFL of $\sim 11 \%$ is much different than the calculated prediction of $17 \%$.

\subsection{CONCLUSIONS}

The lowest flammable concentrations in air (LFLs) of all possible equimolar combinations from the four specified volatile organic compounds (VOCs) and hydrogen $\left(\mathrm{H}_{2}\right)$ were determined in a relatively large (19-L) laboratory flammability chamber at ambient temperature, , using a strong spark ignition source. The concentrations were determined by establishing the desired partial pressure for each component, and care was taken to insure that the injected VOC liquids had turned to vapor in the low chamber pressure that existed prior to adding the needed air. The experimental LFL values generally agreed with predicted LFL calculations for the mixtures to within $10 \%$. Mixtures with $\mathrm{H}_{2}$, particularly those also containing the heavy halogenated species (carbon tetrachloride and 1,2 dichloroethane), deviated from the calculated values with a bias in the direction of the 5\%-LFL of $\mathrm{H}_{2}$. The greatest deviation from the calculated value occurred for mixture number 28 , which featured 
a combination of the lightest and most diffusible molecule $\left(\mathrm{H}_{2}\right)$ with the heaviest $\left(\mathrm{CCl}_{4}\right)$. The experimental LFL of $-11 \%$ was biased in favor of $\mathrm{H}_{2}$, and gave a considerably lower value than the calculated value of $17 \%$. The LFL of $4.85 \%$ that was determined for the flammable halogenated species, 1,2 dichloroethane (DCE) is below the range of values cited in the literature. The measured LFL values reported here are considered more accurate than the previous literature values since a larger chamber was used in combination with a more energetic spark, and it is known that the halogenated species are prone to exhibiting wall effects and ignition limitations. The LFLs of the other flammable VOCs were within the relatively narrow range of values cited in the basic review of flammability data by Coward and Jones [4]. 


\subsection{REFERENCES}

1. Connolly, M. J., S. Djordjevic, L. Evans, K. Liekhus, and C. Loehr. Flammability Assessment Methodology Program Tests Plan. INEL 96/0352, February 1997.

2. Cashdollar, K. L., and M. Hertzberg. 20-L Explosibility Test Chamber for Dusts and Gases. Rev. Sci. Instrum., Vol. 56, pp. 596-602, 1985.

3. Zlochower, I. A., K. L. Cashdollar, and G. M. Green. Experimental Apparatus and Procedure for Vapor Explosibility Testing in the 19-L Chamber. Revision 0, Project No. 14-09-0050-3738, April 1997.

4. Coward, H. F., and G. W. Jones. Limits of Flammability of Gases and Vapors. U.S. Bureau of Mines Bulletin 503, 1952, 155 pp.

5. Zabetakis, M. G. Flammability Characteristics of Combustible Gases and Vapors. U.S. Bureau of Mines Bulletin 627, 1965, 121 pp.

6. Kuchta, J. M. Investigation of Fire and Explosion Accidents in the Chemical, Mining, and Fuel-Related Industries - A Manual. U.S. Bureau of Mines Bulletin 680, 1985, 84 pp.

7. AIChE. Procedure B: Method for Estimating Lower Flammability Limit of Pure Compounds in the Data Prediction Manual. American Institute of Chemical Engineers, New York, NY, 1994.

8. NRC. Safety Analysis Report for the TRUPACT-II Shipping Package. Revision 14, NRC Doc. No. 9218, U.S. Nuclear Regulatory Commission, Washington, DC, 1994.

9. NRC. Clarification of Conditions for Waste Shipments Subject to Hydrogen Generation. SSINS No. 6835, IE Information Notice No. 84-72, September 1984.

10. Cashdollar, K. L., M. Hertzberg, I. A. Zlochower, C. E. Lucci, G. M. Green, and R. A. Thomas, Laboratory Flammability Studies of Mixtures of Hydrogen, Nitrous Oxide, and Air. Final Report, WHC-SD-WM-ES-219, Rev 0, June, 1992, 71 pp.

11. Burgess, D. S., A. L. Furno, J. M. Kuchta, K. E. Mura. Flammability of Mixed Gases. U.S.: Bureau of Mines RI 8709, Pittsburgh, PA, 1982.

12. National Fire Protection Association. Fire Hazard Properties of Flammable Liquids, Gases, and Vapors. Bulletin 325, NFPA, Quincy, MA, 1991. 


\section{APPENDIX}

DETAMED DATA TABLES ON ALL EXPERMMENTAL TESTS 
LMITCO - INEL. $\quad$ I9-L "MSHA" CHAMBER

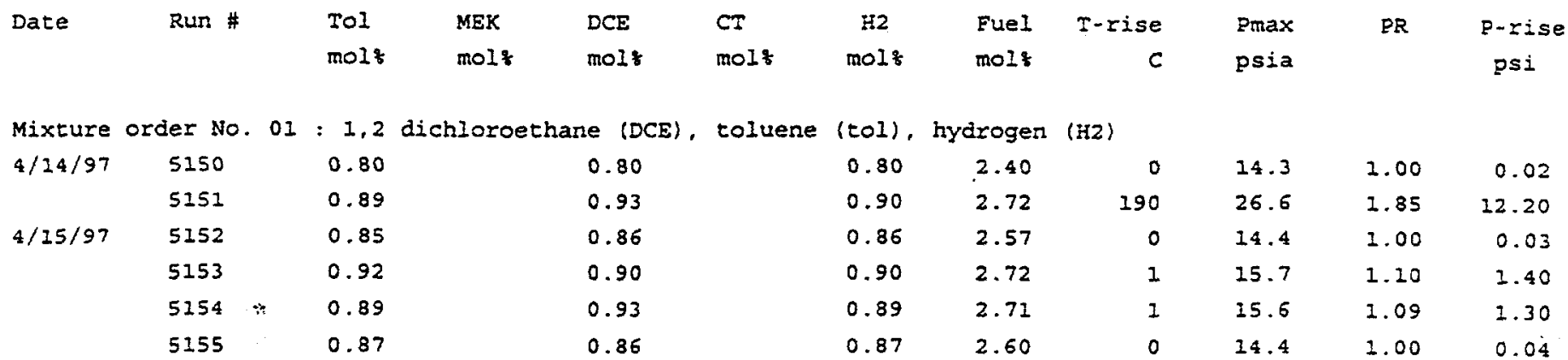

Mixture order No. 02: 2-butanone (MEK), carbon tetrachloride (CT), Hyarogen (H2)

$\begin{array}{rrrrrrrrrr}4 / 17 / 97 & 5156 & 1.60 & 1.59 & 1.61 & 4.80 & 0 & 14.4 & 1.00 & 0.03 \\ & 5157 & 1.81 & 1.82 & 1.80 & 5.43 & 303 & 29.4 & 2.06 & 15.10 \\ & 5158 & 1.67 & 1.66 & 1.66 & 4.99 & 0 & 14.4 & 1.00 & 0.03 \\ & 5159 & 1.76 & 1.79 & 1.76 & 5.31 & 119 & 21.1 & 1.47 & 6.70 \\ & 5160 & 1.69 & 1.71 & 1.69 & 5.09 & 0 & 14.4 & 1.00 & 0.04 \\ 4 / 18 / 97 & 5161 & 1.64 & 1.67 & 1.64 & 4.95 & 0 & 15.3 & 1.00 & 0.03 \\ & 5162 & 1.75 & 1.76 & 1.75 & 5.26 & 2 & 16.1 & 1.13 & 1.80\end{array}$

Mixture order No. 03: 1,2 dichloroethane (DCE), toluene (tol), carbon tetrachloride (CT)

\begin{tabular}{|c|c|c|c|c|c|c|c|c|c|}
\hline \multirow[t]{4}{*}{$4 / 18 / 97$} & 5163 & 1.11 & 1.09 & 1.11 & 3.31 & 0 & 14.4 & 1.00 & 0.03 \\
\hline & 5164 & 1.20 & 1.21 & 1.25 & 3.66 & 359 & 71.7 & 5.04 & 57.50 \\
\hline & 5165 & 1.15 & 1.16 & 1.17 & 3.47 & 0 & 14.3 & 1.00 & 0.05 \\
\hline & 5167 & 3.17 & 1.28 & 1.15 & 3.50 & 296 & 67.0 & 4.70 & 52.70 \\
\hline
\end{tabular}

Mixture order No. 04: 1,2 dichloroethane (DCE), 2-butanone (MEK)

\begin{tabular}{|c|c|c|c|c|c|c|c|c|}
\hline $4 / 24 / 97$ & 5168 & 1.53 & 1.49 & 3.02 & 672 & 70.9 & 4.95 & 56.60 \\
\hline \multirow[t]{4}{*}{$4 / 25 / 97$} & 5169 & 1.37 & 1.38 & 2.75 & 0 & 14.4 & 1.01 & 0.08 \\
\hline & 5170 & 1.45 & 1.44 & 2.90 & 576 & 63.8 & 4.44 & 49.50 \\
\hline & 5171 & 1.22 & 1.22 & 2.43 & 0 & 16.3 & 1.00 & 0.02 \\
\hline & 5172 & 1.41 & 1.41 & 2.82 & 360 & 61.4 & 4.28 & 47.20 \\
\hline \multirow[t]{2}{*}{$5 / 5 / 97$} & 5173 & 1.37 & 1.34 & 2.71 & 10 & 18.4 & 1.23 & 4.20 \\
\hline & 5174 & 1.33 & 1.32 & 2.65 & 0 & 14.4 & 1.01 & 0.09 \\
\hline
\end{tabular}

Mixture order No. 05: toluene (tol), carbon tetrachloride (CT), hydrogen (H2)

\begin{tabular}{|c|c|c|c|c|c|c|c|c|c|}
\hline \multirow[t]{4}{*}{$5 / 7 / 97$} & 5177 & 1.07 & 1.08 & 1.07 & 3.23 & 0 & 14.3 & 1.00 & 0.02 \\
\hline & 5178 & 1.18 & 1.22 & 1.18 & 3.57 & 0 & 14.3 & 2.00 & 0.03 \\
\hline & 5179 & 1.31 & 1.35 & 1.30 & 3.96 & 685 & 68.2 & 4.78 & 53.90 \\
\hline & 5181 & 2.20 & 1.21 & 1.20 & 3.61 & 0 & 14.4 & 1.01 & 0.10 \\
\hline $5 / 8 / 97$ & 5182 & 1.23 & 1.23 & 1.23 & 3.69 & 2 & 15.7 & 1.09 & 1.30 \\
\hline
\end{tabular}


LMITCO - INEL, 19-I, "MSHA" CHAMBER

Date

Run \#

Tol

Tol

MEK

DCE

CT

H2

Fue

C

Pmax

psia

PR

$z-z i s e$

psi

Mixture order No. 06: Eoluene (to1), 2-butanone (MEK)

$\begin{array}{llll}5 / 8 / 97 & 5183 & 0.77 & 0.77 \\ 5184 & 0.69 & 0.67 \\ 5185 & 0.72 & 0.71 \\ 5186 & 0.76 & 0.75\end{array}$

1.54

1.37

1.43

1.50

0.00

0.00

14.3

63.9

4.45

49.60

$5 / 9 / 97 \quad 5187$

5188

Blank (aiz)

(2)

(ct)

Mixture order No. 08: Carbon tetrachloride (CT), 2-butanone (MEK). Hydrogen (H2)

$\begin{array}{rrrrrrrrrr}5 / 9 / 97 & 5189 & 1.72 & 1.72 & 1.73 & 5.17 & 0 & 14.8 & 1.03 & 0.42 \\ & 5190 & 1.76 & 1.77 & 1.77 & 5.31 & 274 & 26.9 & 1.87 & 12.50 \\ 5 / 12 / 97 & 5191 & 1.71 & 1.70 & 1.70 & 5.11 & 0 & 14.4 & 1.00 & 0.05 \\ & 5192 & 1.75 & 1.75 & 1.74 & 5.24 & 3 & 17.6 & 1.23 & 3.30\end{array}$

Mixture order No. 09: 1,2 dichloroethane (DCE), 2-butanone (MEK), Hydrogen (H2)

$\begin{array}{rrrrrrrrrr}5 / 12 / 97 & 5193 & 1.12 & 1.12 & 1.12 & 3.36 & 0 & 14.4 & 1.01 & 0.09 \\ & 5194 & 1.20 & 1.20 & 1.20 & 3.60 & 403 & 53.7 & 3.74 & 39.30 \\ 5195 & 1.16 & 1.17 & 1.17 & 3.50 & 10 & 18.5 & 1.29 & 4.20 \\ & 5195 & 1.10 & 1.10 & 1.10 & 3.30 & 0 & 14.4 & 1.01 & 0.07 \\ 5197 & 1.15 & 1.15 & 1.14 & 3.44 & 303 & 27.4 & 1.91 & 13.10\end{array}$

Mixture order No. 10: toluene (to1), 1,2 dichloroethane (DCE), Carbon tet. (CT), 2-butanone (MEX), Hydrogen

$\begin{array}{rrrrrrrrrrrr}5 / 14 / 97 & 5198 & 0.62 & 0.66 & 0.64 & 0.68 & 0.62 & 3.22 & 0 & 14.4 & 1.00 & 0.02 \\ & 5199 & 0.70 & 0.72 & 0.70 & 0.73 & 0.70 & 3.54 & 663 & 68.2 & 4.77 & 53.90 \\ & 5200 & 0.66 & 0.64 & 0.66 & 0.69 & 0.66 & 3.32 & 0 & 14.3 & 1.00 & 0.06 \\ & 5201 & 0.70 & 0.68 & 0.69 & 0.72 & 0.69 & 3.49 & 580 & 65.3 & 4.64 & 51.20 \\ & 5202 & 0.66 & 0.66 & 0.69 & 0.67 & 0.65 & 3.33 & 0 & 14.3 & 1.00 & 0.04\end{array}$

Mixture order No. 11: 2 butanone (MEK), toluene (tol), Carbon tetrachloride (CT) hydrogen (H2)

$\begin{array}{rlrllllrrrrr}5 / 15 / 97 & 5203 & 0.69 & 0.70 & 0.71 & 0.69 & 2.79 & 0 & 14.3 & 1.00 & 0.02 \\ 5 / 16 / 97 & 5204 & 0.75 & 0.75 & 0.75 & 0.75 & 3.01 & 206 & 62.5 & 4.34 & 48.20 \\ & 5205 & 0.73 & 0.73 & 0.74 & 0.72 & 2.91 & 0 & 14.5 & 1.00 & 0.03 \\ & 5206 & 0.74 & 0.75 & 0.74 & 0.74 & 2.96 & 399 & 59.8 & 4.18 & 45.50\end{array}$

Mixture order No. 12: 1,2 dichloroethane (DCE), carbon tetrachloride (CT)
$5 / 20 / 97$
5207
$9.06 \quad 6.56$
15.62
0
14.3
1.00
0.02

liquid did not all evaporate 
LMITCO - INEL. $\quad 29-2$ "MSHA" CHAMBER

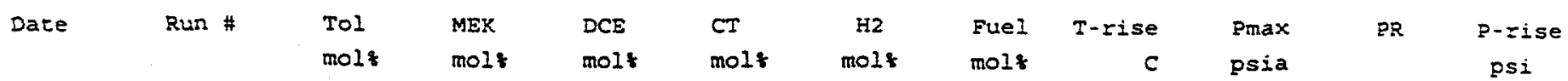

Mixture order No. 13: toluene (tol), 1,2 dichloroethane (DCE), 2-butanone (MEX), Hydrogen (H2)

$\begin{array}{rllllllllll}5 / 21 / 97 & 5208 & 0.62 & 0.63 & 0.62 & 0.62 & 2.50 & 467 & 59.5 & 4.16 & 45.30 \\ & 5209 & 0.59 & 0.58 & 0.59 & 0.58 & 2.34 & 0 & 14.5 & 1.00 & 0.06 \\ 5 / 22 / 97 & 5210 & 0.60 & 0.61 & 0.59 & 0.60 & 2.40 & 1 & 15.6 & 1.09 & 1.20 \\ & 5211 & 0.58 & 0.58 & 0.58 & 0.57 & 2.31 & 0 & 14.5 & 1.00 & 0.03\end{array}$

Mixture order No. 14: 1,2 dichloroethane (DCE), 2-butanone (MEK), carbon tetrachloride (CT)

$\begin{array}{rrrrrrrrrr}5 / 22 / 97 & 5212 & 1.64 & 1.66 & 1.67 & 4.98 & 334 & 69.1 & 4.84 & 54.80 \\ & 5213 & 1.50 & 1.49 & 1.51 & 4.50 & 0 & 14.4 & 1.00 & 0.01 \\ & 5214 & 1.63 & 1.63 & 1.64 & 4.90 & 307 & 67.4 & 4.72 & 53.10 \\ 5 / 23 / 97 & 5215 & 1.56 & 1.57 & 1.56 & 4.68 & 0 & 14.4 & 1.00 & 0.03 \\ & 5216 & 1.60 & 1.60 & 1.60 & 4.81 & 0 & 14.5 & 1.00 & 0.06\end{array}$

Mixture order No. 15: Blank (air)

$\begin{array}{lllllll}5 / 23 / 97 & 5217 & 0.00 & 0 & 14.4 & 1.00 & <0.03\end{array}$

Mixture order No. 16: 1,2 dichloroethane (DCE), 2-butanone (MEK)

$\begin{array}{rrrrrrrrr}5 / 23 / 97 & 5218 & 1.33 & 1.34 & 2.67 & 0 & 14.5 & 1.01 & 0.08 \\ & 5219 & 1.36 & 1.36 & 2.72 & 258 & 56.5 & 3.92 & 42.10 \\ & 5220 & 1.30 & 1.30 & 2.60 & 0 & 14.5 & 1.00 & 0.02 \\ 5 / 27 / 97 & 5221 & 1.35 & 1.35 & 2.70 & 0 & 14.5 & 1.00 & 0.02 \\ & 5222 & 1.36 & 1.36 & 2.73 & 1 & 15.3 & 1.07 & 1.00\end{array}$

Mixture order No. 17: 1,2 dichloroethane (DCE). Carbon tet. (CT), 2-butanone (MEX), HYdrogen (H2)

$\begin{array}{rrrrrrrrrrr}5 / 27 / 97 & 5223 & 1.25 & 1.25 & 1.25 & 1.25 & 5.00 & 0 & 14.4 & 1.00 & 0.04 \\ 5 & 5224 & 1.30 & 1.30 & 1.30 & 1.29 & 5.20 & 405 & 51.3 & 3.61 & 37.10 \\ 5 / 28 / 97 & 5225 & 1.26 & 1.28 & 1.25 & 1.25 & 5.04 & 0 & 14.4 & 1.00 & 0.02 \\ & 5226 & 1.30 & 1.30 & 1.30 & 1.30 & 5.21 & 82 & 20.50 & 1.43 & 6.10 \\ & 5227 & 1.28 & 1.30 & 1.27 & 1.27 & 5.13 & 0 & 14.4 & 1.00 & 0.03\end{array}$

Mixture order No. 18: toluene (to1), carbon tetrachloride (CT)

\begin{tabular}{|c|c|c|c|c|c|c|c|c|}
\hline \multirow[t]{4}{*}{$5 / 28 / 97$} & 5228 & 1.39 & 1.39 & 2.79 & 0 & 14.3 & 1.00 & 0.02 \\
\hline & 5229 & 1.50 & 1.50 & 3.00 & 375 & 72.4 & 5.12 & 58.30 \\
\hline & 5230 & 3.46 & 1.46 & 2.93 & 261 & 68.5 & 4.79 & 54.20 \\
\hline & 5231 & 1.43 & 1.43 & 2.86 & 0 & 14.3 & 1.00 & 0.03 \\
\hline \multicolumn{9}{|c|}{ Mixture order No. 19: } \\
\hline \multirow[t]{2}{*}{$5 / 29 / 97$} & 5232 & 1.21 & & 1.21 & 272 & 64.3 & 4.45 & 49.90 \\
\hline & 5235 & 1.17 & & 1.17 & 0 & 14.5 & 1.01 & 0.11 \\
\hline
\end{tabular}


IMITCO - INEL, I9-L "MSHA" CHAMBER

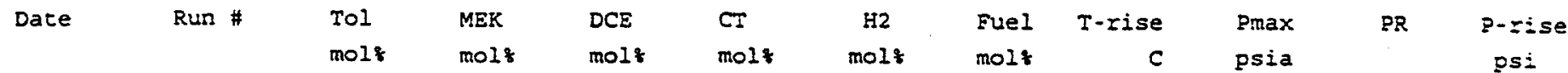

Mixture order No. 20: 2 butanone (MEK), toluene (tol), Carbon tetrachloride (CT)

$\begin{array}{rrrrrrrrrr}5 / 30 / 97 & 5236 & 0.80 & 0.80 & 0.80 & 2.40 & 256 & 65.2 & 4.51 & 50.80 \\ & 5237 & 0.71 & 0.73 & 0.71 & 2.15 & 0 & 14.3 & 1.00 & 0.01 \\ & 5238 & 0.76 & 0.76 & 0.77 & 2.30 & 0 & 14.5 & 1.02 & 0.17 \\ & 5239 & 0.78 & 0.78 & 0.80 & 2.36 & 2 & 25.1 & 1.05 & 0.75\end{array}$

Mixture order No. 21: 2 butanone (MEK)

$\begin{array}{rrrrrrrr}6 / 2 / 97 & 5240 & 2.01 & 2.01 & 565 & 62.7 & 4.36 & 48.30 \\ & 5241 & 1.98 & 1.98 & 348 & 61.7 & 4.29 & 47.30 \\ 5242 & 1.95 & 1.95 & 0 & 14.5 & 1.01 & 0.17 \\ 5243 & 1.94 & 1.94 & 488 & 61.1 & 4.27 & 45.80 \\ 5244 & 1.90 & 1.90 & 0 & 14.5 & 1.01 & 0.11 \\ 5245 & 1.92 & 1.92 & 0 & 14.7 & 1.02 & 0.32\end{array}$

Mixture order No. 22: 2-butanone (MEK), Hydrogen (H2)

$\begin{array}{rrrrrrrrr}6 / 3 / 97 & 5246 & 1.40 & 1.41 & 2.81 & 0 & 14.5 & 1.00 & 0.03 \\ & 5247 & 1.50 & 1.49 & 3.00 & 0 & 14.5 & 1.01 & 0.15 \\ 5248 & 1.61 & 1.61 & 3.22 & 474 & 56.6 & 3.92 & 42.20 \\ 5249 & 1.55 & 1.55 & 3.11 & 0 & 14.6 & 1.01 & 0.39 \\ 5250 & 1.59 & 1.59 & 3.17 & 403 & 52.8 & 3.66 & 38.40\end{array}$

Mixture order No. 23: toluene (tol), 1,2 dichloroethane (DCE), 2-butanone (MEK). Hydrogen (H2)

$\begin{array}{rllllllrrrr}6 / 3 / 97 & 5251 & 0.60 & 0.60 & 0.60 & 0.60 & 2.40 & 1 & 15.6 & 1.08 & 1.15 \\ 6 / 4 / 97 & 5252 & 0.66 & 0.65 & 0.68 & 0.64 & 2.64 & 575 & 66.7 & 4.59 & 52.20 \\ & 5253 & 0.64 & 0.64 & 0.65 & 0.62 & 2.55 & 237 & 61.4 & 4.27 & 47.10 \\ & 5254 & 0.57 & 0.59 & 0.57 & 0.57 & 2.31 & 0 & 14.4 & 1.00 & 0.02 \\ 6 / 5 / 97 & 5255 & 0.58 & 0.59 & 0.61 & 0.58 & 2.36 & 0 & 14.5 & 1.00 & 0.00\end{array}$

Mixture order No. 24: 1,2 dichloroethane (DCE), Carbon tet. (CT), Hydrogen (H2)

$\begin{array}{rllrrrrrrrr}6 / 5 / 97 & 5256 & 3.42 & 3.48 & 3.36 & 10.26 & 1 & 14.9 & 1.04 & 0.57 \\ & 5257 & 3258 & 3.47 & 3.45 & 3.46 & 10.38 & 1 & 15.0 & 1.04 & 0.61 \\ & 5259 & 3.52 & 3.52 & 3.52 & 10.56 & 1 & 15.1 & 1.06 & 0.83 \\ 6 / 6 / 97 & 5260 & 3.31 & 3.30 & 3.34 & 9.95 & 0 & 14.8 & 1.03 & 0.45 \\ & 5261 & 3.22 & 3.26 & 3.22 & 9.70 & 0 & 14.8 & 1.02 & 0.33 \\ & 5262 & 3.68 & 3.75 & 3.67 & 11.11 & 4 & 16.9 & 1.17 & 2.45 \\ & 5263 & 4.11 & 4.09 & 4.09 & 12.28 & 351.9 & 23.6 & 1.65 & 9.20 \\ & 5 & 3.01 & 3.02 & 3.00 & 9.03 & 0 & 14.6 & 1.02 & 0.27\end{array}$


LMITCO - INEL, 19-L "MSHA" CHAMBER

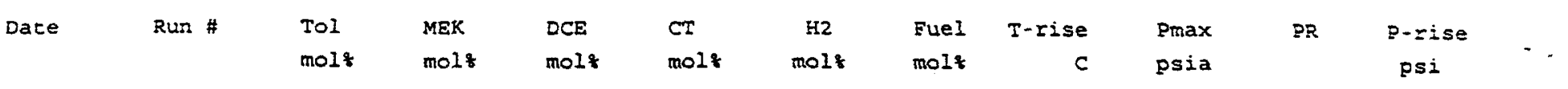

Mixture order No. 25: toluene (tol), Hydrogen (H2)

$\begin{array}{rrrrrrrrr}6 / 9 / 97 & 5264 & 1.00 & 1.01 & 2.01 & 0 & 14.5 & 1.01 & 0.08 \\ & 5265 & 1.10 & 1.10 & 2.21 & 513 & 62.6 & 4.35 & 43.20 \\ 5266 & 1.05 & 1.05 & 2.10 & 295 & 58.9 & 4.11 & 44.50 \\ & 5267 & 1.03 & 1.03 & 2.06 & 427 & 55.2 & 3.84 & 40.80 \\ 5268 & 1.00 & 1.00 & 2.00 & 0 & 14.4 & 1.00 & 0.06\end{array}$

Mixture order No. 26: 1,2 dichloroethane (DCE), Carbon tet. (CT), Hydrogen (H2)

$\begin{array}{rrrrrrrrrr}6 / 9 / 97 & 5269 & 3.69 & 3.70 & 3.68 & 11.07 & 5 & 17.9 & 1.25 & 3.60 \\ & 5270 & 3.52 & 3.49 & 3.52 & 10.53 & 1 & 15.4 & 1.07 & 1.05 \\ 6 / 10 / 97 & 5271 & 3.35 & 3.34 & 3.36 & 10.04 & 1 & 15.0 & 1.05 & 0.54 \\ & 5272 & 3.22 & 3.19 & 3.27 & 9.68 & 1 & 14.9 & 1.03 & 0.49 \\ & 5273 & 3.07 & 3.04 & 3.05 & 9.15 & 0 & 14.6 & 1.02 & 0.25\end{array}$

Mixture order No. 27: Hydrogen (in2)

5274
5275
5276
5277
5278

$\begin{array}{ll}5.02 & 5.02 \\ 4.22 & 4.22 \\ 5.93 & 5.93 \\ 4.52 & 4.52 \\ 5.53 & 5.53\end{array}$

$14.9 \quad 2.04$

0.53

275

5276

5278

$\begin{array}{ll}4.52 & 4.52 \\ 5.53 & 5.53\end{array}$

14.6

1.01

0.20

$\begin{array}{lll}15.6 & 1.08 & 1.20\end{array}$

$\begin{array}{lll}14.6 & 1.02 & 0.26\end{array}$

Mixture order No. 28: Carbon tet. (CT), Hydrogen (H2)

$\begin{array}{ll}6 / 11 / 97 & 5279 \\ & 5280 \\ & 5281 \\ & 5282 \\ 6 / 12 / 97 & 5283 \\ & 5284 \\ & 5285\end{array}$

$\begin{array}{rrr}9.00 & 10.19 & 19.19 \\ 8.10 & 8.07 & 16.18 \\ 7.02 & 7.02 & 14.04 \\ 5.61 & 5.60 & 11.20 \\ 4.50 & 4.51 & 9.01 \\ 4.82 & 4.81 & 9.63 \\ 5.30 & 5.31 & 10.61\end{array}$

15.2

1.05

0.72

Mixture order No. 29: toluene (to1), 2-butanone (MEK), Hyarogen (H2)

$\begin{array}{rrrrrrrrrrr}6 / 12 / 97 & 5286 & 0.67 & 0.67 & 0.67 & 2.00 & 0 & 14.6 & 1.01 & 0.09 \\ & 5287 & 0.73 & 0.73 & 0.74 & 2.20 & 594 & 66.5 & 4.57 & 51.90 \\ & 5288 & 0.71 & 0.72 & 0.71 & 2.14 & 471 & 62.4 & 4.31 & 47.90 \\ & 5289 & 0.71 & 0.70 & 0.69 & 2.10 & 358 & 61.0 & 4.22 & 45.60 \\ & 5290 & 0.67 & 0.67 & 0.65 & 1.99 & 23 & 19.6 & 1.34 & 5.00 \\ & 5291 & 0.63 & 0.66 & 0.65 & 1.94 & 0 & 14.5 & 1.00 & 0.04\end{array}$


LMITCO - INEL, 19-L "MSHA" CHAMBER

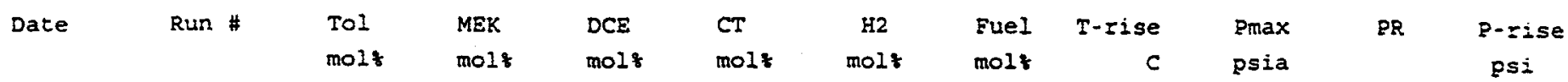

Mixture order No. 30: 2 butanone (MEX), Carbon tetrachloride (CT)

$\begin{array}{rrrrrrrr}5292 & 2.51 & 2.51 & 5.02 & 757 & 77.7 & 5.35 & 63.20 \\ 5293 & 2.35 & 2.35 & 4.70 & 494 & 66.1 & 4.55 & 52.50 \\ 5294 & 2.31 & 2.31 & 4.62 & 0 & 14.5 & 1.00 & 0.03 \\ 5295 & 2.32 & 2.32 & 4.65 & 337 & 68.2 & 4.69 & 53.70 \\ 5296 & 2.27 & 2.27 & 4.54 & 0 & 14.6 & 1.01 & 0.08\end{array}$

Mixture order No. 31: 1,2 dichloroethane (DCE)

\begin{tabular}{|c|c|c|c|c|c|c|}
\hline 5297 & 5.53 & 5.53 & 697 & 73.3 & 5.03 & 58.80 \\
\hline 5298 & 5.03 & 5.03 & 267 & 62.6 & 4.31 & 48.00 \\
\hline 5299 & 4.83 & 4.83 & 0 & 14.5 & 1.00 & 0.02 \\
\hline 5301 & 4.81 & $4.8 I$ & 400 & 49.6 & 3.44 & 35.20 \\
\hline 5302 & 4.70 & 4.70 & 0 & 14.5 & 1.00 & 0.02 \\
\hline 5303 & 4.82 & 4.82 & 0 & 24.5 & 1.00 & 0.03 \\
\hline 5304 & 4.76 & 4.76 & 0 & 14.5 & 1.00 & 0.02 \\
\hline
\end{tabular}

Mixture order No. 32: toluene (tol), 1,2 dichloroethane (DCE), Carbon tet. (CT), Hydrogen (F2)

$\begin{array}{rrrrrrrrrr}5305 & 0.95 & 0.95 & 0.95 & 0.95 & 3.80 & 0 & 14.5 & 1.00 & 0.01 \\ 5306 & 1.00 & 1.03 & 1.00 & 1.00 & 4.03 & 340 & 65.7 & 4.56 & 51.30 \\ 5307 & 1.02 & 1.02 & 1.01 & 1.01 & 4.05 & 351 & 63.8 & 4.40 & 49.30 \\ 5308 & 0.97 & 0.97 & 0.96 & 0.97 & 3.88 & 0 & 14.5 & 1.00 & 0.04 \\ 5309 & 0.99 & 1.00 & 0.99 & 0.99 & 3.97 & 3 & 17.5 & 1.21 & 3.00\end{array}$

Mixture ordez No. 33: toluene (tol). Hydrogen (स2)

$\begin{array}{rrrrrrrr}5310 & 1.00 & 1.00 & 2.01 & 0 & 14.5 & 1.01 & 0.10 \\ 5311 & 1.05 & 1.06 & 2.11 & 425 & 56.7 & 3.91 & 42.20 \\ 5312 & 1.02 & 1.03 & 2.05 & 0 & 14.7 & 1.01 & 0.18 \\ 5313 & 1.05 & 1.05 & 2.10 & 268 & 55.7 & 3.85 & 41.20\end{array}$

Mixture order No. 34: 2 butanone (MEK), toluene (tol), Carbon tetrachloride (CT)

\begin{tabular}{|c|c|c|c|c|c|c|c|c|}
\hline 5314 & 0.80 & 0.81 & 0.80 & 2.41 & 0 & 14.5 & 1.00 & 0.03 \\
\hline 5315 & 0.84 & 0.84 & 0.84 & 2.51 & 450 & 69.9 & 4.82 & 55.40 \\
\hline 5316 & 0.83 & 0.81 & 0.83 & 2.47 & 498 & 64.5 & 4.45 & 50.00 \\
\hline 5317 & 0.79 & 0.80 & 0.79 & 2.38 & 0 & 14.5 & 1.00 & 0.03 \\
\hline
\end{tabular}

Mixture order No. 35: toluene (tol), 1,2 dichloroethane (DCE), 2-butanone (MEK), carbon tet. (CT)

$\begin{array}{rrrrrrrrrr}5318 & 0.69 & 0.70 & 0.70 & 0.69 & 2.78 & 0 & 14.5 & 1.00 & 0.03 \\ 5319 & 0.75 & 0.76 & 0.78 & 0.77 & 3.06 & 627 & 70.6 & 4.86 & 56.00 \\ 5320 & 0.73 & 0.73 & 0.72 & 0.74 & 2.93 & 324 & 66.4 & 4.58 & 51.90 \\ 5321 & 0.70 & 0.72 & 0.71 & 0.71 & 2.83 & 282 & 63.7 & 4.39 & 49.10 \\ 5322 & 0.70 & 0.69 & 0.71 & 0.72 & 2.82 & 0 & 14.6 & 1.00 & 0.05\end{array}$


IMITCO - INEL, 29-L "MSHA" CHAMBER

\begin{tabular}{|c|c|c|c|c|c|c|c|c|c|c|c|}
\hline Dace & Run \# & $\begin{array}{l}\text { Tol } \\
\text { molt }\end{array}$ & $\begin{array}{l}\text { MEK } \\
\text { molt }\end{array}$ & $\begin{array}{l}\text { DCE } \\
\text { molt }\end{array}$ & $\begin{array}{l}C T \\
\text { molt }\end{array}$ & $\begin{array}{c}\mathrm{F} 2 \\
\text { molt }\end{array}$ & $\begin{array}{l}\text { Fuel } \\
\text { molt }\end{array}$ & $\begin{array}{r}\text { T-rise } \\
\mathrm{C}\end{array}$ & $\begin{array}{l}\text { Pmax } \\
\text { psia }\end{array}$ & FR & $\begin{array}{c}\text { P-rise } \\
\text { psi }\end{array}$ \\
\hline
\end{tabular}

Mixture order No. 36 : 1,2 dichloroethane (DCE), Hydrogen (H2)

$\begin{array}{llllllll}5323 & 2.62 & 2.61 & 5.23 & 0 & 14.8 & 1.02 & 0.36 \\ 5324 & 2.60 & 2.61 & 5.22 & 0 & 14.8 & 1.03 & 0.38 \\ 5325 & 2.65 & 2.66 & 5.31 & 0 & 14.9 & 1.03 & 0.44 \\ 5326 & 2.76 & 2.76 & 5.53 & 3 & 16.8 & 1.16 & 2.40 \\ 5327 & 2.70 & 2.71 & 5.42 & 0 & 15.0 & 1.04 & 0.60 \\ 5328 & 2.56 & 2.55 & 5.12 & 0 & 14.7 & 1.02 & 0.30 \\ 5329 & 2.86 & 2.85 & 5.72 & 141 & 20.7 & 1.43 & 6.30\end{array}$

Mixture order No. 37: toluene (to1), 1,2 dichloroethane (DCE)

$\begin{array}{rrrrrrrr}5330 & 1.00 & 1.01 & 2.01 & 0 & 14.5 & 1.00 & 0.05 \\ 5331 & 1.06 & 1.05 & 2.11 & 594 & 65.8 & 4.56 & 51.40 \\ 5332 & 1.02 & 1.04 & 2.06 & 0 & 14.7 & 1.01 & 0.23 \\ 5333 & 1.05 & 1.05 & 2.10 & 412 & 66.6 & 4.60 & 52.10 \\ 5334 & 0.99 & 1.01 & 2.00 & 0 & 14.5 & 1.01 & 0.07\end{array}$

Mixture order No. 38: toluene (tol), 1,2 dichloroethane (DCE), 2-butanone (MEX)

$\begin{array}{rrrrrrrrr}5335 & 0.67 & 0.67 & 0.70 & 2.04 & 518 & 61.9 & 4.27 & 47.40 \\ 5336 & 0.65 & 0.63 & 0.63 & 1.92 & 1 & 15.4 & 1.07 & 0.98 \\ 5337 & 0.63 & 0.64 & 0.63 & 1.89 & 0 & 14.5 & 1.00 & 0.03 \\ 5338 & 0.62 & 0.62 & 0.63 & 1.87 & 0 & 14.5 & 1.00 & 0.05 \\ 5339 & 0.64 & 0.65 & 0.64 & 1.93 & 0 & 14.6 & 1.00 & 0.04 \\ 5340 & 0.65 & 0.66 & 0.67 & 1.97 & 1 & 15.4 & 1.07 & 0.95 \\ 5341 & 0.68 & 0.67 & 0.67 & 2.01 & 574 & 64.3 & 4.45 & 49.80\end{array}$

Mixture order No. 39: toluene (to1), 1,2 dichloroethane (DCE), carbon tet. (CT)

$\begin{array}{rrrrrrrrr}5342 & 1.20 & 1.21 & 1.21 & 3.62 & 541 & 74.2 & 5.13 & 59.70 \\ 5343 & 1.17 & 1.18 & 1.17 & 3.52 & 355 & 69.7 & 4.83 & 55.20 \\ 5344 & 1.10 & 1.12 & 1.10 & 3.33 & 0 & 14.5 & 1.00 & 0.02 \\ 5345 & 1.13 & 1.14 & 1.15 & 3.42 & 0 & 14.5 & 1.00 & 0.04 \\ 5346 & 1.15 & 1.15 & 1.15 & 3.45 & 0 & 14.6 & 1.00 & 0.05\end{array}$

Mixture order No. 40 : carbon tet. (CT)

$\begin{array}{ccccccc}5347^{\circ} & >12.3 & >12.3 & 0 & 14.6 & 1.00 & <0.01 \\ 5348 & 12.19 & 12.19 & 0 & 14.5 & 1.00 & <0.01\end{array}$




\section{Appendix C \\ MIXTURE LOWER EXPLOSIVE LIMIT AND LIMITING ADIABATIC FLAME TEMPERATURE MODELS}




\section{Appendix C}

\section{Mixture Lower Explosive Limit and Limiting Adiabatic Flame Temperature Models}

\section{C.1 Le Chatelier's Rule and Modified Le Chatelier Method}

Le Chatelier's rule (Le Chatelier Original) has been tested for many fuel mixtures in air (Kuchta 1985; Burgess et al. 1982), the results of these studies indicated the average absolute error between experimentally determined mixture lower explosive limits (MLELs) and the values calculated using Le Chatelier's rule were approximately $4.2 \%$, with approximately half the calculated lower explosive limits (LELs) being higher than those determined experimentally. Therefore, the experimental results from the Flammability Assessment Methodology Program (FAMP) will be used to evaluate Le Chatelier's rule for the mixtures of interest, including those containing inert chlorocarbons (e.g., carbon tetrachloride).

Given the flammability limits of each of the components in a mixture, the MLEL of the mixture may be calculated by Le Chatelier's rule (Kuchta 1985). For the gas mixtures containing only flammable components in air, the test data for these gas mixtures will be compared to MLEL values calculated by Le Chatelier's rule:

$$
\text { MLEL }=\frac{100}{\sum\left(\frac{C_{i}}{L E L_{i}}\right)}
$$

where

$M L E L=$ mixture lower explosive limit (vol\%)

$C_{i} \quad=$ proportion of flammable compound $i$ in the flammable gas mixture on an air-free and nonflammable volatile organic compound-free basis (\%) (i.e., the concentration of $i$ divided by the sum of all flammable gas concentrations)

$L E L_{i} \quad=\quad$ lower explosive limit for compound $i$ in the mixture (vol\%).

Equation C-1 is useful for calculating the MLELs of mixtures that contain only flammable components. It is not an appropriate equation for calculating MLELs for the test mixtures containing inert or nonflammable gases (i.e., carbon tetrachloride). The flammability for gas mixtures containing flammable and nonflammable components could be determined using flammability diagrams. The construction of flammability diagrams is outside the scope of work for the FAMP. However, a modified Le Chatelier method (Le Chatelier with Nonflammabale Mole Fraction) was used to predict MLELs, which was based on defining the proportions of each flammable volatile organic compound (VOC) as the concentration of the VOC divided by the sum of all flammable VOCs, nonflammable VOCs, and hydrogen concentrations. Thus, a nonflammable VOC is accounted for by reducing the proportion of a flammable gas from the proportion that would be used with the Le Chatelier Original method. 


\section{C.2 Group Method and Modified Group Methods}

The Group method is based on an extension of the method presented in the American Institute of Chemical Engineers' (AIChE) Procedure B: Method for Estimating Lower Flammability Limit of Pure Compounds in the Data Prediction Manual (AIChE 1994). This method predicts the MLEL of a mixture based on knowledge of the chemical structure of each individual component in the mixture. The LEL values based on the group contribution method will be calculated by the following equation:

$M L E L=\frac{100}{\sum f_{i} \times G C F_{i}}$

where

$M L E L=$ mixture lower explosive limit (vol\%)

$f_{i}=$ proportion of gas $i$ in mixture on an air free basis (\%) (i.e., the concentration of $i$ divided by the sum of the concentrations of flammable VOCs, nonflammable VOCs and flammable gas)

$G C F_{i}=$ group contribution factor for compound $i$.

The group contribution factor for a compound is calculated by the following method:

$G C F_{i}=\sum n_{j} \times G F_{j}$

where

$n_{j}=$ number of group type $j$ in compound $i$

$G F_{j}=$ group factor for group type $j$.

Table C-1 contains the FAMP calculated group factor (GF) values for the various groups used to determine the GCF for compounds of interest. The group contribution factors (GCFs) that were calculated for the various compounds as well as other physical and chemical properties required by the other methods are summarized in Table C-2 .

Table C-1. Flammability Assessment Methodology Program group factor values.

\begin{tabular}{lc}
\hline Group & Group Factor \\
\hline $\mathrm{C}$ & 9.10 \\
$\mathrm{H}$ & 2.17 \\
$\mathrm{H}_{2}$ & 20 \\
$\mathrm{O}$ & -2.68 \\
$\mathrm{~N}$ & 1.38 \\
$\mathrm{Cl}$ & -4.38 \\
$\mathrm{C}=\mathrm{C}$ & 14.07 \\
$\mathrm{~F}$ (No.H>No.F atoms) & -4.18 \\
$\mathrm{~F}$ (No.H<No.F atoms) & -2.55 \\
$\mathrm{I}$ & 17.5 \\
$\mathrm{P}$ & 10.9 \\
\hline
\end{tabular}


Table C-2. Component physical and chemical properties

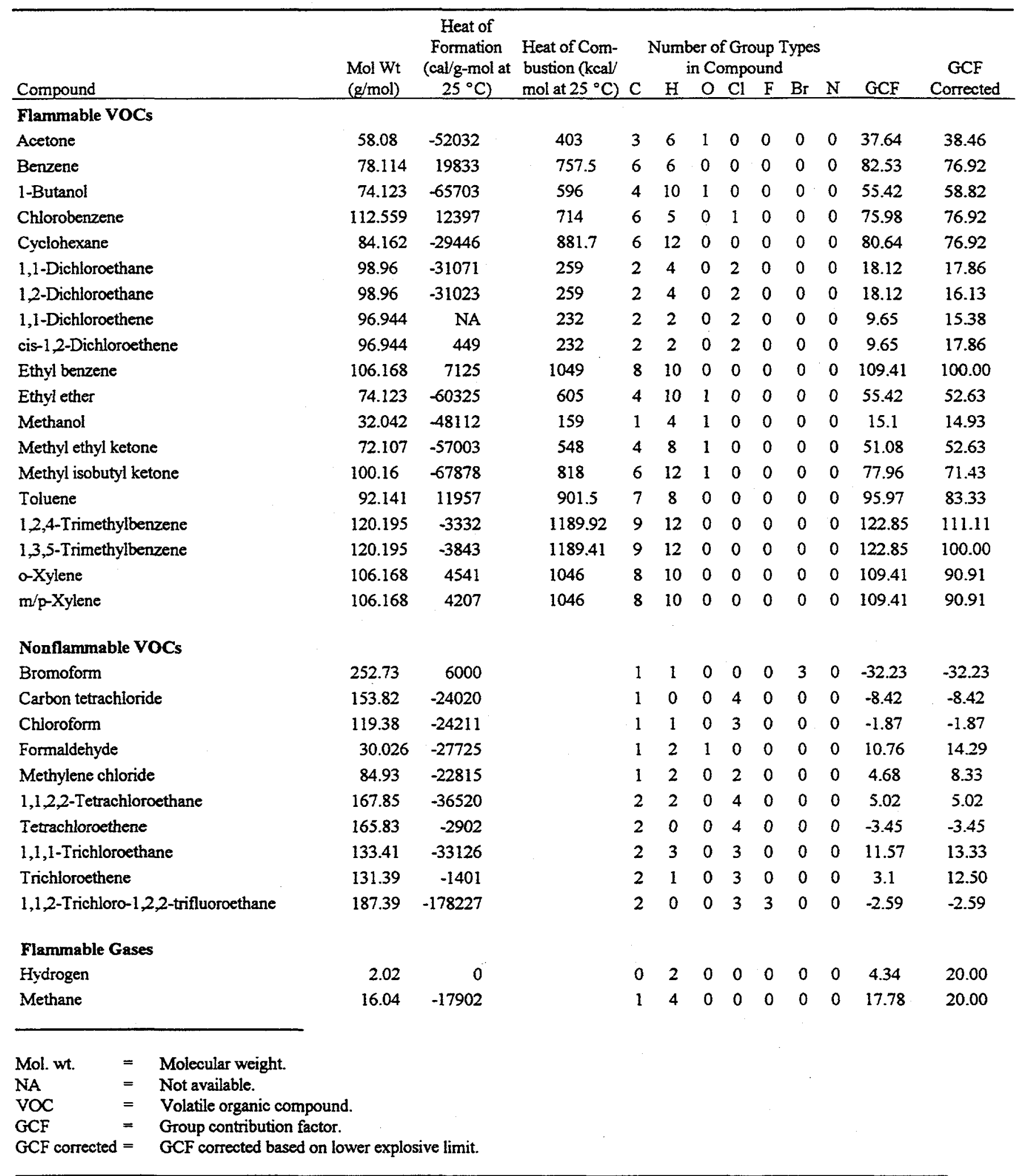


The Flammable Group method is based on changing the way the proportions are calculated in Equation C-2 as follows:

$f_{i}=$ proportion of flammable gas $i$ in mixture on an air free and nonflammable VOC free basis (\%) (i.e., the concentration of flammable compound $i$ divided by the sum of the concentrations of flammable VOCs and flammable gas).

The Group Corrected method is based on calculating the GCF for each compound using the experimentally determined LEL of each flammable compound as shown in Equation C-4 instead of using Equation C-3 as follows:

$G C F_{i}=\frac{100}{L E L_{i}}$

where

$G C F_{\mathrm{i}}=$ group contribution factor for compound $i$

$L E L_{\mathrm{i}} \quad=$ lower explosive limit for compound $i$ (volume percent). C-1.

The GCFs of nonflammable VOCs are calculated as for the Group method using Equation C-3 and Table

The Group Absolute Adjusted method is based on the flammable group method with an adjustment based on the absolute mean experimental error plus two standard deviations. The adjustment results in predictions using the flammable group method being adjusted downward by 0.44972 .

The Group Relative Adjusted method is based on the flammable group method with adjustments made based on the relative mean experimental error plus two standard deviations. The adjustment results in predictions being multiplied by the factor (1-0.05781).

\section{C.3 ASTM CHETAH 7.1 Code Predictions}

The ASTM CHETAH 7.1 is a beta version of a computer software package for predicting both thermochemical properties and certain reactive chemical hazards associated with chemicals and their reactions. For thermochemical estimations, CHETAH is designed to conveniently and accurately calculate properties such as heat capacity, enthalpy, entropy, and Gibbs energy of reactions as a function of temperature. The output of the "Energy Release Evaluation" option provides information about the ability of a material to decompose with violence if subjected to a severe impact.

The new Windows-based release of CHETAH has a number of enhancements including the ability to predict the LEL for a substance along with an increased user friendliness. CHETAH is approved by ASTM Committee E27 on Hazardous Potential of Chemicals.

The following are some of the functions performed using CHETAH:

- Calculate the heat of combustion of a compound or mixture.

- Calculate thermochemical properties for reactions: heat capacity of reaction, enthalpy of reaction, entropy of reaction, Gibbs energy of reaction, $\log \mathrm{K}$. 
- Calculate thermochemical properties for compounds: heat capacity, entropy, enthalpy of formation, Gibbs energy of formation, $\log \mathrm{K}_{f}$ Gibbs energy function.

- Build compounds from library or user-entered groups, gases, or solid crystals.

- Build crystals from ionic groups.

- Enter private thermochemical data (Benson's groups, gases, or crystals).

- Classify a material or mixtures on its/their ability to decompose with violence when subjected to severe impact.

- Classify mixtures for flammability and estimate LEL.

Because documentation for the CHETAH code was not available for the current study, it is not known how the code estimates the MLEL for gas mixtures. However, for the case of hydrogen in air, the code estimated an LEL of $22 \%$, which does not correspond to any literature values. It is widely accepted that the LEL for hydrogen ranges from about $4 \%$ (for upward propagation of the flame) to around $8 \%$ (for downward propagation of the flame). Such a high LEL predicted by the CHETAH code more closely corresponds to the stoichiometric concentration of hydrogen in air rather than to the lean limit. In addition, the code provided poor correlations with other methods when carbon tetrachloride was present in the gas mixture.

\section{C.4 Adiabatic Flame Temperature Method}

The adiabatic flame temperature method is based on calculating and comparing the adiabatic flame temperature of a potentially flammable gas mixture with the critical or limiting adiabatic flame temperature. If a flammable gas mixture explodes in an adiabatic system (one in which there is no transfer of heat to or from the system), then it is possible to calculate an adiabatic flame temperature that corresponds to the temperature of the system after the explosion. The minimum temperature at which a flame can be sustained is referred to as the critical or limiting adiabatic flame temperature. The data from the flammability experiments were used to derive a linear predictive model for the critical or limiting adiabatic flame temperatures (see Section C.5). If the calculated adiabatic flame temperature of a potentially flammable gas mixture is above the predicted critical or limiting flame temperature, the mixture is flammable.

The adiabatic flame temperature method is the most rigorous of the five general methods used and is based on well-established chemical thermodynamic principles. It is the only method that directly accounts for the effects of the inert or nonflammable VOCs on gas mixture flammability. The energy balance for a combustion system can be expressed as follows:

$$
\Delta H=\frac{n_{a} \Delta H_{c}^{\circ}}{\mathrm{v}}+\sum_{\text {prochucts }} n_{i} H_{i}-\sum_{\text {feed }} n_{i} H_{i}
$$

where

$$
\begin{aligned}
& \Delta H=\text { total change of enthalpy of the combustion reaction (Btu/mole) } \\
& \Delta H_{c}{ }^{\circ}=\text { standard heat of combustion for the fuel at } 25^{\circ} \mathrm{C}(\mathrm{Btu} / \mathrm{mole}) \\
& n_{a} \quad=\text { combustion fuel consumed (moles) }
\end{aligned}
$$


$n_{i} \quad=i^{\text {th }}$ component in the feed or product (moles)

$H_{i} \quad=$ specific enthalpy of the $i^{t h}$ component relative to this component at $25^{\circ} \mathrm{C}$ (Btu/mole)

$v=$ stoichiometric coefficient of the combustion fuel, normally $v$ equals 1 .

Since the transfer of heat to or from the system equals zero for an adiabatic reaction, the change in enthalpy is zero $(\Delta H=0)$. Setting Equation $\mathrm{C}-7$ to zero, the combustion temperature (adiabatic temperature) can be calculated. However, to solve Equation C-7 the specific enthalpies for the products at the adiabatic temperature are needed. The specific enthalpies of the products are calculated using their specific heat capacities evaluated from the reference temperature to the unknown adiabatic temperature. The solution to Equation C-7 involves solving a polynomial equation. However, a direct calculation for the adiabatic flame temperature can be used as an approximation.

Since the heat capacities of the products for complete combustion reactions are nearly the same for all hydrocarbons, the adiabatic flame temperature at the LEL is nearly a constant (Drysdale 1985). For a wide range of carbon-, hydrogen-, and oxygen-containing fuels, the adiabatic flame temperature at the lower flammable limit is approximately $1,600 \mathrm{~K}( \pm 150 \mathrm{~K})$. Notable exceptions include hydrogen at $980 \mathrm{~K}$, carbon monoxide at 1,300 $\mathrm{K}$, and acetylene at $1,280 \mathrm{~K}$. Based on this approximate condition, the average thermal heat capacity for the mixture can be calculated for the combustion mixture and the adiabatic flame temperature can be calculated directly from Equation C-8. The adiabatic flame temperature is calculated as:

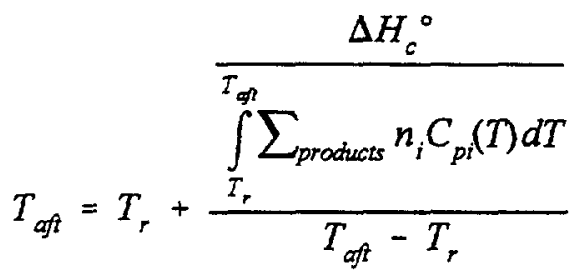

where

$$
\begin{aligned}
& T_{a f t}=\text { adiabatic flame temperature }\left({ }^{\circ} \mathrm{C}\right) \\
& T_{r}=\text { reference temperature, typically } 25^{\circ} \mathrm{C} \\
& \Delta H_{c}^{\circ}=\text { standard heat of combustion for fuel at } 25^{\circ} \mathrm{C}(\mathrm{kJ} / \text { mole) } \\
& n_{i} \quad=\text { product } i \text { produced (moles) } \\
& C_{p i} \quad=\text { specific heat capacity of product } i\left(\mathrm{~kJ} / \mathrm{mole} \cdot{ }^{\circ} \mathrm{C}\right) .
\end{aligned}
$$

A number of computer codes are available to perform the complex thermodynamic chemical equilibrium calculations for a combustion reaction, including the ASTM CHETAH code (ASTM 1997), the NASA Lewis Research Center CET93/CETPC code (McBride et al. 1994), the Lawrence Livermore National Laboratory CHEETAH code (Fried 1995), the Aspen Plus code from AspenTech, Inc., and the University of Arizona CHEMEQ code (Wendt 1993). Two of the more popular codes namely Aspen Plus Release 9.3-1 and the CET93/CETPC codes were used to estimate the limiting adiabatic flame temperature for each of the 40 test gas mixtures by supplying the experimentally determined concentrations of each component at the MLEL. Each of the codes is described below. 


\section{C.4.1 Aspen Plus}

Aspen Plus simulates the behavior of various models involving chemical interaction and vapor-liquid processes. Typical applications of the code include calculation of viscosity and thermal conductivity of various substances, determination of parameters for chemical systems, hydrogenation and distillation systems, solids handling, costing and economic evaluation, electrolyte systems, and advanced physical properties. The code uses one of the most comprehensive physical property databases in the world that includes pure component databanks for 5,000 components including organic, inorganic, and aqueous ionic species and binary parameter databanks for over 4,000 component pairs.

\section{C.4.2 CET93/CETPC}

The CET93/CETPC code is the most widely used code for analyzing combustion problems (NFPA 1988). The program calculates the final equilibrium conditions for adiabatic combustion given the initial conditions, such as the initial temperature and pressure, and the identities of the relative proportions of constituents in a potentially flammable gas mixture. The program contains thermodynamic data for 1,136 components and has the ability to analyze user-defined components if the user specifies basic thermodynamic properties of the additional components (McBride et al. 1994). The output that is created by running the code includes the calculated adiabatic flame temperature of any potentially flammable gas mixture.

\section{C.5 Linear Regression Model}

\section{C.5.1 Limiting Adiabatic Flame Temperatures for Flammability Test Mixtures}

Results from modeling adiabatic flame temperatures were used to develop an empirical model for predicting limiting adiabatic flame temperatures. Limiting adiabatic flame temperatures are needed in order to assess flammability of a mixture for which an adiabatic flame temperature has been predicted. The model is described by the following equation:

$T_{\text {laf }}=\exp \left(c_{0}+c_{1} X_{1}+c_{2} X_{2}+c_{3} X_{1} X_{2}+c_{4} X_{1} X_{3}+c_{5} X_{1} X_{2} X_{3}\right)$

where

$$
\begin{aligned}
& T_{\text {laf }}=\text { limiting adiabatic flame temperature }(\mathrm{K}) \\
& c_{\mathrm{i}}=\begin{array}{l}
\text { coefficients obtained through linear regression of the limiting adiabatic flame temperature on } X_{\mathrm{i}} \text { and } \\
\text { cross products of } X_{\mathrm{i}}
\end{array} \\
& X_{1}=\text { proportion of hydrogen } \\
& X_{2}=\text { proportion of flammable VOCs } \\
& X_{3}=\text { proportion of nonflammable VOCs. }
\end{aligned}
$$

The coefficients in the equations were obtained through standard least-squares statistical techniques using the STATA software package. Model terms were selected stepwise for their significant contribution from the full model (all possible combinations of products of independent variables $X_{j}$ ) toward predicting the log of the limiting adiabatic flame temperature. 
The coefficients were estimated using proportions $X_{\mathrm{i}}$ for the mixtures in the flammability test and the corresponding limiting adiabatic flame temperatures calculated using Aspen Plus and CET93/CETPC as described earlier. The coefficients are given in Table C-3.

Table C-3. Coefficients for limiting adiabatic flame temperature linear regression models.

\begin{tabular}{lcc}
\hline Model Coefficients & Aspen Plus Input & CET93/CETPC Input \\
\hline$c_{0}$ & 7.670438 & 7.651376 \\
$c_{1}$ & -1.088749 & -1.070299 \\
$c_{2}$ & -0.2940651 & -0.274459 \\
$c_{3}$ & 1.083313 & 1.095424 \\
$c_{4}$ & -1.490213 & -0.4694683 \\
$c_{5}$ & 5.602375 & 2.88831 \\
\hline
\end{tabular}

Model fits to the input data were excellent, with the coefficient of determination $\left(R^{2}\right)$ for each model greater than 0.95 . Table $\mathrm{C}-4$ gives limiting adiabatic flame temperature predictions from the linear regressions and from the Aspen Plus and CET93/CETPC codes for the test mixtures.

In order to evaluate the effectiveness of the models, the CET93/CETPC code was run using headspace data from the 532 drums used in the FAMP. Because of the large number of runs needed to analyze the FAMP drums, a pre- and post-processor for the CET93/CETPC code was developed. The pre-processor used a drum data file generated using the STATA program. This drum data file contained the unique drum number and the concentration in ppm of each of the 28 VOCs and hydrogen that was predicted in the innermost confinement layer from measured drum headspace concentrations. The pre-processor reads each of the concentrations, converts them to mole fraction and calculates the amount of oxygen and nitrogen present using the following equations:

$$
\begin{aligned}
& X_{\text {axygen }}=0.21\left(1.0-X_{\text {hydrogen }}-\sum_{i} X_{i}\right) \\
& X_{\text {nirogen }}=0.79\left(1.0-X_{\text {hydrogen }}-\sum_{i} X_{i}\right)
\end{aligned}
$$

where:

$$
\begin{aligned}
& X_{\text {oxygen }}=\text { concentration of oxygen (mole fraction) } \\
& X_{\text {nitrogen }}=\text { concentration of nitrogen (mole fraction) } \\
& X_{i}=\text { concentration of VOC " } i \text { " (mole fraction) } \\
& X_{\text {hydrogen }}=\text { concentration of hydrogen (mole fraction). }
\end{aligned}
$$


Table C-4. Results of predictive limiting adiabatic flame temperature modeling.

\begin{tabular}{|c|c|c|c|c|}
\hline Mixture No. & $\begin{array}{l}\text { Aspen Plus } \\
\text { (K) }\end{array}$ & $\begin{array}{c}\text { CET93/CETPC } \\
\text { (K) }\end{array}$ & $\begin{array}{c}\text { Aspen Plus } \\
\text { Linear Regression } \\
\text { (K) }\end{array}$ & $\begin{array}{c}\text { CET93/CETPC } \\
\text { Linear Regression } \\
\text { (K) }\end{array}$ \\
\hline 1 & 1722.75 & 1716.6 & 1774.18 & 1727.85 \\
\hline 2 & 1709.25 & 1697.77 & 1597.79 & 1598.65 \\
\hline 3 & 1556.75 & 1556.6 & 1597.79 & 1598.65 \\
\hline 4 & 1612.55 & 1612.39 & 1602.49 & 1603.05 \\
\hline 5 & 1566.65 & 1567.18 & 1604.91 & 1608.97 \\
\hline 6 & 1477.75 & 1478.77 & 1560.89 & 1564.96 \\
\hline 7 & 1642.35 & 1635.91 & 1752.10 & 1710.29 \\
\hline 8 & 1812.85 & 1794.86 & 1765.79 & 1755.02 \\
\hline 9 & 1712.65 & 1706.63 & 1719.67 & 1712.20 \\
\hline 10 & 1693.35 & 1690.53 & 1597.79 & 1598.65 \\
\hline 11 & 1874.95 & 1854.57 & 1765.79 & 1755.02 \\
\hline 12 & 1587.75 & 1587.42 & 1560.89 & 1564.96 \\
\hline 13 & 1737.55 & 1727.62 & 1752.10 & 1710.29 \\
\hline 14 & 1341.05 & 1343.36 & 1407.91 & 1412.13 \\
\hline 15 & 1606.65 & 1596.56 & 1589.43 & 1602.90 \\
\hline 16 & $\mathrm{NA}$ & $\mathrm{NA}$ & $\mathrm{NA}$ & $\mathrm{NA}$ \\
\hline 17 & 1565.65 & 1567.06 & 1597.79 & 1598.65 \\
\hline 18 & 1812.45 & 1794.79 & 1850.86 & 1833.80 \\
\hline 19 & 1559.35 & 1560.92 & 1597.79 & 1598.65 \\
\hline 20 & 1462.45 & 1464.49 & 1407.91 & 1412.13 \\
\hline 21 & 1625.55 & 1623.52 & 1752.10 & 1710.29 \\
\hline 22 & 1597.95 & 1599.22 & 1597.79 & 1598.65 \\
\hline 23 & 1853.15 & 1835.58 & 1850.86 & 1833.80 \\
\hline 24 & 1503.15 & 1505.14 & 1407.91 & 1412.13 \\
\hline 25 & 1722.45 & 1714.35 & 1589.43 & 1602.90 \\
\hline 26 & 707.65 & 708.88 & 721.76 & 721.32 \\
\hline 27 & 837.65 & 1082.33 & 857.06 & 1095.38 \\
\hline 28 & 1711.15 & 1706.44 & 1765.79 & 1755.02 \\
\hline 29 & 1511.95 & 1519.07 & 1560.89 & 1564.96 \\
\hline 30 & 1605.55 & 1601.13 & 1589.43 & 1602.90 \\
\hline 31 & $\mathrm{NA}$ & $\mathrm{NA}$ & $\mathrm{NA}$ & NA \\
\hline 32 & $\mathrm{NA}$ & NA & $\mathrm{NA}$ & $\mathrm{NA}$ \\
\hline 33 & 1856.75 & 1837.74 & 1765.79 & 1755.02 \\
\hline 34 & 1663.45 & 1660.15 & 1765.79 & 1755.02 \\
\hline 35 & 1649.35 & 1632.81 & 1589.43 & 1602.90 \\
\hline 36 & 1605.55 & 1601.13 & 1589.43 & 1602.90 \\
\hline 37 & NA & NA & NA & NA \\
\hline 38 & 1576.35 & 1575.82 & 1597.79 & 1598.65 \\
\hline 39 & 1503.15 & 1505.14 & 1407.91 & 1412.13 \\
\hline 40 & 1566.65 & 1567.18 & 1604.91 & 1608.97 \\
\hline
\end{tabular}

$\mathrm{NA}=$ Not available. 
Using the heat of formation and number of atoms in each compound from Table C-2, the pre-processor generates 532 drum input files. Each input file is saved using the drum number in the filename to provide unique file names. In addition, the pre-processor creates a file with all of the drum numbers and a batch file to automatically execute the CET93/CETPC code for each of the 532 drum input files. The post-processor uses the file containing all of the drum numbers and sequentially opens each of the 532 output files. The post-processor searches through each output file and extracts the adiabatic flame temperature calculated for the mixture entered. The post processor then creates a new output file containing the drum number and the adiabatic flame temperature for the gas in the drum headspace.

The adiabatic flame temperatures for the 532 drums were compared to predictions using the limiting adiabatic flame temperature models, i.e., the linear regressions based on Aspen Plus and CET93/CETPC calculations for the flammability test mixtures. In addition, the CET93/CETPC predictions were biased downward by $100 \mathrm{~K}$ and $200 \mathrm{~K}$ for two additional comparisons. For the comparisons, a drum was counted as flammable if the calculated drum adiabatic flame temperature is greater than the limiting adiabatic flame temperature. Table $\mathrm{C}-5$ gives the comparison results, the number of drums determined to be flammable using the MLEL Flammable Group model, and the number of drums determined to be flammable by both the MLEL method and the limiting adiabatic flame temperature method. The linear regression model based on Aspen Plus tends to identify more flammable drums than the linear regression model based on CET93/CETPC because the temperature predictions are slightly higher in the latter. The statistics also show that the most biased linear regression model for limiting adiabatic flame temperature does not identify the same drums as being flammable as the MLEL method. The limiting adiabatic flame temperature method tends to be more sensitive to higher hydrogen concentrations than higher flammable VOC concentrations, while the Flammable Group is not. This discrepancy may be attributed to the varying limiting adiabatic flame temperatures for individual flammable VOCs (not accounted for in the linear regression models).

\section{C.5.2 Mixture Lower Explosive Limits}

The MLEL data obtained from the flammability experiments was used to develop linear regression models for predicting MLELs for mixtures of VOCs and flammable gases in TRU waste containers. The models express the flammable gas MLEL as a function of the total concentrations of compounds for each functional/LEL group used in the flammability testing. One regression was performed without transformation of the test MLELs and one was performed with log transformations of the test data. The transformation improved the ability of the model to meet the assumption of normal errors and reduced the influence of test values for a mixture with $50 \%$ hydrogen and $50 \%$ carbon tetrachloride and a mixture of 100\% 1,2-dichloroethane; however, variance heteroscedasicity (nonconstant error variance over all observations) was more pronounced. Bias adjustments to the linear regression on logs of MLELs were made to derive two additional models evaluated in the study. The untransformed model is described by

$$
\begin{aligned}
\text { MLEL }=c_{0}+ & c_{1} X_{1}+c_{2} X_{2}+c_{3} X_{3}+c_{4} X_{4}+c_{5} X_{1} X_{3}+c_{6} X_{1} X_{5}+c_{7} X_{1} X_{2}+c_{8} X_{1} X_{4}+c_{9} X_{3} X_{5}+c_{10} X_{4} X_{5} \\
& +c_{11} X_{2} X_{3}+c_{12} X_{2} X_{4}+c_{13} X_{3} X_{4}+c_{14} X_{1} X_{5} X_{2}+c_{15} X_{2} X_{3} X_{4}+c_{16} X_{1} X_{2} X_{3} \\
& +c_{1} X_{1} X_{2} X_{4}+c_{18} X_{1} X_{3} X_{4}+c_{19} X_{5} X_{3} X_{4}+c_{20} X_{5} X_{2} X_{4}+c_{21} X_{1} X_{5} X_{3}
\end{aligned}
$$

where

$$
\begin{aligned}
& \text { MLEL }=\text { mixture lower explosive limit (ppmv) } \\
& c_{i}=\text { coefficients obtained through linear regression of the experimental mixture lower explosive } \\
& \text { limits on } X_{i} \text { and } X_{i} \text { cross products }
\end{aligned}
$$


Table C-5. Drum evaluation results.

\begin{tabular}{|c|c|c|}
\hline Evaluation Criteria & Number of Drums & Percent of Drums \\
\hline Flammable by $F^{a}{ }^{a}$ MLEL model & 13 & 2.44 \\
\hline Flammable by LAFT model based on Aspen Plus & 5 & 0.94 \\
\hline Flammable by LAFT model based on CET93/CETPC & 4 & 0.75 \\
\hline $\begin{array}{l}\text { Flammable by LAFT model based on CET93/CETPC } \\
\text { minus } 100 \mathrm{~K}\end{array}$ & 6 & 1.13 \\
\hline $\begin{array}{l}\text { Flammable by LAFT model based on CET93/CETPC } \\
\text { minus } 200 \mathrm{~K}\end{array}$ & 12 & 2.26 \\
\hline $\begin{array}{l}\text { Flammable by } \text { FG }^{\mathrm{a}} \text { model \& LAFT model based on Aspen } \\
\text { Plus }\end{array}$ & 5 & 0.94 \\
\hline $\begin{array}{l}\text { Flammable by } F^{a} \text { model \& LAFT model based on } \\
\text { CET93/CETPC }\end{array}$ & 4 & 0.75 \\
\hline $\begin{array}{l}\text { Flammable by } F^{\mathrm{a}} \text { model \& LAFT model based on } \\
\text { CET93/CETPC minus } 100 \mathrm{~K}\end{array}$ & 5 & 0.94 \\
\hline $\begin{array}{l}\text { Flammable by } \mathrm{FG}^{3} \text { model \& LAFT model based on } \\
\text { CET93/CETPC minus } 200 \mathrm{~K}\end{array}$ & 5 & 0.94 \\
\hline
\end{tabular}


$\mathrm{X}_{1}=$ proportion of constituents in lower explosive limit group 3 (represented by 1,2-dichloroethane in flammability tests)

$\mathrm{X}_{2}=$ proportion of constituents in lower explosive limit group 1 (represented by toluene in flammability tests)

$\mathrm{X}_{3}=$ proportion of hydrogen

$\mathrm{X}_{4}=$ proportion of nonflammable constituents (represented by carbon tetrachloride in flammability tests)

$\mathrm{X}_{5}=$ proportion of constituents in lower explosive limit group 2 (represented by methyl ethyl ketone flammability tests).

The model for the log transformed data is described by

$$
\begin{aligned}
\text { MIEL }=c_{0}+c_{1} X_{1} & +c_{2} X_{2}+c_{3} X_{3}+c_{4} X_{4}+c_{5} X_{1} X_{3}+c_{6} X_{1} X_{5}+c_{7} X_{1} X_{2}+c_{8} X_{2} X_{5}+c_{9} X_{4} X_{5}+c_{10} X_{2} X_{3} \\
& +c_{11} X_{2} X_{4}+c_{12} X_{3} X_{4}+c_{13} X_{2} X_{3} X_{5}+c_{14} X_{1} X_{5} X_{2}+c_{15} X_{2} X_{3} X_{4} \\
& +c_{16} X_{1} X_{2} X_{3}+c_{17} X_{1} X_{3} X_{4}+c_{18} X_{5} X_{3} X_{4}+c_{19} X_{5} X_{2} X_{4}+c_{20} X_{1} X_{5} X_{4}
\end{aligned}
$$

Model fits to the input data were excellent, with $\mathrm{R}^{2}$ each model greater than 0.99 . The coefficients for the unadjusted linear regression models are given in Table C-6. For biased models, the adjustment is applied to the predicted value and coefficients do not change. The bias adjustments are based on experimental error in absolute scale and in relative scale. Downward adjustments of 0.44972 are made to the predicted value, which represents the mean absolute error plus two standard deviations, for the absolute scale. The adjustment results in predictions being multiplied by (1-0.05781) for the relative scale. The relative scale adjustment is a downward proportional adjustment of the mean relative error plus two standard deviations. Adjustments are made in untransformed space.

Section 3.1 of the report provides MLEL model evaluations. 
Table C-6. Coefficients for MLEL linear regression models.

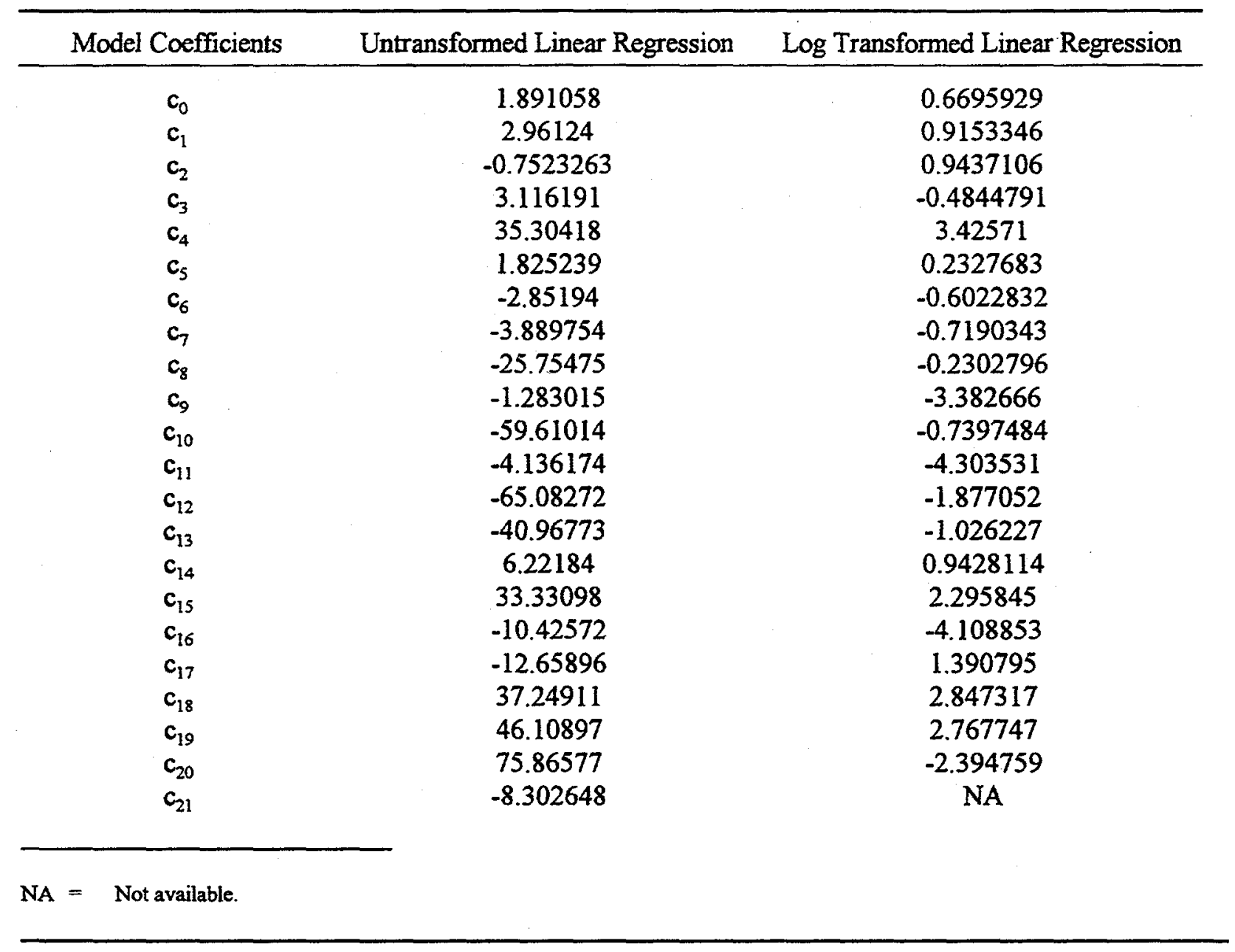

